\title{
CHARACTERIZATION OF BACTERIAL LIPOPOLYSACCHARIDES \\ (Pseudomonas syringae pv. tomato and Pseudomonas syringae pv. apii) AND \\ PECTINS OF TOMATO AND CELERY PLANTS (Lycopersicon \\ esculentum and Apium graveolens) REGARDING THEIR POSSIBLE \\ ROLE IN HOST/PATHOGEN-INTERACTION
}

\author{
Dissertation \\ Zur Erlangung des Doktorgrades \\ Der Mathematisch-Naturwissenschaftlichen Fakultäten \\ Der Georg-August-Universität zu Göttingen
}

Vorgelegt von

Balakrishnan Venkatesh

aus Madras, India

Göttingen 2002 
D7

Referent

Korreferent

Tag der mündlichen Prüfung
Prof. Dr. B. Bowien

Prof. Dr. G. Braus

18.06.2002 
Dedicated to my teachers 


\section{Chapter 1}

\section{Relatedness between Pseudomonas syringae pathovars tomato and apii based on plant inoculations and molecular analyses}

\subsection{Introduction 1}

1.2. Materials and Methods 5

1.2.1. Bacterial cultures 5

1.2.2. Plant material 6

1.2.3. Growth media

$\begin{array}{ll}\text { 1.2.3.1. Chalk agar medium } & 7\end{array}$

$\begin{array}{ll}\text { 1.2.3.2. King's medium B } & 7\end{array}$

$\begin{array}{ll}\text { 1.2.3.3. Nutrient broth } & 7\end{array}$

1.2.4. Stock solutions and buffers used for the isolation and analysis of DNA $\quad 8$

1.2.5. Cultivation of bacteria 8

1.2.6. Viability of bacteria in $\mathrm{MgSO}_{4}$

1.2.7. Inoculum preparation 9

1.2.8. Growth conditions for plants 9

$\begin{array}{lll}\text { 1.2.9. Plant inoculation assays } & 10\end{array}$

$\begin{array}{ll}\text { 1.2.9.1. Test for hypersensitivity } & 10\end{array}$

1.2.9.2. Screening for susceptible cultivars of tomato and celery 10

1.2.9.3. Tests for cross-infection $\quad 11$

1.2.9.4. Disease evaluation 11

$\begin{array}{ll}\text { 1.2.10. Molecular analysis } & 11\end{array}$

1.2.10.1. Preparation of genomic DNA from bacterial strains 11

1.2.10.2. Quantification of DNA 12

$\begin{array}{ll}\text { 1.2.10.3. Polymerase chain reactions } & 13\end{array}$ 
1.2.10.3.1. Detection of the gene for coronatine

1.2.10.4. Resolution of amplified fragments

1.2.10.4.1. Agarose gel electrophoresis 14

1.2.10.5. Repetitive PCR 15

1.2.10.6. Polyacrylamide gel electrophoresis (PAGE) 17

1.2.10.6.1. Preparation of polyacrylamide gel 17

1.2.10.6.2. Electrophoresis conditions $\quad 18$

$\begin{array}{ll}\text { 1.2.11. Numerical taxonomic analysis } & 18\end{array}$

$\begin{array}{lr}\text { 1.3. Results } & 20\end{array}$

1.3.1. Viability of Pseudomonas syringae pv. apii in $\mathrm{MgSO}_{4}$

$\begin{array}{ll}\text { 1.3.2. Plant inoculation assays } & 21\end{array}$

$\begin{array}{ll}\text { 1.3.2.1. Test for hypersensitivity } & 21\end{array}$

1.3.2.2. Screening for susceptible selectants of cv. Ontario no. 7710.

1.3.2.3. Screening for susceptible celery cultivars $\quad 25$

1.3.2.4. Tests for cross-infection (inoculations on non-host plants) 26

$\begin{array}{ll}\text { 1.3.3. Molecular analysis } & 29\end{array}$

1.3.3.1. Numerical taxonomic analysis $\quad 29$

1.3.3.2. Amplification of a region of $c f l$ gene out of

two closely related pathovars of Pseudomonas syringae 32

1.4. Discussion 34

1.5. Summary 39 


\section{Chapter 2}

Biophysical characterization of interactions between bacterial lipopolysaccharides and plant pectins

2. 1. Introduction

2.2.1. Model systems used for the study

2.2.2. Equipment used

2.2.3. Mathematical calculations

Chapter 3

Biochemical characterization of the lipopolysaccharide from Pseudomonas syringae pv. apii 
3.2.1. Bacterial cultures 64

3.2.2. Composition of King's medium B 64

3.2.3 Pre-culture 64

3.2.4 Extraction of bacterial lipopolysaccharides (LPS) from

P. syringae pv. apii GSPB 2548 and P. s. pv. tomato 65

GSPB 2317 race 0

3.2.5. Purification of the LPS 65

3.2.6. Biochemical analysis of LPS 66

3.2.6.1. Phosphate analysis 66

3.2.6.2. Analysis of KDO 66

3.2.6.3. Analysis of heptoses 66

3.2.6.4. Analysis of fatty acids 67

3.2.6.5. Analysis of sugars $\quad 67$

3.2.7. Sodium dodecyl sulphate polyacrylamide gel

electrophoresis (SDS-PAGE) 68

3.2.7.1. Buffers, chemicals and reagents used for SDS- PAGE 68

3.2.7.2. Procedure for preparing the polyacrylamide gel 69

3.2.7.3. Preparation of LPS samples $\quad 70$

3.2.7.4. Electrophoresis conditions 70

$\begin{array}{ll}\text { 3.2.7.5. Visualization } & 70\end{array}$

$\begin{array}{ll}\text { 3.3. Results } & 71\end{array}$

3.3.1.Biochemical Analysis 71

3.3.2. SDS-PAGE 73

$\begin{array}{ll}\text { 3.4. Discussion } & 74\end{array}$ 


\section{Chapter 4}

Biochemical characterization of pectins from cultivars of celery and tomato resistant or susceptible to Pseudomonas syringae pvs. tomato and apii and isolation and characterization of putative carbohydrate binding proteins from $P$. $s$. pvs. tomato and apii by haemagglutination inhibition studies

\subsection{Introduction 79}

4.1.1. Pectins $\quad 80$

4.1.2. Carbohydrate binding proteins $\quad 82$

4.2. Materials and Methods $\quad 84$

4.2.1. Extraction of pectins $\quad 84$

4.2.2. Analysis and characterization of pectins $\quad 85$

4.2.2.1. Volumetric analysis $\quad 85$

4.2.2.1.1. Determination of equivalent weight 85

4.2.2.1.2. Estimation of methoxyl content 85

4.2.2.1.3. Determination of the degree of esterification (DE) 86

4.2.2.2. Acid hydrolysis of pectins 86

4.2.2.3. Thin layer chromatography (TLC) 87

$\begin{array}{ll}\text { 4.2.2.4. Gas chromatography } & 87\end{array}$

4.2.2.5. Enzymatic digestion of pectins 88

4.2.2.6. Carbohydrate binding proteins from phytopathogenic

Pseudomonas spp. $\quad 88$

4.2.2.6.1. Extraction of carbohydrate binding proteins

(haemagglutinin) $\quad 88$ 
4.2.2.6.2. Characterization of the proteins by native and

$\begin{array}{ll}\text { SDS-PAGE } & 89\end{array}$

4.2.2.6.2.1. Native polyacrylamide gel electrophoresis $\quad 89$

4.2.2.6.2.1.1.Buffers, chemicals and reagents used for native PAGE 89

4.2.2.6.2.1.2.Electrophoresis conditions 90

4.2.2.6.2.2. Sodium dodecyl sulphate polyacrylamide gel electrophoresis (SDS-PAGE) $\quad 90$

4.2.2.6.2.1.1.Buffers, chemicals and reagents used for native PAGE 91

4.2.2.6.2.2.2. Preparation of protein samples 91

4.2.2.6.2.2.3. Electrophoresis conditions 91

4.2.2.6.2.2.4. Detection of proteins after SDS-PAGE by Coomassie staining 92

4.2.2.6.2.2. Detection of proteins after SDS-PAGE by silver staining 92

4.2.2.6.3. Haemagglutination and inhibition assays $\quad 92$

$\begin{array}{ll}\text { 4.4. Results } & 94\end{array}$

4.4.1. Extraction of pectins 94

4.4.2. Characterization of pectins 94

4.4.2.1.Volumetric analysis 94

4.4.2.1.1 Determination of equivalent weight 94

4.4.2.1.2. Estimation of methoxyl content 94

4.4.2.1.3. Determination of the degree of esterification (DE) 95

4.4.3. Thin layer chromatography (TLC) 95

4.4.4. Gas chromatography 96

4.4.5. Enzymatic digestion of pectins by pectate lyase and

$\begin{array}{ll}\text { polygalacturonase } & 99\end{array}$ 
4.4.6. Carbohydrate binding proteins from two

Pseudomonas syringae pathovars

4.4.6.1 Isolation of a carbohydrate binding protein from

$$
\text { P. s. pv. apii and P. s. pv. tomato }
$$

105

4.4.6.2. Characterization of the carbohydrate binding proteins

by native polyacrylamide gel electrophoresis

105

4.4.6.3. Characterization of the carbohydrate binding proteins

by sodium dodecyl sulphate polyacrylamide

gel electrophoresis

105

4.4.6.4. Haemagglutination inhibition studies

108

\subsection{Discussion}

115

4.6. Summary

Literature cited

124 


\section{LIST OF ABBREVIATIONS}

\begin{tabular}{ll} 
AFLP & Amplified Fragment Length Polymorphism \\
AluI & Enzyme obtained from Arthrobacter luteus \\
AP-PCR & Arbitrary Primer-PCR \\
APS & Ammoniumpersulphate \\
Bd & Bidistilled \\
bp & Base pairs \\
BSA & Bovine serum albumin \\
${ }^{\circ}$ C & Degree Celsius \\
cfu & Colony forming units \\
cm & Centimetre \\
co & Company \\
CTAB & Cetyl-trimethyl-ammoniumbromid \\
cv. & Cultivar \\
DD & Double distilled \\
DE & Degree of Esterification \\
DMSO & Dimethylsulfoxid \\
DNA & Deoxyribonucleic acid \\
DNTP & Deoxynucleoid -5-triphosphate \\
EDTA & Ethylenediaminetetraacetic acid \\
ERIC & Enterobacterial Repetitive Intergenic Consensus \\
et al. & et alei (and others) \\
Fig. & Figure \\
g & Gram \\
G C & Gas Chromatography \\
GSPB & Göttinger Sammlung (Collection) Phytopathogener Bakterien \\
h & Hours \\
HPLC & High Performance Liquid Chromatography \\
\hline
\end{tabular}




\begin{tabular}{|c|c|}
\hline M & Molar \\
\hline $\mathrm{mg}$ & Milligram \\
\hline $\min$ & Minutes \\
\hline $\mathrm{ml}$ & Millilitre \\
\hline $\mathrm{mM}$ & millimolar \\
\hline mol. wt & Molecular weight \\
\hline $\mathrm{Mr}$ & Molecular marker \\
\hline$\mu$ & Micron \\
\hline NCBI & National Center for Biotechnology Information \\
\hline ng & Nanogram \\
\hline OD & Optical density \\
\hline OTUs & Operational Taxonomic Units \\
\hline PAGE & Polyacrylamide gel electrophoresis \\
\hline PBS & Phosphate- buffered saline \\
\hline PCR & Polymerase chain reaction \\
\hline PG & Polygalacturonase \\
\hline $\mathrm{pH}$ & Negative logarithm of Hydrogen ion concentration \\
\hline PL & Pectate lyase \\
\hline pmol & Picomole \\
\hline$P s a$ & Pseudomonas syringae pv. apii \\
\hline Pst & Pseudomonas syringae pv. tomato \\
\hline PU & Palindromic Unit \\
\hline pv. & Pathovar \\
\hline RAPD & Random Amplified Polymorphic DNA \\
\hline Rep & Repetitive \\
\hline RFLP & Restriction Fragment Length Polymorphism \\
\hline rpm & Revolutions per minute \\
\hline SDS & Sodium dodecyl sulphate \\
\hline Taq & Thermus aquaticus \\
\hline TBE & Tris -boric acid-EDTA \\
\hline $\mathrm{TE}$ & Tris EDTA \\
\hline TEMED & $\mathrm{N}, \mathrm{N}, \mathrm{N}, \mathrm{N},-$ Tetramethy -Ethylenediamine \\
\hline TLC & Thin Layer Chromatography. \\
\hline $\mathrm{U}$ & Unit \\
\hline
\end{tabular}


UPGMA Unweighted Pair-Group using Arithmetic Average

UV Ultra violet

V Volt

v/v Volume per volume

W/v Weight per volume

w/w Weight per weight 


\section{Chapter 1}

\section{Relatedness between Pseudomonas syringae pathovars tomato and apii based on plant inoculations and molecular analyses}

\subsection{Introduction}

A number of bacterial pathogens are known to cause several destructive diseases on plants resulting in heavy economic losses. Species of Pseudomonas and Xanthomonas constitute a major group of such phytopathogens. Both are Gram-negative and have a very narrow host range. Besides others, one mechanism for the host-specificity of these pathogens may reside on interactions of bacterial cell surface components with those of its host plant. Being the outer most layer of all Gram-negative bacterial cells, the lipopolysaccharides could play a governing role in the determination of their host-spectrum. It would therefore be prudent to postulate that bacteria possessing an identical LPS structure should also possess the ability to infect the same hosts.

Pseudomonas syringae pv. tomato $(P s t)$ is the casual agent of bacterial speck, an important disease of tomato (Lycopersicon esculentum), a highly consumed vegetable throughout the world. The disease symptoms are characterized by small necrotic lesions surrounded by cholorotic haloes on the leaves. The bacteria enter the host through the stomata and the bases of leaf trichomes and multiply in the intercellular spaces (Bashan et al., 1981). Resistance of some tomato cultivars to bacterial speck requires the presence of a functional Pto gene, encoding a protein kinase in the host and a corresponding avirulence gene, avrPto (Martin et al., 1993) in the pathogen.

P. syringae pv. apii $(P s a)$ is a bacterial pathogen which causes northern bacterial blight (syn. early blight) in celery plants. Celery (Apium graveolens) is the third most important salad crop in the United States and popular among the european countries. It contains significant amount of the vitamins $\mathrm{A}$ and $\mathrm{C}$, calcium and sodium and very little amounts of carbohydrate. 
Pseudomonas syringae pv. tomato (Pst) and P. syringae pv. apii (Psa) are closely related pathovars and were selected for the present study. Earlier studies showed that not only do both have similar nutritional profiles (Hildebrand et al., 1982) but that they also have several common biochemical characteristics. Quite remarkable is the fact that both pathogens have identical O-chain patterns in their lipopolysaccharides (Ovod et al., 1997). Also, recent biophysical investigations demonstrated that certain assumed incompatible combinations between bacterial components and those of the non-hosts showed signs of synergistic interactions (Venkatesh and Rudolph, 2001a), questioning the true identity of the two pathovars. Thus the extent of relatedness between the two pathovars remains still a long standing debate and calls for more precise tools to arrive at definite conclusions.

Conventionally, assignment of taxonomic groups at the sub species level was based on the host range of the bacterial cells. This method is bound to be incomplete and open to alterations since several extraneous factors could easily influence the outcome of the experiments. A number of different phenotypic methods such as serologic testing, comparison of fatty acid profiles and protein analysis etc., were subsequently followed to address the issues. Such methods, too, had their limitations. Consequently, molecular tools such as restriction fragment length polymorphism (RFLP) analysis, random amplified polymorphic DNA (RAPD) analysis, arbitrary primed polymerase chain reaction (AP-PCR) (Welsh and McClelleand, 1990) and amplified fragment length polymorphism analysis (AFLP) are presently being employed for microbial identification and classification (Louws et al., 1994). In fact, the assignment of genera/species has traditionally been based on DNA-DNA hybridization methods and modern phylogeny is increasingly based on 16S rRNA sequence analysis (Woese, 1987; Goebel and Stackebrandt, 1994). 
A more recent method referred to as rep-PCR (repetitive elements) genomic fingerprinting is a DNA amplification based technique, which has been found to be extremely reliable, reproducible, rapid and highly discriminatory (Martin et al., 1992; Versalovic et al., 1994; Louws et al., 1994). Rep-PCR genomic fingerprinting makes use of DNA primers complementary to naturally occurring highly conserved repetitive DNA sequences, present in multiple copies in the genomes of most Gram-negative and several Gram-positive bacteria (Lupski and Weinstock, 1992). Three families of repetitive sequences have been identified, including the $35-40$ bp repetitive extragenic palindromic (REP) sequence, the 124-127 bp enterobacterial repetitive intergenic consensus (ERIC) sequence, and the 154 bp BOX element (Gilson et al., 1984; Hulton et al., 1991; Versalovic et al., 1994). These sequences appear to be located in distinct, intergenic positions (Higgins et al., 1982) around the genome and in general have the ability to form stem loop structures and may play an important role in the organization of the bacterial genome (Krawiec and Riley, 1990; Sharples and Lloyd, 1990; Lupski and Weinstock, 1992). The use of these primer(s) and PCR leads to the selective amplification of distinct genomic regions located between REP, ERIC or BOX elements that can be resolved in a gel matrix, yielding a profile referred to as a rep-PCR genomic fingerprint (Versalovic et al., 1994). The rep-PCR genomic fingerprints generated from bacterial isolates permit differentiation to the species, subspecies and strain level.

Louws et al. (1994) demonstrated that the repetitive elements present in pseudomonads and xanthomonads have sequences which are ubiquitous and that they are suitable for the rapid molecular characterization of plant pathogenic bacteria at their pathovar levels. These methods are very efficient in discerning the pathovars based on whether they represent a single evolutionary line or are composed of several lines that converged to exhibit a similar pathogenic phenotype. 
Many species of Pseudomonas produce non-host specific toxins such as phaseolotoxins, coronatine, syringomycin and tagetitoxin which play a role as virulence factors in disease development by inhibiting specific enzymes of the host plants' primary metabolism. In many cases the toxins produce visible symptoms, such as chlorosis, in a localized area in plants. However their exact role in interactions with plants is still undeciphered. Pseudomonas syringae pv. tomato is known to produce high amounts of coronatine during its multiplication within the host plant (Bender et al., 1987). A novel polymerase chain reaction (PCR) method was developed by Bereswill et al. (1994) to detect sequences involved in coronatine production. This method has been employed as a part of the present investigation in order to establish the level of relatedness between $P$. $s$. pv. tomato and P. s. pv. apii.

The main objective of our study was to determine the relatedness between strains of Pseudomonas syringae pv. apii and P. s. pv. tomato race 0 based on conventional plant inoculation assays as well as based on their rep-PCR genomic fingerprints. The issue of cross-pathogenicity of the bacteria on non-host plants has also been addressed on the basis of their molecular characteristics. 


\subsection{Materials and Methods}

\subsubsection{Bacterial cultures}

The following bacterial cultures were used in this study. The cultures were available as lyophilized powders from the Göttinger Sammlung Phytopathogener Bakterien (GSPB).

Table 1.2.1. List of Pseudomonas syringae strains used in the study

\section{Bacterial strain}

P. syringae pv. apii 2545

P. syringae pv. apii 2546

P. syringae pv. apii 2547

P. syringae pv. apii 2548

P. syringae pv. apii 2153

P. syringae pv. tomato 2317

P. syringae pv. tomato 1778

P. syringae pv. tomato 2650

P. syringae pv. tomato 2900

\section{Race \\ Original source}

- $\quad$ Dr. D. W. Dye, Michigan, USA

- $\quad$ Dr. D. W. Dye, Michigan, USA

- $\quad$ Dr. D. W. Dye, Michigan, USA

- $\quad$ Dr. D. W. Dye, Michigan, USA

- $\quad$ Dr. D. W. Dye, Michigan, USA

0 Dr. Mavridis, Göttingen, Germany

1 Dr. MacNeill, Canada

- $\quad$ Dr. Nabizadeh-Ardekani, Turkey

- $\quad$ Dr. Obradovic, Yugoslavia 


\subsubsection{Plant material}

Seeds of the tomato cv. Ontario no. 7710 were obtained from R. E. Pitblado, Ontario, Canada, and seeds of the celery cultivars were purchased from Royal Sluis, Holland, and Hild Samen, Germany.

Table 1.2.2. List of cultivars of celery and tomato plants used in this study

\begin{tabular}{|c|c|c|}
\hline Cultivars & Sub species & Source \\
\hline \multicolumn{3}{|l|}{ Celery } \\
\hline Alabaster & A.g. dulce & Hild Samen, Germany \\
\hline Bergens & A.g. dulce & Hild Samen, Germany \\
\hline Claret & A.g. rapaceum & Royal Sluis, Holland \\
\hline Erfort & A.g. dulce & Hild Samen, Germany \\
\hline Jablorag & A.g. dulce & Hild Samen, Germany \\
\hline Loret & A.g. rapaceum & Royal Sluis, Holland \\
\hline Mars & A.g. dulce & Hild Samen, Germany \\
\hline Magdeburger & A.g. dulce & Hild Samen, Germany \\
\hline Monarch & A.g. dulce & Hild Samen, Germany \\
\hline Odendi & A.g. dulce & Hild Samen, Germany \\
\hline Phoenix & A.g. dulce & Hild Samen, Germany \\
\hline Prinz & A.g. dulce & Hild Samen, Germany \\
\hline Rokary & A.g. dulce & Hild Samen, Germany \\
\hline
\end{tabular}

Tomato

\begin{tabular}{|c|c|c|}
\hline Ontario 7710 Selectant & L. esculentum & Selected in Göttingen \\
\hline Ontario 7710 & L. esculentum & R. E. Pitblado, Ontario, Canada \\
\hline
\end{tabular}

Ontario no. 7710 "selectant " was selected in Göttingen from the original Ontario no. 7710 by F. Nabizadeh-Ardekani (1999) and further propagated by self fertilization. The "selectant" was susceptible to $P$. s. pv. tomato race 0 and showed a different habitus than the original Ontario no. 7710 (see section 1.3.2.2) 


\subsubsection{Growth media}

King's medium B, chalk agar medium and nutrient broth were routinely used in this study for the growth and maintenance of the bacterial cultures. The composition of the various media are given below.

1.2.3.1. Chalk agar medium (Stead, 1990)

$\mathrm{g} / \mathrm{l}$

Yeast extract $\quad 10.0$

Glucose 20.0

$\mathrm{CaCO}_{3} \quad 20.0$

Agar $\quad 15.0$

Demineralized water to 11

$\mathrm{pH}$ of the medium was adjusted to 7.2

1.2.3.2. King's medium B (King et al., 1954)

$\mathrm{g} / \mathrm{l}$

Proteose Peptone 20.0

Glycerine $\quad 10.0$

$\mathrm{K}_{2} \mathrm{HPO}_{4}$

$\mathrm{MgSO}_{4} .7 \mathrm{H}_{2} \mathrm{O} \quad 1.5$

Agar $\quad 15.0$

Demineralized water to 11

$\mathrm{pH}$ of the medium was adjusted to 7.0

\subsubsection{Nutrient broth}

Peptone $\quad 5.0$

Yeast extract $\quad 3.0$

Beef extract 2.0

$\mathrm{NaCl} \quad 5.0$

Demineralized water to 11

The $\mathrm{pH}$ of the medium was adjusted to 7.2 


\subsubsection{Stock solutions and buffers used for the isolation and analysis of DNA}

$\begin{array}{ll}\text { CTAB buffer } & 10 \%(\mathrm{w} / \mathrm{v}) \mathrm{CTAB} \\ & 0.7 \mathrm{M} \mathrm{NaCl} \\ & \text { in } 1 \mathrm{X} \mathrm{TE} \\ 1 \mathrm{X} \mathrm{TE} & 10 \mathrm{mM} \text { Tris }(\mathrm{pH} .7 .6) \\ & 1 \mathrm{mM} \text { EDTA } \\ 10 \mathrm{X} \text { TBE } & 0.9 \mathrm{M} \text { Tris } \\ & 0.9 \mathrm{M} \text { boric acid } \\ & 20 \mathrm{mM} \text { EDTA }\left(\mathrm{Na}^{2+}\right)(\mathrm{pH} 8.0) \\ & \\ & 0.25 \%(\mathrm{w} / \mathrm{v}) \text { bromophenol blue } \\ & 0.25 \%(\mathrm{w} / \mathrm{v}) \text { xylene cyanol } \\ & 30 \%(\mathrm{v} / \mathrm{v}) \text { glycerol } \\ & 50 \mathrm{mM} \text { EDTA }\end{array}$

\subsubsection{Cultivation of bacteria}

Lyophilized bacterial strains were revived by suspending in $1 \mathrm{ml}$ King's medium B (King et al., 1954), and a loopful of the bacterial suspension was streaked on King's medium B agar in Petri plates. The plates were incubated at $37{ }^{\circ} \mathrm{C}$ for $24-48$ $\mathrm{h}$ for the appearance of colonies. A single colony was then transferred to chalk agarslants (Stead, 1990) and the slants were incubated at $37^{\circ} \mathrm{C}$ for $48 \mathrm{~h}$. The cultures were stored at $4{ }^{\circ} \mathrm{C}$ until further use. 


\subsubsection{Viability of bacteria in $\mathrm{MgSO}_{4}$}

This experiment was carried out in order to find out if the bacteria survived for several hours in the inoculum suspension. The bacterial strains were suspended in 10 $\mathrm{mM} \mathrm{MgSO}_{4}$ and the optical density (OD) of the cell suspension was adjusted to 0.06 at $660 \mathrm{~nm}$. The suspensions were diluted to 1:50 and 1:500. Further serial dilutions of the cultures were carried out at $0 \mathrm{~h}$ and at the end of $5 \mathrm{~h}$ in $10 \mathrm{mM} \mathrm{MgSO}_{4}$ and plated on King`s medium B agar. The plates were incubated for $48 \mathrm{~h}$ and the bacterial colonies were counted using a colony counter (Schütt Co., Germany) to check the survival ability of the bacterial strains in $\mathrm{MgSO}_{4}$.

\subsubsection{Inoculum preparation}

For preparing the inoculum, $24 \mathrm{~h}$ old cultures were used. The bacterial cultures were grown on King's medium B agar for $24 \mathrm{~h}$ and were transferred to clean test tubes containing $5 \mathrm{ml}$ of $10 \mathrm{mM} \mathrm{MgSO}$. The final concentration of the suspension was adjusted to $10^{8} \mathrm{cfu} / \mathrm{ml}$ by adjusting the optical density at $660 \mathrm{~nm}$ to 0.06 , compared to water and further diluted to $1: 100$. The bacterial inoculum was prepared freshly on the day of inoculation.

\subsubsection{Growth conditions for plants}

The seeds of tomato and celery plants were germinated in sterile soil and grown in an insect free greenhouse at $24{ }^{\circ} \mathrm{C}$ and $80 \%$ relative humidity with supplementary lighting (15,000 Lux, W9 mercury fluorescent lamps) for a $16 \mathrm{~h}$ photoperiod (long day). Three-week-old seedlings were transplanted individually per pot $(15 \mathrm{~cm} \mathrm{x} 14 \mathrm{~cm})$ into fresh soil and grown further for 5 weeks. Apparently healthy plants were used for the greenhouse experiments. 


\subsubsection{Plant inoculation assays}

\subsubsection{Test for hypersensitivity (Klement, 1963)}

The ability of the bacterial strains to elicit a hypersensitive response (HR) in an intact tobacco (Nicotiana tabacum) leaf was tested for all the bacterial strains. For this purpose, the injection infiltration method (Klement, 1963) was followed.

A leaf of a 4-week-old tobacco plant was injected with a bacterial suspension containing ca. $10^{8}$ cells $/ \mathrm{ml}$ using a sterile hypodermic needle, and the inoculated plant was placed at $24{ }^{\circ} \mathrm{C}$ in the greenhouse. The leaf was monitored after 12 and $24 \mathrm{~h}$ for appearance of HR.

\subsubsection{Screening for susceptible cultivars of tomato and celery}

Apparently healthy plants of tomato and celery cultivars (Table 1.2.2.) were mechanically inoculated with a freshly prepared bacterial suspension of Pseudomonas syringae pv. apii or $P$. s. pv. tomato race 0 in $10 \mathrm{mM} \mathrm{MgSO}_{4}$. The suspension was atomized on the lateral side of the young leaves of 8-week-old plants during the morning. Inoculations were performed in isolated batches for each of the 2 bacterial suspensions to avoid cross-contamination. The inoculated plants were maintained in the greenhouse under ambient conditions $\left(24{ }^{\circ} \mathrm{C}\right.$, R. H. $\left.80 \%\right)$ for 7 days for development of symptoms. Plants that were not sprayed with a bacterial suspension served as negative controls.

A minimum of 4 replications were carried out for each of the combinations and the experiment was repeated three times. 


\subsubsection{Tests for cross-infection (inoculations on non-host plants)}

The bacterial suspensions of $P$. s. pv. apii GSPB 2548 and $P$. s. pv. tomato race 0 GSPB 2317 were prepared and inoculated on their non-host plants of tomato and celery cultivars, respectively, as described above and observed for development of disease symptoms after 7 days.

\subsubsection{Disease evaluation}

Leaves of inoculated plants were inspected for development of disease symptoms seven days after spraying with a bacterial suspension. Plants showing characteristic water-soaked lesions were recorded as susceptible while those with no symptoms or with tiny necrotic spots were recorded as resistant (Mavridis, 1982).

\subsubsection{Molecular analysis}

\subsubsection{Preparation of genomic DNA from bacterial strains}

The DNA was extracted from bacterial strains following the method of Ausubel et al. (1987).

- Bacterial strains were cultivated in nutrient broth for $24 \mathrm{~h}$.

- A $1.5 \mathrm{ml}$ aliquot of the culture was micro centrifuged (Hettich Universal $30 \mathrm{RF}$ ) at $8,000 \mathrm{rpm}$ for $3 \mathrm{~min}$.

- The pellet was resuspended in $567 \mu 1$ of 1 X TE buffer and vortexed.

- Thirty $\mu \mathrm{l}$ of $10 \%(\mathrm{w} / \mathrm{v})$ SDS and $3 \mu \mathrm{l}$ of $20 \mathrm{mg} / \mathrm{ml}$ proteinase $\mathrm{K}$ were admixed to the resuspended pellet and incubated for $1 \mathrm{~h}$ at $37^{\circ} \mathrm{C}$.

- One hundred $\mu 1$ of $5 \mathrm{M} \mathrm{NaCl}$ were added and mixed thoroughly.

- Eighty $\mu \mathrm{l}$ of $\mathrm{CTAB} / \mathrm{NaCl}$ solution were admixed, to the above and incubated for a further $10 \mathrm{~min}$ at $65{ }^{\circ} \mathrm{C}$ followed by cooling on a ice bath for $15 \mathrm{~min}$; this step was performed to precipitate the exopolysaccharides and contaminating macromolecules. 
- An equal volume of chloroform/isoamyl alcohol (24:1) was admixed, incubated for 5 min on ice, and centrifuged at $11,000 \mathrm{rpm}$ for $10 \mathrm{~min}$ at $4{ }^{\circ} \mathrm{C}$.

- The supernatant was transferred to a fresh tube and an equal volume of phenol/chloroform/isoamyl alcohol (25:24:1) was added and centrifuged at 12,500 rpm for 5 min at $4{ }^{\circ} \mathrm{C}$.

- The supernatant was siphoned off to a fresh Eppendorf tube, 0.6 vol. of isopropanol were added, incubated on ice for $30 \mathrm{~min}$, and finally centrifuged at 11,000 rpm for 10 $\min$ at $4{ }^{\circ} \mathrm{C}$.

- The pellets were resuspended and washed in $500 \mu 1$ of $70 \%$ ethanol and centrifuged at $12,500 \mathrm{rpm}$ for $5 \mathrm{~min}$ at $4{ }^{\circ} \mathrm{C}$; this step was repeated twice.

- The supernatants were discarded and tubes were dried at room temperature overnight, the pellets were suspended in $50 \mu 1$ of TE buffer ( $\mathrm{pH} 7.6$ ), incubated overnight at $4{ }^{\circ} \mathrm{C}$, and the samples were stored at $-20{ }^{\circ} \mathrm{C}$ until further use.

\subsubsection{Quantification of $D N A$}

The amount of DNA present in the extracted fraction was quantified using a Gene Quant spectrophotometer (Pharmacia, Freiburg, Germany) at two different wavelengths 260 and $280 \mathrm{~nm}$. An OD of 1 corresponds to approximately $50 \mu \mathrm{g} / \mathrm{ml}$ for double stranded DNA. The ratio between the reading at $260 \mathrm{~nm}$ and $280 \mathrm{~nm}\left(\mathrm{OD}_{260}\right.$ $/ \mathrm{OD}_{280}$ ) will give the purity of the nucleic acid (Sambrook et al., 1989). The DNA samples were appropriately diluted in sterile double distilled water or $1 \mathrm{X}$ TE. The samples were stored at $4{ }^{\circ} \mathrm{C}$ or were frozen at $-20{ }^{\circ} \mathrm{C}$ for long term storage.

\begin{tabular}{c} 
Amount of DNA $=\frac{\text { O. D at } 260 \mathrm{~nm}}{\text { O. D at } 280 \mathrm{~nm}}$ \\
\hline
\end{tabular}




\subsubsection{Polymerase chain reactions}

\subsection{Detection of the gene for coronatine (cor A)}

The amplification of specific DNA regions that correspond to the corA biosynthesis gene was performed using recommended primers (Bereswill et al., 1994). The sequence of the primers are as follows:

\section{5 - GGC GCT CCC TCG CAC TT- 3` ( Primer 1) and 5`- GGT ATT GGG GGT GC-3` (Primer 2)}

The PCR conditions were essentially the same as described by NabizadehArdekani et al. (1997). The buffers for the PCR reactions were purchased from Qiagen, Germany and the primers were obtained from Fermentas, Germany. A total volume of $50 \mu \mathrm{l}$ was set up for the reactions and contained the following components.

Table 1.2.10.3.1. Composition of PCR mixtures

\begin{tabular}{llc}
\hline Components & Volume & Final concentration \\
\hline 10 X PCR reaction buffer & $5.0 \mu \mathrm{l}$ & $1 \mathrm{X}$ \\
$\mathrm{dNTP}-\mathrm{mix}(10 \mathrm{mM})$ & $1.0 \mu \mathrm{l}$ & $0.2 \mathrm{mM}$ \\
$\mathrm{MgCl}_{2}(25 \mathrm{mM})$ & $0.9 \mu \mathrm{l}$ & $1.8 \mathrm{mM}$ \\
Primer 1 $(10 \mathrm{pmol} / \mu \mathrm{l})$ & $2.0 \mu \mathrm{l}$ & $20 \mathrm{pmol}$ \\
Primer 2 $(10 \mathrm{pmol} / \mu \mathrm{l})$ & $2.0 \mu \mathrm{l}$ & $20 \mathrm{pmol}$ \\
Tween 20 & $0.5 \mu \mathrm{l}$ & $1 \%(\mathrm{v} / \mathrm{v})$ \\
Bovine serum albumin $(20 \mathrm{mg} / \mathrm{ml})$ & $0.5 \mu \mathrm{l}$ & $1 \%(\mathrm{v} / \mathrm{v})$ \\
Dimethylsulfoxide & $2.5 \mu \mathrm{l}$ & $5 \%(\mathrm{v} / \mathrm{v})$ \\
Taq- DNA- polymerase $(4 \mathrm{U} / \mu \mathrm{l})$ & $0.25 \mu \mathrm{l}$ & $1 \mathrm{U}$ \\
Template DNA & $4 \mu \mathrm{l}$ & $10-20 \mu \mathrm{g}$ \\
$\mathrm{H}_{2} \mathrm{O}$ & to $50 \mu \mathrm{l}$ & \\
& & \\
\hline
\end{tabular}


The reaction mixture was over-layered with $50 \mu \mathrm{l}$ of mineral oil to prevent evaporation of the samples and placed into the blocks of a DNA thermal cylcer (Omnigene HBTR3SM7, Hybaid limited, Heidelberg, Germany).

The following programme was adopted for the amplification.

$\left.\begin{array}{ll}\text { Initial denaturation } & 94{ }^{\circ} \mathrm{C}, 3 \mathrm{~min} \\ \text { Denaturation } & 92^{\circ} \mathrm{C}, 2 \mathrm{~min} \\ \text { Annealing } & 59^{\circ} \mathrm{C}, 2 \mathrm{~min} \\ \text { Extension } & 72^{\circ} \mathrm{C}, 1 \mathrm{~min}\end{array}\right\} \quad 35$ cycles

\subsubsection{Resolution of amplified fragments}

The amplified products were resolved by electrophoresis on a $1.5 \%$ agarose gel $(\mathrm{w} / \mathrm{v}$ in $1 \mathrm{X} \mathrm{TBE})$ and stained with ethidium bromide for visualization as described below.

\subsection{Agarose gel electrophoresis}

The products of PCR amplification were separated on an $1.5 \%$ agarose gel (Roth, Karlschule) in $1 \mathrm{X}$ TBE buffer. The template was cleaned and dried. The open ends of the template were sealed tightly with an adhesive tape so as to form a mould. A comb was placed at one end of the template. Care was taken to ensure that there was enough space between the base of the template and the bottom of the teeth.

The agarose was weighed into an Erlenmeyer flask and suspended in $1 \mathrm{X}$ TBE buffer. The suspension was heated in a micro oven until no "swirls" of agarose were visible and the clean solution was cooled to about $50{ }^{\circ} \mathrm{C}$. The molten agarose was poured into the template and the gel was allowed to set for atleast $30 \mathrm{~min}$. 
The gel was transferred to a horizontal gel apparatus (Biorad, Germany) halffilled with $1 \mathrm{X}$ TBE buffer. Fifteen $\mu$ of the samples were mixed with 1/10 volume of $6 \mathrm{X}$ loading dye solution and loaded into the wells with a micropipette tip. The DNA molecular weight marker PBR 322/Alu I was used as a standard to estimate the molecular weight of the amplified fragments.

Electrophoresis was carried out at a constant voltage of $5 \mathrm{~V} / \mathrm{cm}$, for $2 \mathrm{~h}$. The gels were transferred to a tank containing ethidium bromide (Fluka) at a concentration of $0.05 \mu \mathrm{l} / \mathrm{ml}$ and for $10 \mathrm{~min}$ followed by destaining in water for $5 \mathrm{~min}$ and visualized under a UV transilluminator and documented (Bio-Rad Gel Doc 1000, Munich, Germany).

\subsubsection{Repetitive PCR}

The following primers were purchased from Fermentas, Germany

REP

REP 1 R-I [5'-IIIICGICGICATCIGGC-3 '] and

REP 2-I [ 5'-ICGICTTATCIGGCCTAC-3`]

ERIC

ERIC 1 R [5'-ATGTAAGCTCCTGGGGATTCAC-3`] and

ERIC 2 [5`- AAGTAAGTGACTGGGGTGAGCG-3`])

BOX

BOXA1R [ 5’-CTACGGCAAGGCGACGCTGACG-3`])

The PCR amplifications were carried out as described by Louws et al., (1994). A master mix was prepared with PCR reagents purchased from Qiagen and dispensed equally into $200 \mu 1$ PCR tubes (Biozymes, Hess., Oldendorf). 
Table 1.2.10.5.1. Composition of PCR mixtures

\begin{tabular}{lcc}
\hline Components & Volume & Final concentration \\
\hline 10 X PCR reaction buffer & $5.0 \mu \mathrm{l}$ & $1 \mathrm{X}$ \\
dNTP- Mix $(10 \mathrm{mM})$ & $1.0 \mu \mathrm{l}$ & $0.2 \mathrm{mM}$ \\
Primer 1 $(10 \mu \mathrm{M} / \mu \mathrm{l})$ & $5.0 \mu \mathrm{l}$ & $1.0 \mu \mathrm{M}$ \\
Primer 2 $(10 \mu \mathrm{M} / \mu \mathrm{l})$ & $5.0 \mu \mathrm{l}$ & $1.0 \mu \mathrm{M}$ \\
Taq- DNA- Polymerase $(1.25 \mathrm{U} / \mu \mathrm{l})$ & $1.0 \mu \mathrm{l}$ & $0.025 \mathrm{U} / \mu \mathrm{l}$ \\
Target -DNA & $4.0 \mu \mathrm{l}$ & $10-20 \mu \mathrm{g}$ \\
$\mathrm{H}_{2} \mathrm{O}$ & $29.0 \mu \mathrm{l}$ & \\
& & \\
\hline
\end{tabular}

The mixtures were over-layered with $50 \mu \mathrm{l}$ of mineral oil and amplifications were performed on a DNA-thermal cycler (Omnigene HBTR3SM7, Hybaid Ltd. , Heidelberg, Germany) with the following conditions:

Table 1.2.10.5.2. PCR conditions

\begin{tabular}{|c|c|c|c|c|c|}
\hline \multirow{2}{*}{ PCR } & \multirow{2}{*}{$\begin{array}{c}\text { Initial } \\
\text { Denaturation }\end{array}$} & \multicolumn{3}{|c|}{ Amplification cycles } & \multirow{2}{*}{$\begin{array}{c}\text { Final } \\
\text { elongation }\end{array}$} \\
\hline & & Denaturation & Annealing & Elongation & \\
\hline REP-PCR & $\begin{array}{l}95^{\circ} \mathrm{C}, \\
7 \mathrm{~min}\end{array}$ & $\begin{array}{l}94^{\circ} \mathrm{C}, \\
1 \mathrm{~min}\end{array}$ & $\begin{array}{l}94^{\circ} \mathrm{C}, \\
1 \mathrm{~min}\end{array}$ & $\begin{array}{l}94^{\circ} \mathrm{C}, \\
1 \mathrm{~min}\end{array}$ & $\begin{array}{l}65^{\circ} \mathrm{C}, \\
15 \mathrm{~min}\end{array}$ \\
\hline ERIC -PCR & $\begin{array}{l}95^{\circ} \mathrm{C}, \\
7 \mathrm{~min}\end{array}$ & $\begin{array}{l}44^{\circ} \mathrm{C}, \\
1 \mathrm{~min}\end{array}$ & $\begin{array}{l}52^{\circ} \mathrm{C}, \\
1 \mathrm{~min}\end{array}$ & $\begin{array}{l}53{ }^{\circ} \mathrm{C}, \\
1 \mathrm{~min}\end{array}$ & $\begin{array}{l}65^{\circ} \mathrm{C}, \\
15 \mathrm{~min}\end{array}$ \\
\hline BOX- PCR & $\begin{array}{l}95^{\circ} \mathrm{C}, \\
7 \mathrm{~min}\end{array}$ & $\begin{array}{l}65^{\circ} \mathrm{C}, \\
8 \mathrm{~min}\end{array}$ & $\begin{array}{l}65^{\circ} \mathrm{C}, \\
8 \mathrm{~min}\end{array}$ & $\begin{array}{l}65^{\circ} \mathrm{C}, \\
8 \mathrm{~min}\end{array}$ & $\begin{array}{l}65^{\circ} \mathrm{C}, \\
15 \mathrm{~min}\end{array}$ \\
\hline
\end{tabular}




\subsubsection{Polyacrylamide gel electrophoresis (PAGE)}

The amplified PCR products were resolved on a 5-10\% gradient polyacrylamide gel using a vertical gel electrophoresis apparatus (Biometra, Germany).

\subsection{Preparation of polyacrylamide gel}

\section{a. Stock solutions}

Acrylamide solution $\quad 30 \%(\mathrm{w} / \mathrm{v})$ acrylamide,

$0.8 \%(\mathrm{w} / \mathrm{v})$ bisacrylamide

$10 \mathrm{X}$ TBE buffer

0.9 M Tris

$0.9 \mathrm{M}$ boric acid

20 mM EDTA (pH 8.0)

$87 \%$ Glycerine

$10 \%(\mathrm{w} / \mathrm{v})$ TEMED

$10 \%(\mathrm{w} / \mathrm{v})$ APS

Table 1.2.10.6.1. Formulation for preparing acrylamide gels

\begin{tabular}{lccc}
\hline & \multicolumn{3}{c}{ Percentage of gel } \\
\cline { 2 - 4 } Solutions & $\mathbf{3 \%}$ & $\mathbf{5 \%}$ & $\mathbf{1 0 \%}$ \\
\cline { 2 - 4 } & & & \\
Acrylamide solution & $0.4 \mathrm{ml}$ & $0.7 \mathrm{ml}$ & $1.44 \mathrm{ml}$ \\
TBE-buffer & $0.4 \mathrm{ml}$ & $0.4 \mathrm{ml}$ & $0.4 \mathrm{ml}$ \\
Dm water & $3.2 \mathrm{ml}$ & $2.9 \mathrm{ml}$ & $1.75 \mathrm{ml}$ \\
TEMED & $25 \mu 1$ & $25 \mu l$ & $25 \mu 1$ \\
Glycerine & - & - & $0.4 \mathrm{ml}$ \\
APS & $25 \mu 1$ & $25 \mu l$ & $25 \mu 1$ \\
\hline
\end{tabular}


The glass plates used for preparing the gels were cleaned with $70 \%$ ethanol and air-dried. A polymerization cassette was made using the two glass plates. The solutions required for preparing the $5 \%$ and $10 \%$ separating gels except ammoniumpersulphate (APS) and TEMED were mixed separately in $10 \mathrm{ml}$ side arm Erlenmeyer flasks. The flasks were sealed with rubber stoppers and the contents were de-aerated for ca. $30 \mathrm{~min}$. APS and TEMED were added to the solutions and gently swirled to mix. The solutions were poured into the 2 chambers of a gradient mixer fitted with a peristaltic pump (Perimax, Model no. 7013) to dispense the mixture between the sandwiched glass plates. The unpolymerized gel was immediately overlaid with water-saturated iso-butanol or $\mathrm{H}_{2} \mathrm{O}$ and allowed to polymerize. The solution for a 3\% stacking gel was prepared as described above and layered over the polymerized separating gel using a glass pipette, a comb was carefully fixed into the unpolymerized stacking gel and the gel was allowed to set for $30 \mathrm{~min}$.

\subsection{Electrophoresis conditions}

Eight to ten $\mu 1$ of the PCR product were mixed with $1.5 \mu$ l of $6 \mathrm{X}$ loading dye and pipetted into the wells of the gel. A $100 \mathrm{bp}$ DNA ladder plus (Fermentas, Cat. Nr. SM0323S) was used as marker for determination of the molecular weight of the amplified fragments. The gel was run at $15 \mathrm{mV}$ for $3 \mathrm{~h}$ and stained with ethidium bromide and visualized under UV light using a UV transilluminator and documented (BIO-Rad Gel Doc 1000, Munich, Germany).

\subsubsection{Numerical taxonomic analysis}

The distance between the strains was calculated as a measure of the similarities or differences by pair-wise comparisons of their rep-PCR genomic profiles. The dissimilarity between two strains was expressed as the proportion of different characters, recorded as a binary form called the simple matching coefficient giving a 
simple numerical value for dissimilarity. The measures of the amount of discriminating properties were verified by applying Dice's coefficient (Dice, 1945) as follows :

$$
G_{D}=1-2 a / 2 a+(b+c)
$$

where a represents the no. of common matches, $\mathbf{b}$, the no. of bands in strain A and $\mathbf{c}$, the no. of bands in strain B.

Cluster analysis was performed using the program Syn-Tax 5.18 (Podani, 1993) based on the Unweighted Pair Group Method with Arithmetic Average (UPGMA) as described earlier (Goodfellow and O` Donnel, 1993; McDonnell and Colwell,1985;Sneath and Sokal, 1973). 


\subsection{Results}

\subsubsection{Viability of Pseudomonas syringae pv. apii in $\mathrm{MgSO}_{4}$}

The ability of the various strains of Pseudomonas syringae pv. apii to survive in $10 \mathrm{mM} \mathrm{MgSO}_{4}$ was inferred by the number of bacterial colonies observed during a $5 \mathrm{~h}$ time period. Different dilutions were made to facilitate counting.

The number of colonies present at the end of $5 \mathrm{~h}$ did not vary significantly from the initial values taken at the zero hour at the dilutions which enabled unambiguous counting (see table 1.3.1.).

It was concluded from this experiment that the bacteria survived relatively well for $5 \mathrm{~h}$ in $10 \mathrm{mM} \mathrm{MgSO}_{4}$ although the concentration of viable cells decreased slightly.

Table 1.3.1. Viability of Pseudomonas syringae pv. apii in $10 \mathrm{mM} \mathrm{MgSO}_{4}$

\begin{tabular}{|c|c|c|c|c|}
\hline \multirow[b]{3}{*}{ Dilutions } & \multicolumn{4}{|c|}{ No. of colonies } \\
\hline & \multicolumn{2}{|c|}{$1: 50$} & \multicolumn{2}{|c|}{$1: 500$} \\
\hline & $\mathbf{0 ~ h}$ & $5 \mathrm{~h}$ & $\mathbf{0} \mathbf{h}$ & $5 \mathrm{~h}$ \\
\hline $10^{1}$ & $\mathrm{TNC}$ & $\mathrm{TNC}$ & $\mathrm{TNC}$ & TNC \\
\hline $10^{2}$ & $\mathrm{TNC}$ & 576 & 266 & 250 \\
\hline $10^{3}$ & 246 & 239 & 36 & 24 \\
\hline $10^{4}$ & 33 & 11 & 4 & 4 \\
\hline $10^{5}$ & 6 & 4 & 1 & 0 \\
\hline
\end{tabular}

TNC : too numerous to count 


\subsubsection{Plant inoculation assays}

\subsubsection{Test for hypersensitivity}

A hypersensitive reaction (HR) is induced in the plant against incompatible pathogens and is characterized by rapid cell death or tissue necrosis localizing the pathogen at the infection site.

The bacterial strains were tested for their ability to induce HR in tobacco plants. All the strains used except $P$. syringae pv. apii 2545 were able to elicit HR in tobacco (Table 1.3.2.1.). HR was observed within $12 \mathrm{~h}$ after inoculation.

Table 1.3.2.1. Response of an intact tobacco leaf following inoculation with $P$. syringae strains

\section{Bacterial cultures Hypersensitivity reactionOD}

\begin{tabular}{lcl}
\hline P. syringae pv. apii 2545 & - & 0.06 \\
P. syringae pv. apii 2546 & + & 0.06 \\
P. syringae pv. apii 2547 & + & 0.06 \\
P. syringae pv. apii 2548 & + & 0.06 \\
P. syringae pv. apii2153 & + & 0.06 \\
P. syringae pv. tomato race 02317 & + & 0.06 \\
P. syringae pv. tomato race 11778 & + & 0.06 \\
\hline
\end{tabular}

$+:$ positive response; -: negative response 


\subsubsection{Screening for susceptible selectants of cultivar Ontario no. 7710}

Eighty four plants derived from seeds of a single fruit of the tomato cv. Ontario no. 7710 were tested for their susceptibility to $P$. s. pv. tomato race 0 . They were distinguished as resistant or susceptible on the basis of their reaction to the pathogen. While one-third of them (63 plants) behaved as resistant, the remaining (21 plants) were susceptible. Based on the results two sub-groups within the cv. Ontario no. 7710 were identified. The susceptible sub-group was termed as cv. Ontario no. 7710 selectant (cv. Ontario (S)) and the resistant sub-group of the same cultivar was termed Ontario no. 7710 resistant (cv. Ontario (R)). This nomenclature has been followed throughout this study.

Symptoms of bacterial speck were observed on the leaves of cv. Ontario (S) from the seventh day after inoculation. They appeared as water-soaked lesions surrounded by chlorotic haloes. The spots gradually enlarged and coalesced with each other leading to browning and ultimately necrosis of the entire leaf (Fig. 1.3.2.2.1.). The cv. Ontario (R) was resistant since the leaves remained symptomless.

Besides their differential reaction to $P$. $s$. pv. tomato race 0 the two sub-groups differed in their phenotype. While cv. Ontario (S) was taller and had elongated leaves and smaller fruits, the cv. Ontario (R) was shorter, had broader leaves and bore normal fruits (Fig. 1.3.2.2.2.). 
Table 1.3.2.2. Response of the tomato cv. Ontario 7710 to $P$. syringae pv. tomato race 0

\begin{tabular}{|c|c|c|c|c|c|c|c|}
\hline Plant No. & $\begin{array}{r}\text { Host } \\
\text { response }\end{array}$ & Plant No. & $\begin{array}{c}\text { Host } \\
\text { response }\end{array}$ & Plant No. & $\begin{array}{c}\text { Host } \\
\text { response }\end{array}$ & Plant No. & $\begin{array}{l}\text { Host } \\
\text { response }\end{array}$ \\
\hline 1 & - & 22 & - & 43 & - & 64 & - \\
\hline 2 & - & 23 & + & 44 & - & 65 & - \\
\hline 3 & - & 24 & - & 45 & + & 66 & - \\
\hline 4 & - & 25 & + & 46 & - & 67 & - \\
\hline 5 & - & 26 & - & 47 & - & 68 & - \\
\hline 6 & - & 27 & + & 48 & - & 69 & - \\
\hline 7 & - & 28 & - & 49 & - & 70 & - \\
\hline 8 & + & 29 & + & 50 & + & 71 & - \\
\hline 9 & - & 30 & - & 51 & + & 72 & - \\
\hline 10 & - & 31 & + & 52 & - & 73 & - \\
\hline 11 & + & 32 & + & 53 & + & 74 & - \\
\hline 12 & - & 33 & - & 54 & - & 75 & - \\
\hline 13 & - & 34 & - & 55 & + & 76 & + \\
\hline 14 & - & 35 & - & 56 & - & 77 & - \\
\hline 15 & + & 36 & - & 57 & - & 78 & - \\
\hline 16 & - & 37 & - & 58 & + & 79 & - \\
\hline 17 & - & 38 & - & 59 & - & 80 & - \\
\hline 18 & + & 39 & - & 60 & - & 81 & - \\
\hline 19 & & 40 & - & 61 & + & 82 & - \\
\hline 20 & - & 41 & - & 62 & - & 83 & + \\
\hline 21 & + & 42 & - & 63 & - & 84 & + \\
\hline
\end{tabular}


Fig. 1.3.2.2.1. Bacterial speck caused by $P$. $s$. pv. tomato race 0

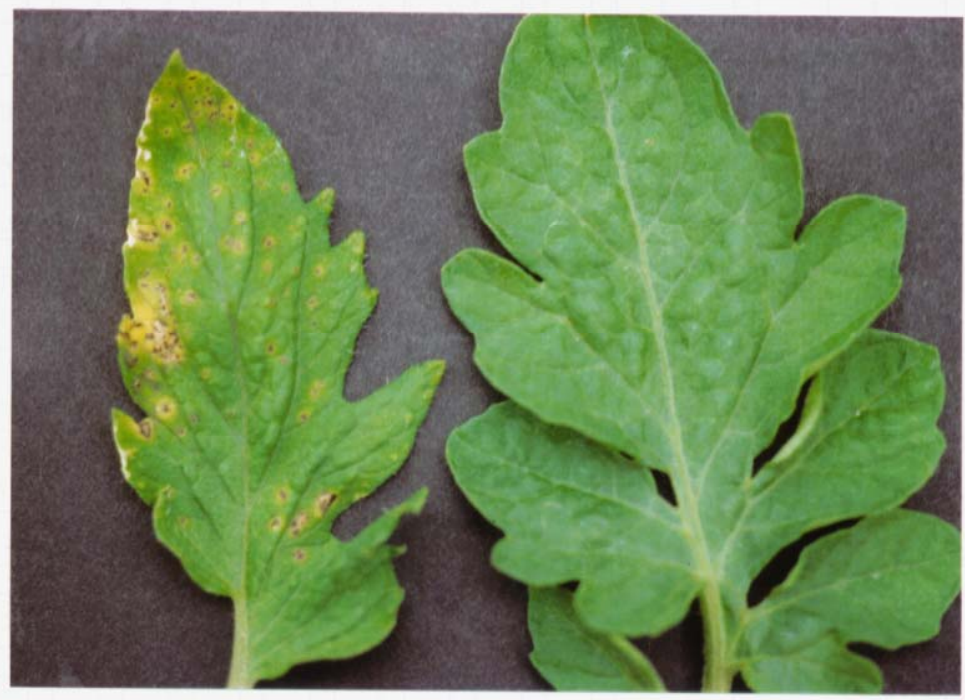

Ontario no. 7710 selectant

Ontario no. 7710 resistant

Fig. 1.3.2.2.2. Phenotypic appearance of Ontario no. 7710 resistant and Ontario no. 7710 selectant

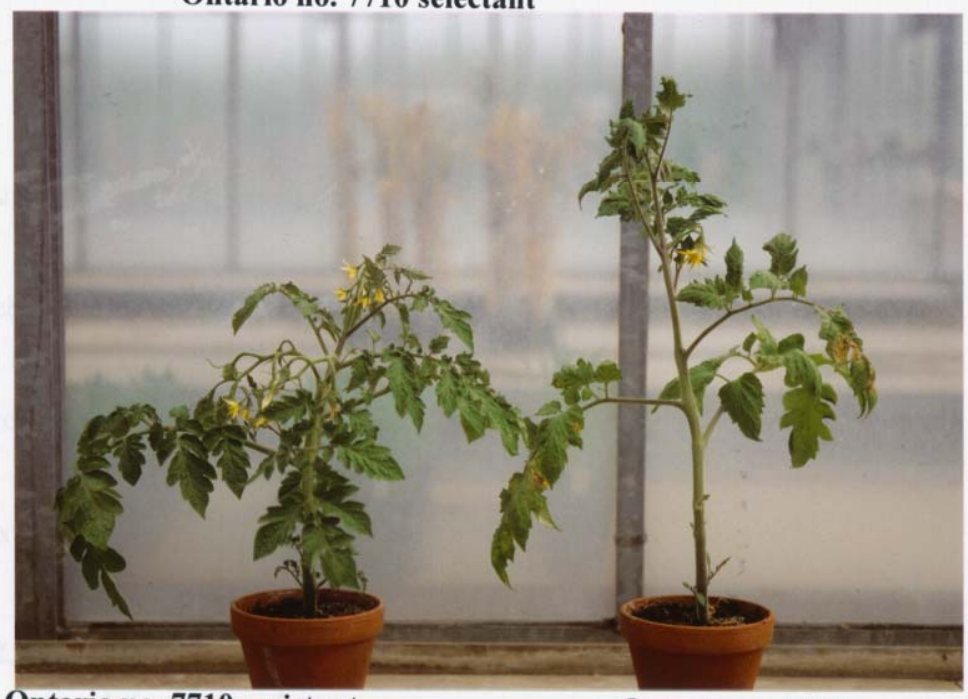

Ontario no. 7710 resistant

Ontario no. 7710 selectant 


\subsubsection{Screening for susceptible celery cultivars}

The bacterial cultures P. s. pv. apii GSPB 2545, 2546, 2547, 2548, 2153 were inoculated on 8-week-old plants of 13 different cultivars of celery (Table 1.3.2.3.). Of the 65 different combinations tested, only one namely P. s. pv. apii 2548 and cv. Claret was truly compatible. In this interaction, the pathogen was able to initiate bacterial blight symptoms on the leaves of the plant within 7 days after inoculation (Fig. 1.3.2.3.1.). The symptoms became evident after seven days.

Among the other cultivars cv. Rokary showed partial susceptible symptoms, however the response could not be reproduced in repeated experiments under the same experimental conditions. Therefore the cv. Claret was selected as the susceptible cultivar. Among the numerous incompatible combinations obtained, the cv. Monarch was selected to serve as the resistant cultivar for this study.

Table 1.3.2.3. Response of the celery cultivars to $P$. syringae pv. apii

\begin{tabular}{|c|c|c|c|c|c|c|}
\hline \multirow[t]{2}{*}{ Celery } & \multirow{2}{*}{ Subspecies } & \multicolumn{5}{|c|}{ Pseudomonas syringae pv. apii strain } \\
\hline & & 2545 & 2546 & 2547 & 2548 & 2153 \\
\hline Alabaster & A. g. dulce & - & - & - & - & - \\
\hline Bergens & A. g. dulce & - & - & - & - & - \\
\hline Claret & A. g. rapaceum & $t-$ & - & - & + & - \\
\hline Erfort & A. g. dulce & - & - & - & - & - \\
\hline Jablorag & A. g. dulce & - & - & - & - & - \\
\hline Loret & A. g. rapaceum & $\imath-$ & - & - & - & - \\
\hline Magdeburger & A. g. dulce & - & - & - & - & - \\
\hline Mars & A. g. dulce & - & - & - & - & - \\
\hline Monarch & A. g. dulce & - & - & - & - & - \\
\hline Odedi & A. g. dulce & - & - & - & - & - \\
\hline Phonex & A. g. dulce & - & - & - & - & - \\
\hline Prinz & A. g. dulce & - & - & - & - & - \\
\hline Rokary & A. g. dulce & - & - & - & +- & - \\
\hline
\end{tabular}

A. g. : Apium graveolens

+ : susceptible, - : resistant, +-: partially susceptible 
Fig. 1.3.2.3.1. Northern bacterial blight on celery cv. Claret by Pseudomonas syringae pv. apii 2548

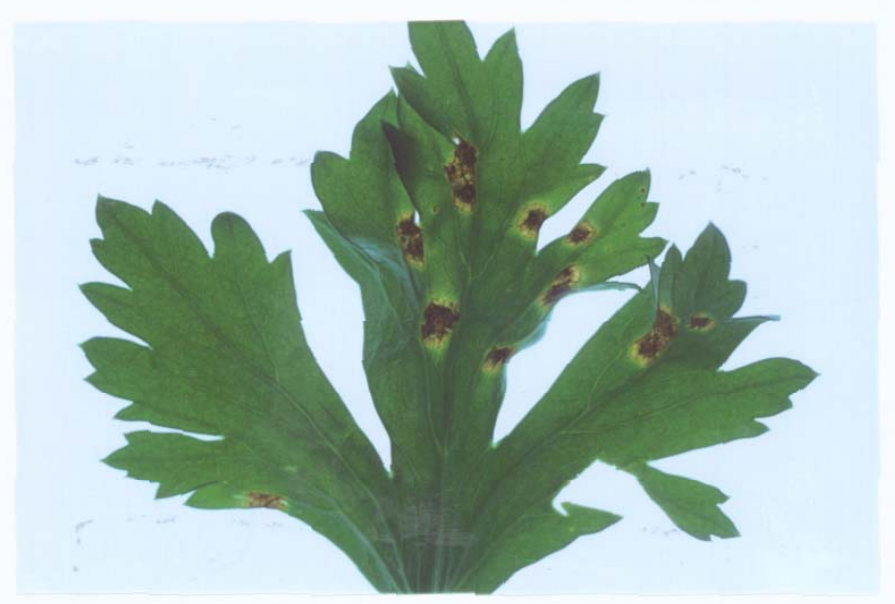

1.3.2.4. Tests for cross-infection (inoculations on non-host plants)

P. s. pv. apii and P. s. pv. tomato (race 0) were inoculated into tomato and celery plants, their respective non-hosts to test their ability to cross-infect. $P . s$. pv. apii was able to successfully colonize the tomato cv. Ontario (S) on which symptoms of bacterial speck appeared from seven days after inoculation (Fig. 1.3.2.4.1a). Conversely, when P. s. pv. tomato was inoculated on celery plants the disease response could not be unambiguously determined. Chlorotic lesions appeared on leaves of the susceptible cv. Claret, however the lesions did not elaborate into characteristic disease symptoms (Fig. 1.3.2.4.1b). 
Table 1.3.2.4. Cross-imfectivity of P. s. pvs. ap $\ddot{\text { and }}$ andoto on tomato and celery cultivars

\begin{tabular}{|c|c|c|c|c|}
\hline \multirow[b]{2}{*}{ Pathogen } & \multicolumn{2}{|c|}{ Celery } & \multicolumn{2}{|c|}{ Tomato } \\
\hline & Claret & Mestarch & Ontaris selectam & Ontario \\
\hline P.s. pv. apii & + & - & + & - \\
\hline$P$.s. pv, tomato & to & - & + & - \\
\hline
\end{tabular}

Fig. 1.3.2.4.1a. Symptoms caused on tomato cv, Ontario no. 7710 selectant by P. s. pv. apii at 7 days after inoculation

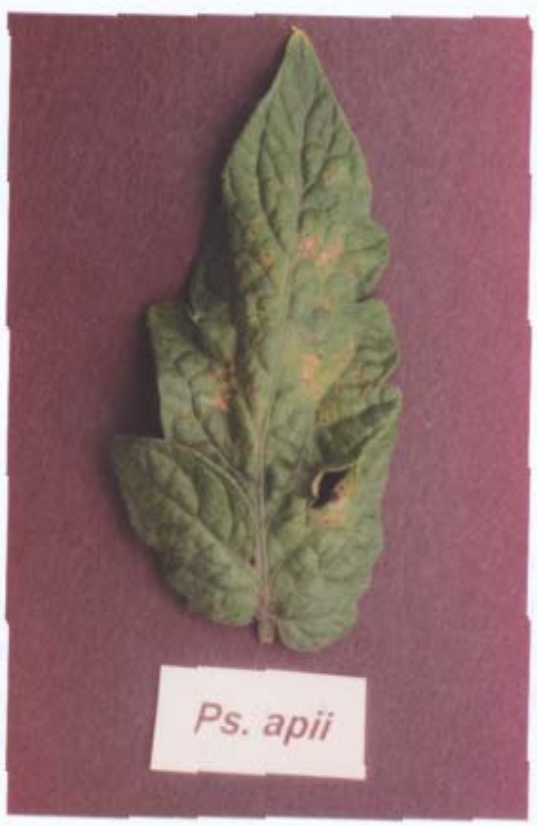


Fig. 1.3.2.4.1b. P. s. pv. tomato (race 0 ) inoculated on celery cvs. Monarch and Claret

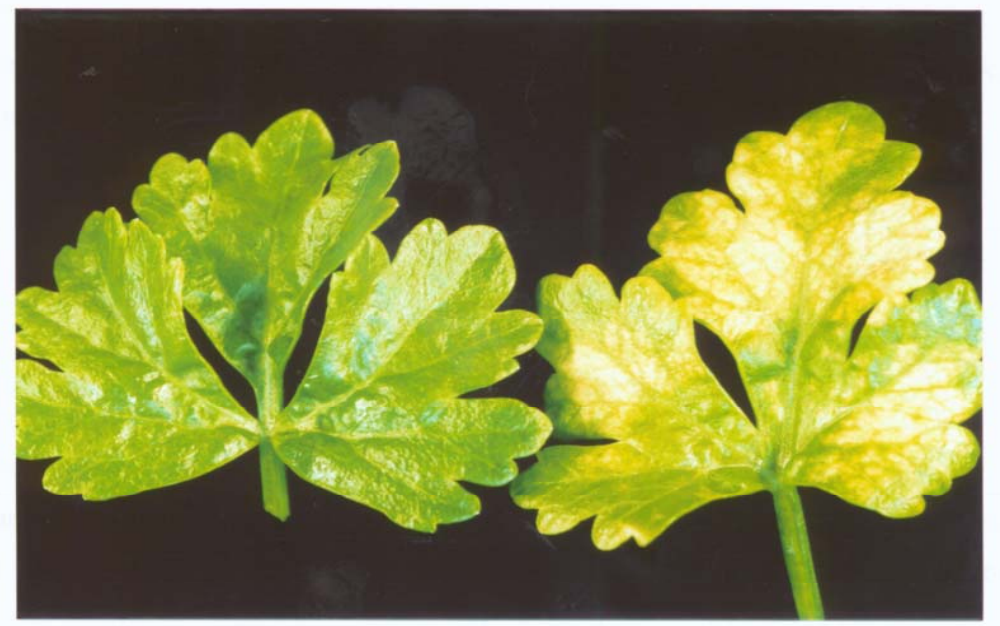

cv. Monarch

cv. Claret

Thus, the experiments revealed that there is only a small difference in host specificity of the P. syringae pathovars apii and tomato. Both pathovars were able to infect tomato leaves, whereas celery appeared to be a little more susceptible to $P$. $s$. pv. apii than to $P$. s. pv. tomato. However, both pathovars did not cause a strong disease on celery in general. 


\subsubsection{Molecular analysis}

\subsubsection{Numerical taxonomic analysis}

The BOX primers amplified specific regions of the bacterial genome which were used to obtain fingerprints for the different strains. The amplified fragments ranged in length from $200 \mathrm{bp}$ to $2,500 \mathrm{bp}$ out of which 16 were used to generate the fingerprints.

Cluster analysis using the UPGMA revealed three distinct groups based on the specific fingerprints (Fig. 1.3.3.1.2.). The first group comprised only P. s. pv. tomato GSPB 2317 and P. s. pv. apii GSPB 2548. In the second group, five strains were included, of which 3 belonged to $P$. s. pv. apii (strain nos. 2545, 2153, 2547) and 2 belonged to $P$. s. pv. tomato (strain nos. 2650 and 1778). The remaining two strains, one each from $P$. s. pvs. tomato and apii, were placed together in the third group. The first group was separated from the other two groups by a distance matrix of $25 \%$ and the groups 2 and 3 were related by a distance matrix of less than $10 \%$.

The REP and ERIC primers were not as efficient for the amplification of specific fragments from the bacterial genome.

In conclusion, genomic fingerprinting of repetitive DNA by using BOX

primers did not reveal clear differences between $P$. syringae pv. apii on one side and P. s. pv tomato on the other side. 
Fig. 1.3.3.1.1. Repetitive DNA fingerprints of Pseudomomas syringae pvs. apii and tomato using BOX primers

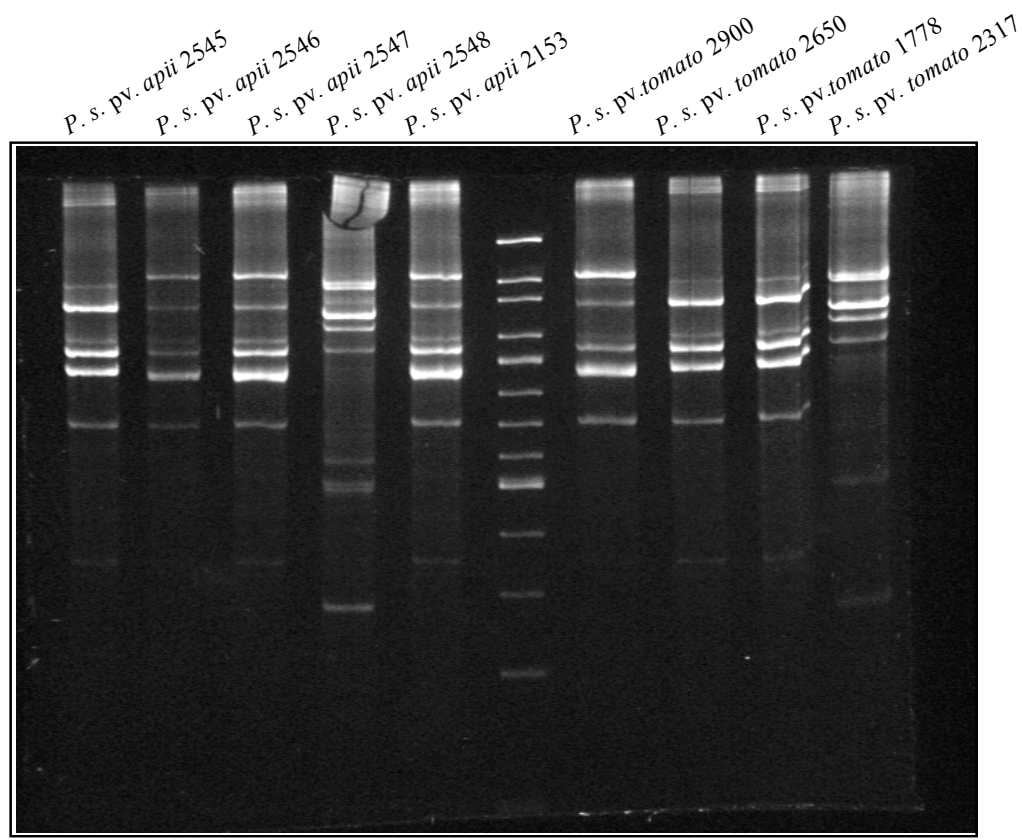

1. P. s. pv. apii 2545, 2 . P. s. pv. apii 2546, 3. P. s. pv. apii 2547, 4. P. s.pv. apii 2548, 5. P. s. pv. apii 2153, 6. Marker Gene ruler TM DNA Ladder Plus, 7. P. s. pv. tomato 2900,8 . P. s. pv. tomato 2650 , 9. P. s. pv. tomato 1778,10 . P. s. pv. tomato 2317 
Fig. 1.3.3.1.2. Cluster analyses of strains of $P$. syringae pvs. tomato and apii based on their BOX-PCR fingerprints

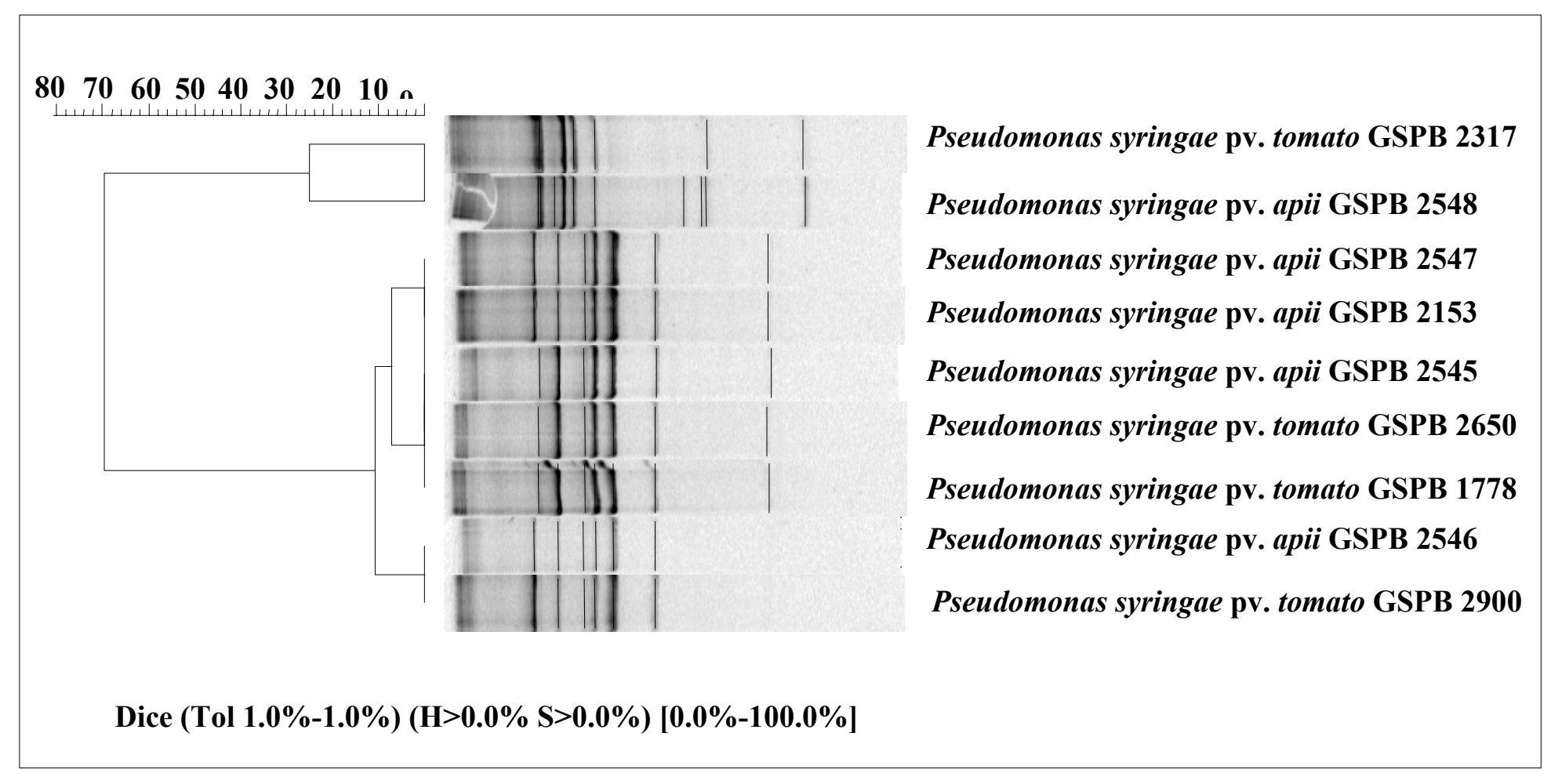

A dendrogram showing the extent of relatedness between strains of Pseudomonas syringae pv. tomato and Pseudomonas syringae pv. apii 


\subsubsection{Amplification of a region of $c f l$ gene out of two closely related pathovars of Pseudomonas syringae.}

The two strains, Pst GSPB 2317 and Psa GSPB 2548, were compared for the amplification of a region involved in coronatine biosynthesis $(C f l)$ using specific primers (Bereswill et al. , 1994). A 656 bp fragment was successfully amplified only from Pseudomonas syringae pv. tomato race 0 and not from the 5 strains of $P$. s. pv. apii tested (see table.1.3.3.2. and Fig. 1.3.3.2.1).

Fig. 1.3.3.2.1. Tests for PCR amplification of the coronatine gene from strains of Pst GSPB 2317 and Psa GSPB 2548.

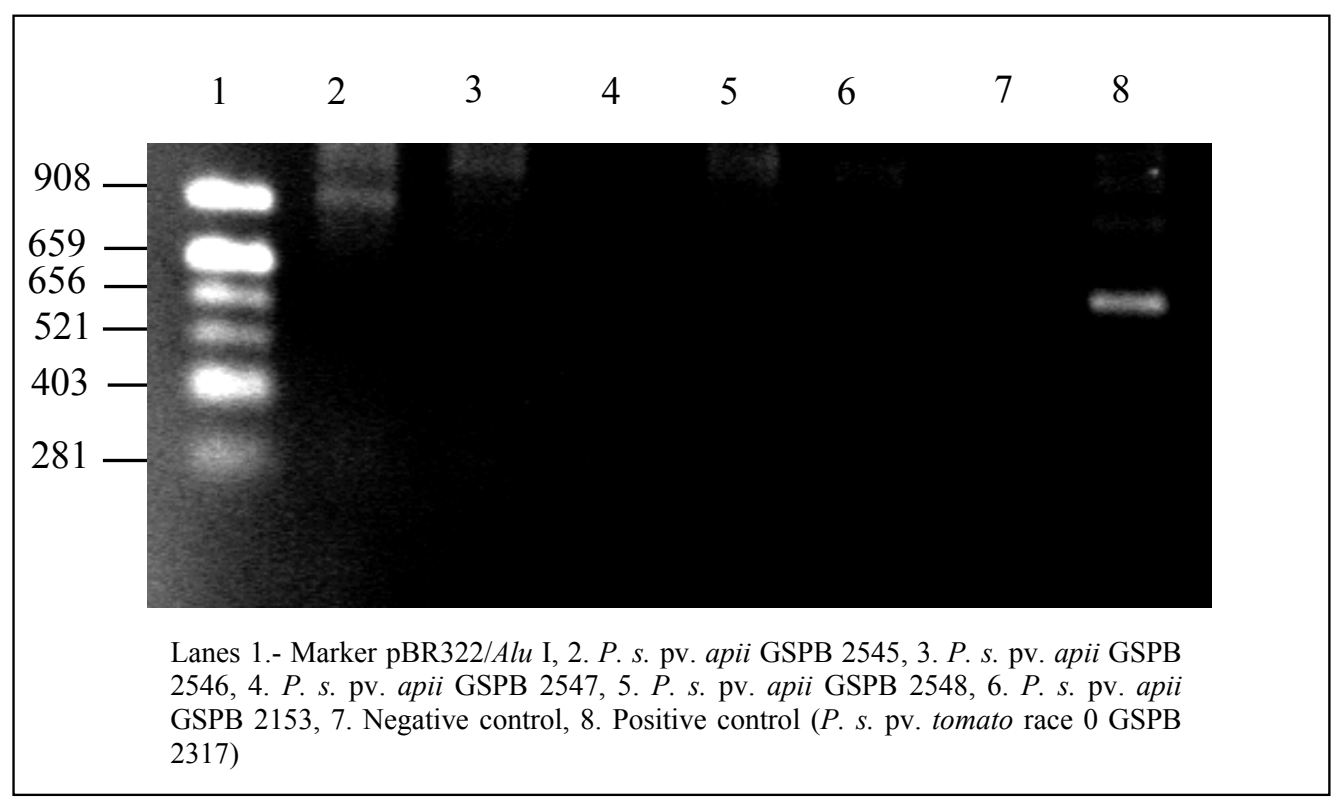

Ethidium bromide staining of PCR products separated on a $1.5 \%$ agarose gel. The presence of the specific region of the bacterial genome involved in the production of coronatine is indicated by a $656 \mathrm{bp}$ fragment that was detected only in Pst (lane 8). This region was not detected in the other strains (lanes 2 to 7 ). 
Table 1.3.3.2. Amplification of a region of $C f l$ gene out of two closely related pathovars of Pseudomonas syringae

\begin{tabular}{|c|c|c|}
\hline Pathogens & GSPB no. & Amplification \\
\hline Pseudomonas syringae pv. apii & 2545 & - \\
\hline Pseudomonas syringae pv. apii & 2546 & - \\
\hline Pseudomonas syringae pv. apii & 2547 & - \\
\hline Pseudomonas syringae pv. apii & 2548 & - \\
\hline Pseudomonas syringae pv. apii & 2153 & - \\
\hline Pseudomonas syringae pv. tomato race 0 & 2317 & + \\
\hline
\end{tabular}

- : negative, + : positive 


\subsection{Discussion}

Phytopathogenic pseudomonads and xanthomonads are generally host specific in nature. Within the pseudomonads especially the Pseudomonas syringae pathovars are characterized by a very narrow host specificity. It has been suggested that the bacterial lipopolysaccharide is one of the primary determinants of host-specificity of these pathogens by directly interacting with surface components of the hosts (Rudolph, 2001). One of the central aims of the present study was to find out whether strains possessing identical LPS structure can have the ability to infect the same hosts. Two closely related pathovars were selected; Pseudomonas syringae pv. tomato causing bacterial speck on tomato and $P$. s. pv. apii causing northern bacterial blight on celery. The rationale behind the selection is that both pathovars possess identical O-chain structures in their LPS (Ovod et al., 1997) yet have been classified into distinct pathovars. Therefore, in the present study, it has been attempted to clarify the degree of relatedness between the two pathovars by plant inoculation assays as well as molecular analyses based on rep-PCR fingerprints and coronatine synthesis.

For plant inoculations the bacteria were suspended in $10 \mathrm{mM} \mathrm{MgSO}_{4}$. This concentration does not alter the viability or virulence of the bacteria and has been used routinely in many plant inoculation experiments to prevent plasmolysis of the bacterial cells (Mavridis, per. communication). The viability of $P$. s. pv. apii was tested in 10 $\mathrm{mM} \mathrm{MgSO}$. There were no indications that the solution was harmful to the bacterial cells since no significant decline was observed in the number of colonies counted during a time interval of $5 \mathrm{~h}$. The values were obtained from experiments carried out at different dilutions (refer table 1.3.1.) in order to rule out ambiguity in the counting of colonies. $\mathrm{MgSO}_{4}$ at a concentartion of $10 \mathrm{mM}$ has been used to maintain the viability of P. s. pv. tomato (Müller, 1998), P. s. pv. glycinea (Laux, 1998) and P. s. pv. coriandricola (Liehe, 1998). Therefore, similar experiments were not performed for $P$. $s$. pv. tomato, the other bacterial strain used in this study. 
Prolonged storage and repeated sub culturing are known to decrease the virulence of the bacterial pathogens. Hypersensitivity tests were carried out in order to test the virulence of the bacterial strains used in this study despite the fact that the strains were stored and obtained as lyophilized powders, a condition which does not affect virulence characteristics. An injection infiltration method developed by Klement (1963) that permits rapid detection of pathogenicity for Pseudomonas strains was followed for the purpose. Seven highly virulent strains were tested for their ability to induce necrosis in tobacco plants. Six strains were able to elicit a quick response in tobacco plants within $24 \mathrm{~h}$ indicating that they are highly virulent strains. However one strain (Pseudomonas syringae pv. apii 2545) did not elicit a response on tobacco plants even after $24 \mathrm{~h}$ suggesting a loss of virulence. Therefore, this strain was not used in most of the further experiments.

An initial screening was carried out in order to select both susceptible and resistant cultivars of tomato to be used in various experiments for the study. The plants were screened for susceptibility or resistance against their pathogen $P$. s. pv. tomato race 0 . The aim was to select tomato geneotypes which differ mainly in the genes for resistance against $P$. s. pv. tomato race 0. It was reported earlier by NabizadehArdekani (1997) that the progeny of tomato cv. "Ontario no. 7710" which is resistant against $P$. s. pv. tomato race 0 , includes tomato genotypes reacting susceptible to $P$. $s$. pv. tomato race 0 . Therefore, such plants were selected for these studies. Among 84 plants generated from a single fruit 63 were resistant and 21 were susceptible. The heterogeneity can be attributed to heterozygosity of the germplasm with respect to the resistance genes since the resistant phenotype was found to segregate in the ratio $3: 1$, similar to that for the Mendelian monohybrid cross. The differences were also evident in the height of the plants and even in the shape of their leaves and fruits. Nevertheless, for experimental purposes these two sub groups namely cv. Ontario resistant and susceptible (termed selectant and denoted with a ' $S$ ' in parantheses) phenotypes were used as the resistant and susceptible cultivars. 
Thirteen cultivars of celery plants were screened for the incidence of northern bacterial blight caused by P. s. pv. apii . Five different strains (Table 1.3.2.3.) of this host specific pathogen were used for the experiments. All the cultivars except cv. "Claret" (Apium graveolens var. rapaceum) were resistant to the strains tested. Cv. "Claret" was highly susceptible to P. s. pv. apii 2548. This strain was also able to produce weak symptoms on cv. "Rokary". However, the susceptible symptoms could not always be reproduced under the same experimental conditions. Therefore, cv. "Claret" was used as the susceptible cultivar and one from the several resistant cultivars, viz., cv. Monarch was selected at random as the resistant cultivar.

Unexpectedly, the cross-infection experiments revealed, that both pathovars had the ability to cross infect the susceptible cultivars of the non-host plants although the extent of symptoms induced was variable. While $P$. s. pv. apii was able to incite characteristic symptoms when inoculated on the tomato cv. Ontario (selectant), P. s . pv. tomato produced less severe symptoms on the susceptible celery cv. Claret. However, even the pathovar apii caused only weak symptoms on celery, since only one celery cultivar from 13 cultivars tested reacted susceptible towards one strain of $P$. s. pv. apii. Secondly, the disease symptoms caused in this unique combination were still weaker than those of $P$. s. pv. tomato on tomato leaves. Obviously, bacterial blight is only a minor disease of celery, which has been reported in rare cases in California (Little and Gilbertson, 1997). On the other hand, both pathovars caused stronger symptoms on tomato than on celery. Therefore, the differentiation of pv. apii appears questionable. Instead, $P$. s. pv. apii strains could be included in $P$. s. pv. tomato. The finding that the $P$. s. pv. apii strains do not synthesize the toxin coronatine does not contradict this suggestion, since coronatine-negative strains of $P$. s. pv. tomato have also been reported (Mavridis, 1982, Nabizadeh-Ardekani et al., 1997).

Cross infection of $P . s$. pv. apii and P. s. pv. tomato on tomato and celery (susceptible cultivars in each case), their respective non hosts, can be explained on the basis of their identical LPS O-chain patterns. It is inferred that the structure of the LPS provides the necessary conformation for interactions with a host and hence occurrence 
of cross infection. This assumption is strongly supported by the rheological studies, which revealed synergistic interactions of LPS preparation from both pathovars with pectins from leaves of tomato and celery (Chapter 2).

It has also been suggested that the ability to cross-infect is a residual ancestral trait (Little and Gilbertson, 1997) since the pathovars diverged from a common ancestor. Weibe and Campbell (1993) showed a close relatedness between some strains of $P$. s. pv. maculicola and $P$. s. pv. tomato based on the production of toxins and on their ability to cross infect their host plants. In their study it was demonstrated that $P$. s. pv. maculicola had the ability to infect crucifers and tomatoes but $P$. s. pv. tomato did not infect crucifers. A parallel situation was encountered during the course of the present study. It is seen that isolates of $P$. $s$. pv. apii exhibited a wider host spectrum than P. s. pv. tomato since the former infected cultivars of celery as well as tomato in contrast to the latter which did not infect its non-host, viz., celery. Based on these results it can be inferred that the two pathovars shared a common ancestor and that the latter had co-evolved with tomato and therefore has specialized itself to infect only that particular host. Thus, the ability of Pst to infect celery appears to be an ancestral trait and explains the absence of robust symptoms.

A rep-PCR based DNA fingerprinting method was adopted in the present study to investigate the extent of similarity between isolates of $P$. s. pv. tomato and $P$. s. pv. apii. PCR amplification using the BOX-primers allowed for the characterization of genetic variations but ERIC and rep- primers did not. Cluster analysis identified three heterogeneous groups among the 9 isolates. Surprisingly, the highly virulent $P s a$ strain P. s. pv. apii 2545 shared close similarity with the Pst strain $P$. s. pv. tomato race 0 and therefore the two strains were placed in the same group. This group had a $25 \%$ distance matrix with the other groups. The heterogeneity of all the three groups together with the fact that they share significant levels of similarity indicates that the strains may not represent two different pathovars. It seems on the basis of rep- PCR analyses that the variations can be treated as those that are due to intra-pathovar differences. 
The extent of similarity between different pathovars of $P$. syringae was investigated by Little and Gibertson (1997) using RFLP and RAPD analysis. A close relatedness was demonstrated in their study between isolates of $P$. s. pv. tomato and $P$. s. pv. apii. The strains also shared close similarities with P. s. pv. maculicola.

The relatedness between the strains of $P$. s. pvs. apii and tomato were also characterized based on the production of the non host-specific toxin coronatine using specific primers. Only the strains from tomato race 0 showed a single band which corresponds to a length of $656 \mathrm{bp}$. None of the strains from $P$. s. pv. apii showed any amplification for the primers. It is therefore concluded that Pst gained the ability of coronatine production, one among several traits that places this pathovar closer to many other coronatine producing strains such as $P$. s. pvs. coronafaciens, glycinea, maculicola, atropurpurea, morsprunorum etc. Psa shares several traits with Pst as a consequence of its divergence from a common ancestor, but differs significantly since it lacks in the production of coronatine. The finding that the $P . s . \mathrm{pv}$. apii strains did obviously not synthesize coronatine should not be regarded as evidence that $P$. $s$. pv. apii is a different pathovar than $P$. s. pv. tomato. Even within the strains of pathovars tomato, coronafaciens, glycinea and morsprunorum non-toxin-producers have been recorded. Therefore, additional experiments would be required to demonstrate that Psa indeed constitutes an evolutionary branch that is different from Pst.

It was concluded from these experiments that only very slight differences existed between different strains of $P$. s. pvs. apii and tomato. Thus, the results support the hypothesis that Pseudomonas syringae pathovars with identical LPS-O-chains have the same host specificity. 


\subsection{Summary}

- Strains of Pseudomonas syringae pv. apii were checked for their viability in $10 \mathrm{mM}$ $\mathrm{MgSO}_{4}$. Only a slight decrease in the number of colony forming units was observed within $5 \mathrm{~h}$ after inoculation in $10 \mathrm{mM} \mathrm{MgSO}_{4}$.

- Screening for susceptible selectants from tomato seeds of the tomato cv. Ontario no. 7710 against $P$. s. pv. tomato race 0 revealed that out of 84 plants screened 21 plants were susceptible and all the remaining 63 were resistant.

- When 13 different celery cultivars were inoculated with strains of $P$. $s$. pv. apii (strain nos. 2545, 2546, 2547, 2548 and 2153), only $P$. s. pv. apii 2548 was able to produce disease (bacterial blight) symptoms on cv. "Claret". Therefore, cv. "Claret" was classified as susceptible. Cv. "Monarch" was selected at random from among the other resistant celery cultivars and used in further experiments in comparison with cv. "Claret".

- P. s. pv. tomato strain no. 2137 had the ability to cross infect the susceptible celery cv. "Claret" where cholorotic lesions appeared on the inoculated leaves. Even stronger symptoms were caused by $P$. s. pv. apii in leaves of the tomato cv. Ontario (S) resembling very much the typical bacterial speck disease symptoms.

- Specific primers were used to amplify regions of the genome that are needed for the synthesis of the non-host-specific toxin coronatine. No amplification product was detected in any of the strains of $P$. s. pv. apii tested indicating their lack of ability to synthesize this toxin. Strains of Pst showed a positive signal at $656 \mathrm{bp}$.

- The extent of relatedness between the strains of $P$. s. pvs. tomato and apii was characterized by rep-PCR analysis; only the BOX primers were effective in discerning the strains into discrete groups. The ERIC and REP primers were not as effective. 
- The 9 strains were placed in three heterogeneous groups based on their BOX-PCR fingerprints. All the three groups included strains from P. s. pv. apii as well as from and P. s. pv. tomato.

- P. s. pv. apii 2548 and P. s. pv. tomato race 02317 were placed in the same group. Therefore we conclude that these two pathovars are very closely related to each other.

- It was concluded from these experiments that only very slight differences existed between different strains of $P$. s. pvs. apii and tomato. Thus, the results support the hypothesis that Pseudomonas syringae pathovars with identical LPS-O-chains have the same host specificity. 


\section{Chapter 2}

\section{Biophysical characterization of interactions between bacterial lipopolysaccharides and plant pectins}

\section{1. Introduction}

Rheology is the science of deformation and flow of matter and involves the study of the manner in which materials respond to applied stress or strain. The word owes its origin to the greek words 'panta rhei' meaning 'everything flows'. Rheology is a useful tool to study the physical properties of matter and has immediate applications in various fields such as geology, soil mechanics, polymer industries, tribology, bioengineering, cosmetics, pharmaceutics and in food industry.

The ability of a polymer to form a gel depends on the molecular weight of the polymer and the nature of intermolecular interactions. These interactions have been broadly classified as Newtonian or non-Newtonian. By definition, Newtonian interactions have a straight line relation between the shear stress (the ratio of force to area gives a shear stress across the liquid and is usually expressed in Pascal, $\mathrm{N} / \mathrm{m}^{2}$ ) and shear rate (the velocity gradient which forms between the two surfaces gives a shear rate) with a zero intercept ( $\tau=\eta \times D$, where $\eta=$ viscosity, $\tau=$ torque, $D=$ shear rate). All fluids that do not obey the above rule are known as non-Newtonian fluids ( $\eta$ $=\tau / \mathrm{D})$. The equations that relate the stress and strain are called rheological equations.

In certain instances, mixing of polymers gives gels characterized by high rigidity and superior to that which would be expected from a linear combination of the rigidities of the gels formed by each individual polymeric component. In other situations, the addition of a small amount of a nongelling polymer to a gelling one may induce a strengthening of the resulting gel or even, some polymers that are individually nongelling can yield gels on mixing. Many such polysaccharide mixed systems show this nonadditive behavior, which is currently termed as synergism (Copetti et al., 1997). 
Synergistic interactions occur rarely in nature, but have been reported in several cases such as oil spill in marine life and plant viral synergism (Vance et al., 1995). Such intermolecular interactions are consequences of chemical, physical or thermodynamic factors and the interaction is a function of the different primary and secondary structures of the component chains in the polymer system. Cairns et al. (1997) classified the synergistic interactions between polysaccharides as a. single polymer network containing a second polymer, b. interpenetrating networks, $\mathbf{c}$. phase-separated network, and d. coupled network, depending on the kind of polymer network that results from the interactions.

In most of the cases studied, biological polymers such as bacterial lipopolysaccharides (LPS) and plant pectins from different sources show no synergistic interaction or exclusion. Only in very rare cases the interaction between polymers of different origin is synergistic, leading to an increase in viscosity when two polymers are mixed.

The interactions between bacterial LPS and plant pectins were studied earlier (Grolms, 1996; Laux, 1998) and it was demonstrated that the bacterial LPS in general and their O-chains in particular bind to pectins from susceptible cultivars. The molecular interactions were always accompanied by an increase in viscosity and yield stress characteristic of a synergistic effect. An antagonistic phenomenon observed in incompatible combinations resulted in no synergistic effect or exclusion.

Whenever a synergistic interaction between bacterial LPS and plant pectins was recorded the pectins originated from a plant that was susceptible to the bacteria. Therefore, the hypothesis was set forward that the narrow host specificity of the Pseudomonas syringae pathovars is due to the specific structure of the LPS molecule, mainly the O-chain (Rudolph, 2001).

To further verify this hypothesis we selected the $P$. syringae pathovars apii and tomato, which possess identical LPS-O-chains (Ovod et al., 1997) and studied the rheological interactions of the partially purified LPS with pectins from both host plants, celery and tomato. 


\subsection{Materials and Methods}

\subsubsection{Model systems used for the study}

Lipopolysaccharides were extracted from one strain each of $P . s$. pv. apii and P. s. pv. tomato (chapter 3). Pectins were obtained from leaves of susceptible and resistant cultivars of both tomato and celery plants (chapter 4). Fifty milligrams of pectins and $5 \mathrm{mg}$ of LPS were dissolved in $1 \mathrm{ml}$ of $25 \mathrm{mM} \mathrm{Na}-\mathrm{K}$ phosphate buffer (pH 7.0) separately. Plastic viscosity and shear stress were measured for the following combinations from which the consistency index and yield stress were calculated.

1. P. s. pv. apii GSPB $2548 \quad$ vs.

a. Celery cv. Claret (susceptible)

b. Celery cv. Monarch (resistant)

c. Tomato cv. Ontario no. 7710 selectant susceptible to $P$. s. pv. tomato race 0

d. Tomato cv. Ontario no. 7710 resistant against $P$. s. pv. tomato race 0

2. P. s. pv. tomato race 0 GSPB 2317

vs.

a. Tomato cv. Ontario selectant (susceptible)

b. Tomato cv. Ontario (resistant)

c. Celery cv. Claret, susceptible to $P$. s. pv. apii

d. Celery cv. Monarch, resistant against P. s. pv. apii

The rheological properties of the polymers were initially measured separately and later for their mixtures blended in different ratios $(80: 20,60: 40,40: 60,20: 80)$ to a total volume of $500 \mu 1$. 


\subsubsection{Equipment used}

All rheological experiments were conducted using a rotation viscosimeter (Brookfield Model DV-III, Fa., Brookfield, Karlschule, Germany) using a CP 4/40 cone and plate according to the manufacturer's instructions. The rheometer was calibrated initially using the Brookfield standard oil for 70 cycles. The viscosity measurements were averaged over 40 seconds for 70 cycles in total. The temperature was maintained by means of a circulating water bath at $21^{\circ} \mathrm{C}$ during the measurements.

\subsubsection{Mathematical calculations}

Plastic viscosity and shear stress were measured and yield stress $\left(\tau_{0}\right)$ and consistency index $(k)$ were calculated using Bingham's and Power's equations. All rheological data were processed using the Microsoft Xact 6.0 computer programme for graphing.

\section{Bingham's equation}

$$
\tau=\tau_{0+} \boldsymbol{\eta D}
$$

$\tau=$ shear stress, $\tau_{0}=$ yield stress (shear stress at zero shear rate),

$\eta=$ plastic viscosity, $\mathrm{D}=$ shear rate

\section{Power's equation}

$$
\tau=k \mathbf{D}^{\mathbf{n}}
$$

$\tau=$ shear stress, $\mathrm{D}=$ shear rate, $k=$ consistency index, $\mathrm{n}=$ flow index 


\subsection{Results}

The experimental data obtained for interactions between bacterial LPS and plant pectins are summarized in table 2.3.1.

Table 2.3.1. Overview of plant-pathogen interactions characterized in this study

\begin{tabular}{|c|c|c|}
\hline$\overbrace{\text { Cultivar }}$ Pathogen & $\begin{array}{l}\text { Pseudomonas syringae pv. } \\
\text { apii GSPB } 2548\end{array}$ & $\begin{array}{l}\text { Pseudomonas syringae pv. } \\
\text { tomato race } 0 \text { GSPB } 2317\end{array}$ \\
\hline $\begin{array}{l}\text { Tomato cv. Ontario no. } \\
7710 \text { selectant (susceptible)* }\end{array}$ & $\begin{array}{l}\text { compatible } *^{*} \\
(\text { synergistic interaction })^{+}\end{array}$ & $\begin{array}{l}\text { compatible } \\
\text { (synergistic interaction) }\end{array}$ \\
\hline $\begin{array}{l}\text { Tomato cv. Ontario no. } \\
7710 \text { (resistant)* }\end{array}$ & $\begin{array}{l}\text { incompatible } \\
\text { (no interaction) }^{+}\end{array}$ & $\begin{array}{l}\text { incompatible } \\
\text { (no interaction) }\end{array}$ \\
\hline $\begin{array}{l}\text { Celery cv. Claret } \\
\text { (susceptible) }\end{array}$ & $\begin{array}{l}\text { compatible } \\
\text { (synergistic interaction) }\end{array}$ & $\begin{array}{l}\text { compatible } \\
\text { (partial synergistic interaction) }^{\S}\end{array}$ \\
\hline $\begin{array}{l}\text { Celery cv. Monarch } \\
\text { (resistant) }\end{array}$ & $\begin{array}{l}\text { incompatible } \\
\text { (no interaction) }\end{array}$ & $\begin{array}{l}\text { incompatible } \\
\text { (no interaction) }\end{array}$ \\
\hline
\end{tabular}

* Compatible or incompatible and susceptible or resistant, respectively, indicate the reaction between plants and bacteria (see chapter 1)

+ Synergistic and no interaction indicate the results of the rheological reaction between bacterial LPS and plant pectins

$\S$ Exceptional cases of synergistic interactions

Synergistic effects were only recorded in mixtures of bacterial lipopolysaccharides and pectins from leaves of susceptible host plants. Thus, at least a five fold increase in consistency index and yield stress was observed for the combination of LPS from P. s. pv. apii and pectins from the susceptible celery cv. Claret (Fig. 2.3.5.). The increase in consistency index was as high as 15 times for the other compatible combination, viz., P. s. pv. tomato vs. tomato cv. Ontario no. 7710 selectant (Fig. 2.3.2.). Maximum synergism was observed at a critical ratio of 1:4 for LPS to pectins in both interactions. 
No significant changes in consistency index or yield stress were observed for the incompatible combination of $P$. $s$. pv. apii LPS with pectins from resistant celery cv. Monarch (Fig. 2.3.7.). But in a similar incompatible combination of $P$. s. pv. tomato LPS and pectins from the resistant tomato $\mathrm{cv}$. Ontario no interaction was observed. A slight decrease was seen in consistency index and yield stress (Fig. 2.3.4.).

In an exceptional case of an assumed incompatible combination, LPS from $P$. $s$. pv. tomato combined with pectins from susceptible cv. of celery to produce a partial synergistic effect (Fig. 2.3.6.). There was a marginal increase in consistency index of about two fold in this combination. The reciprocal combination i.e., LPS from P. s. pv. apii and pectins from susceptible tomato cv. Ontario selectant behaved synergistically (Fig. 2.3.1.). 
Fig. 2.3.1. Rheological properties of the interaction between LPS from $P$. $s$. pv. apii and pectins from the susceptible tomato cv. Ontario

\section{A. Consistency index}

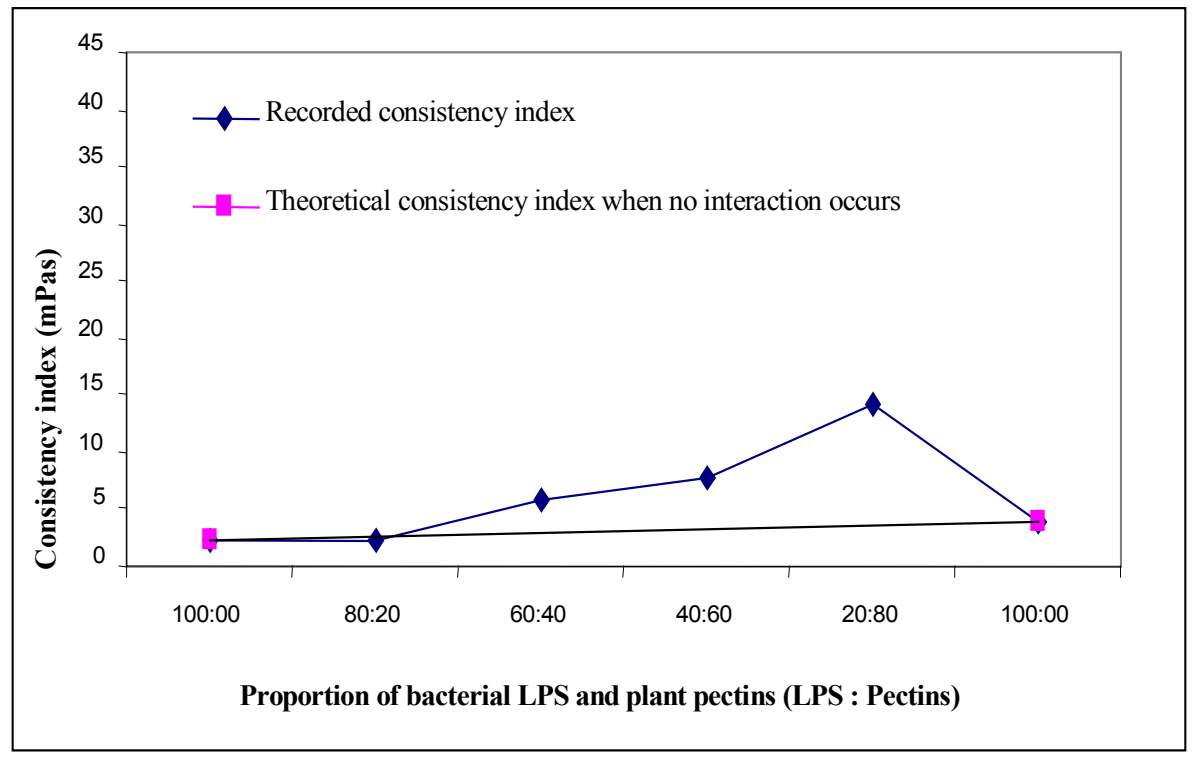

\section{B. Yield stress}

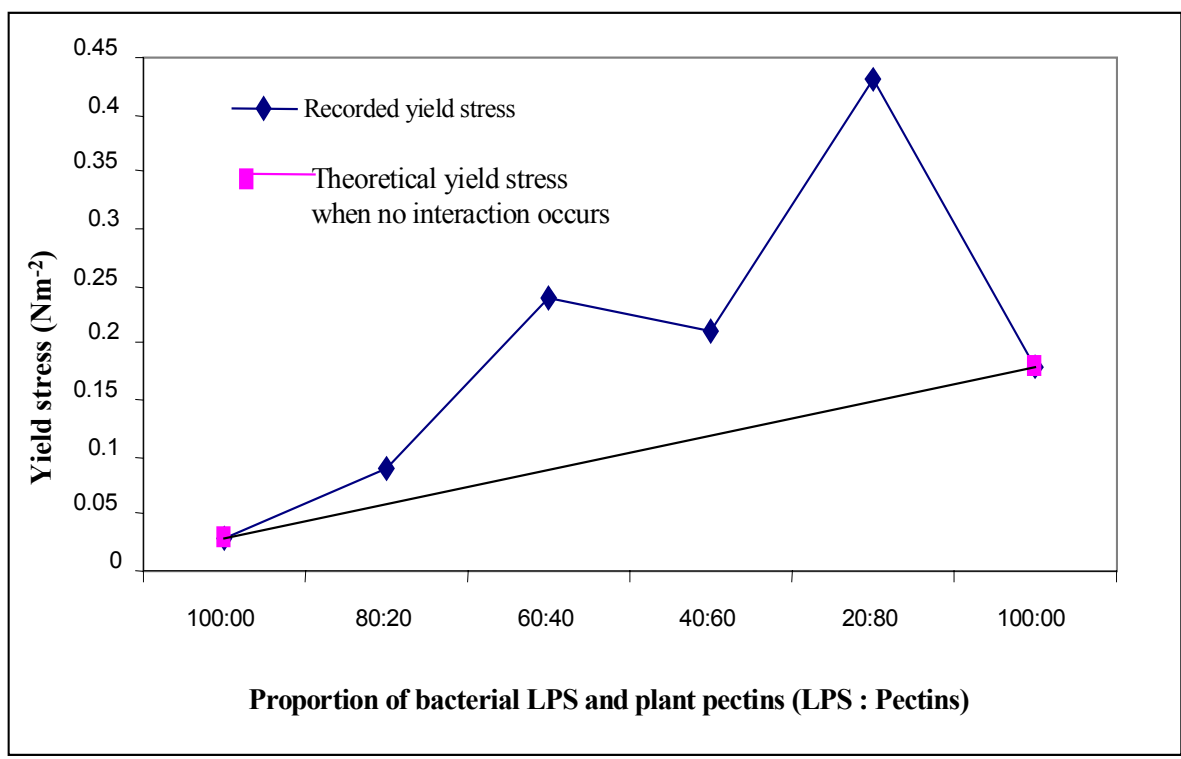


Fig. 2.3.2. Rheological properties of the interaction between LPS from $P$. $s$. pv. tomato race 0 and pectins from the susceptible tomato cv. Ontario

\section{A. Consistency index}

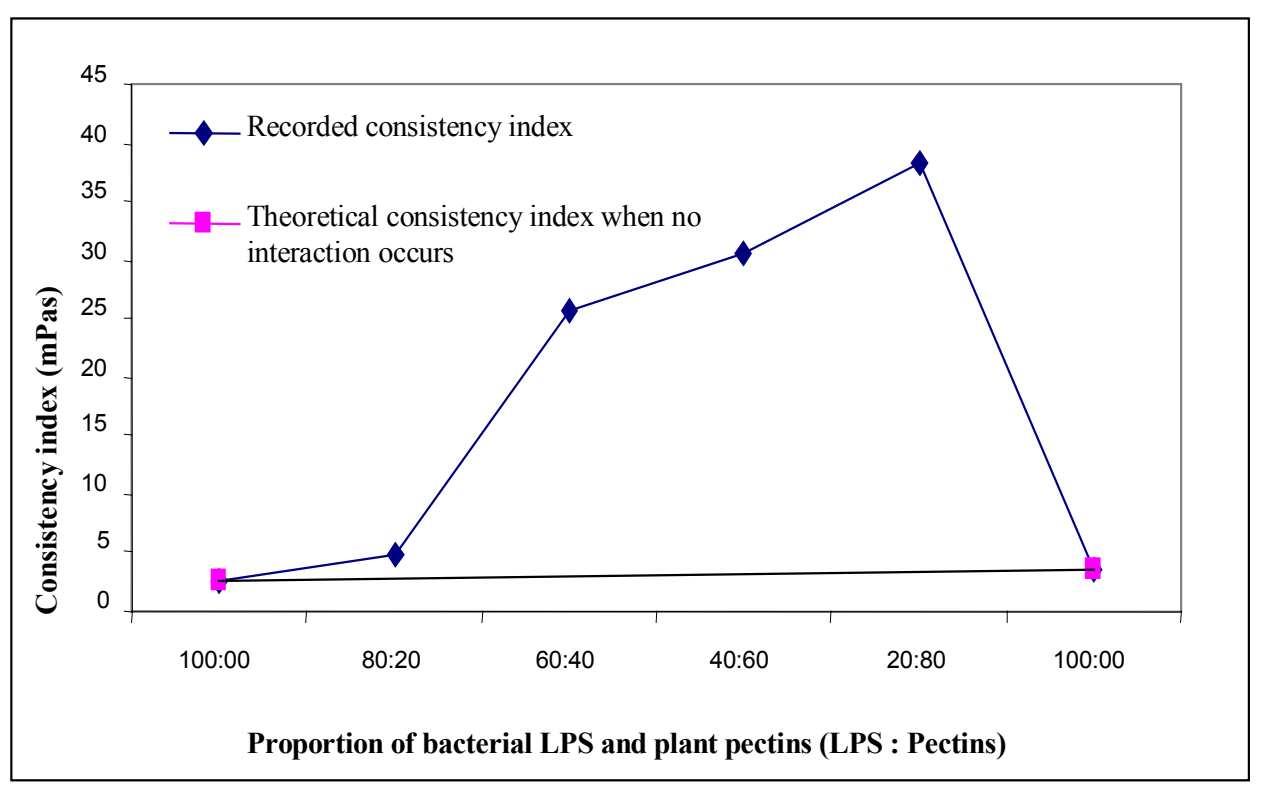

\section{B. Yield stress}

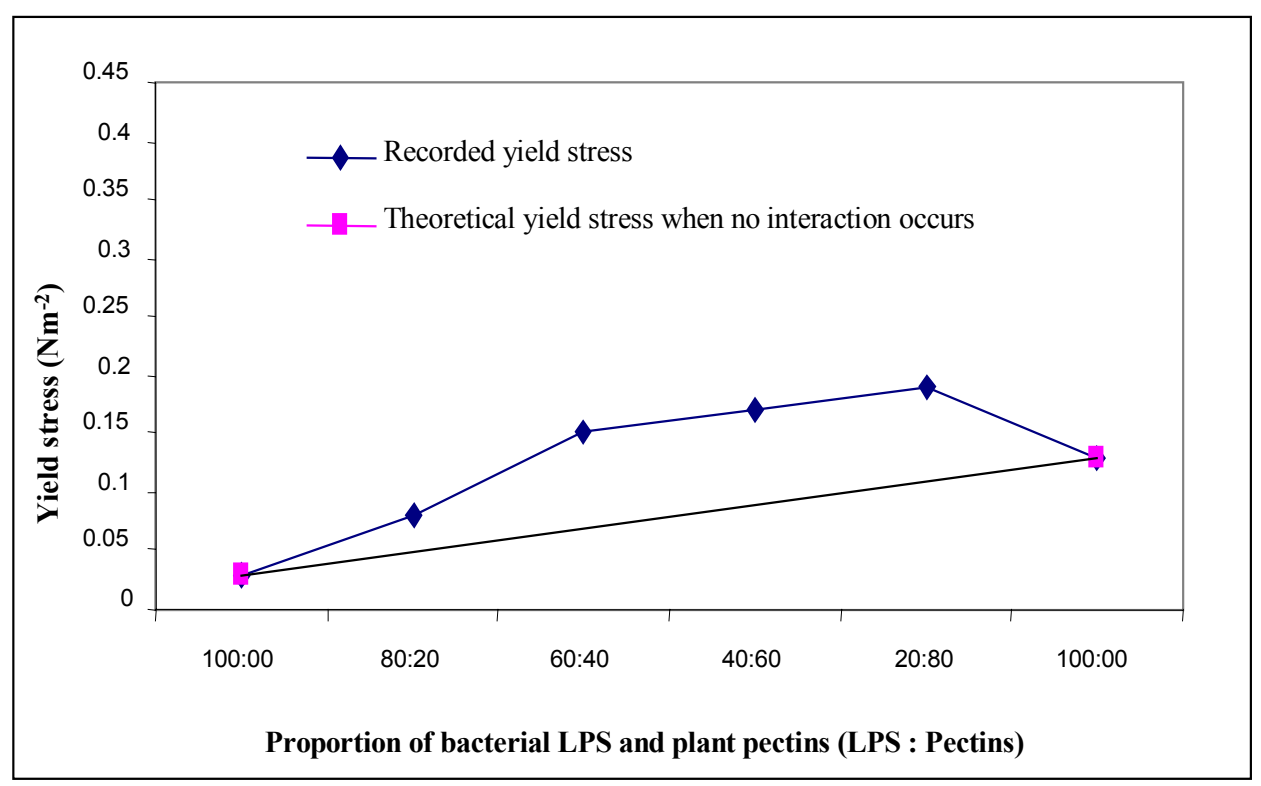


Fig. 2.3.3. Rheological properties of the interaction between LPS from $P$. s. pv. apii and pectins from the resistant tomato cv. Ontario

\section{A. Consistency index}

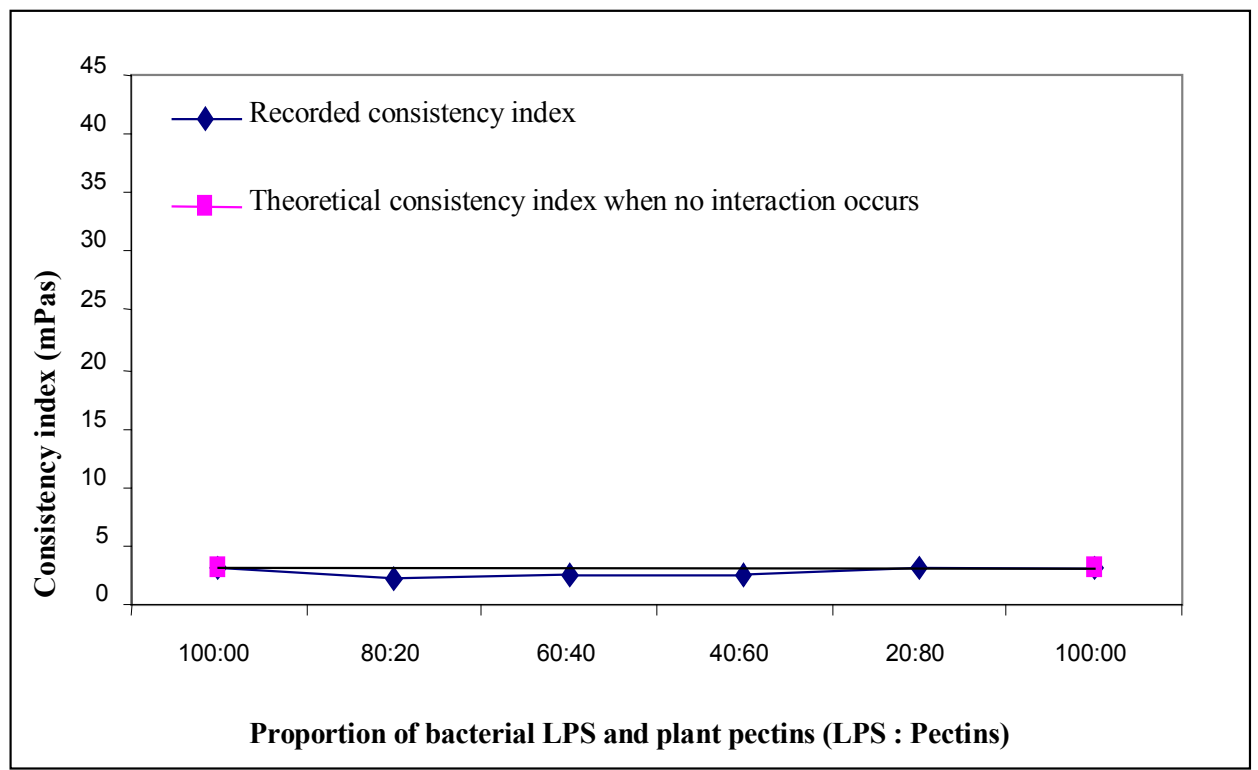

\section{B. Yield stress}

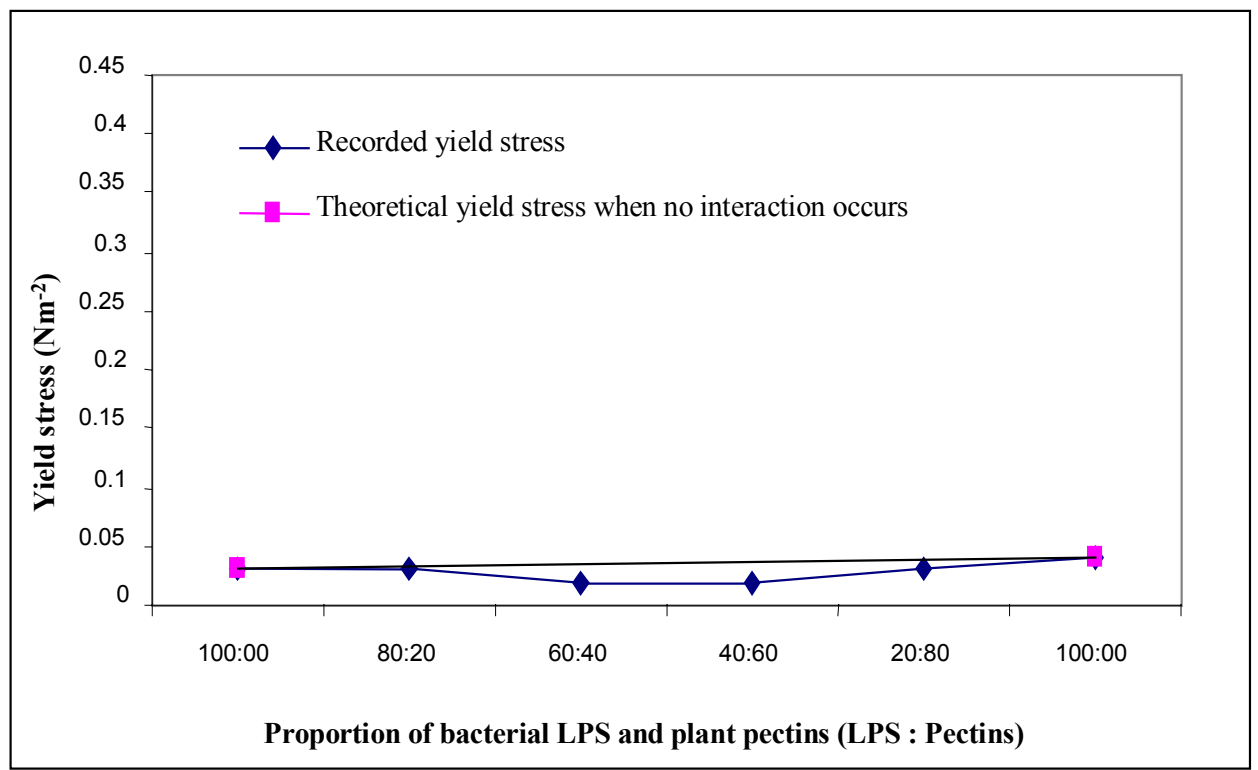


Fig. 2.3.4. Rheological properties of the interaction between LPS from $P$. $s$. pv. tomato race 0 and pectins from the resistant tomato cv. Ontario

\section{A. Consistency index}

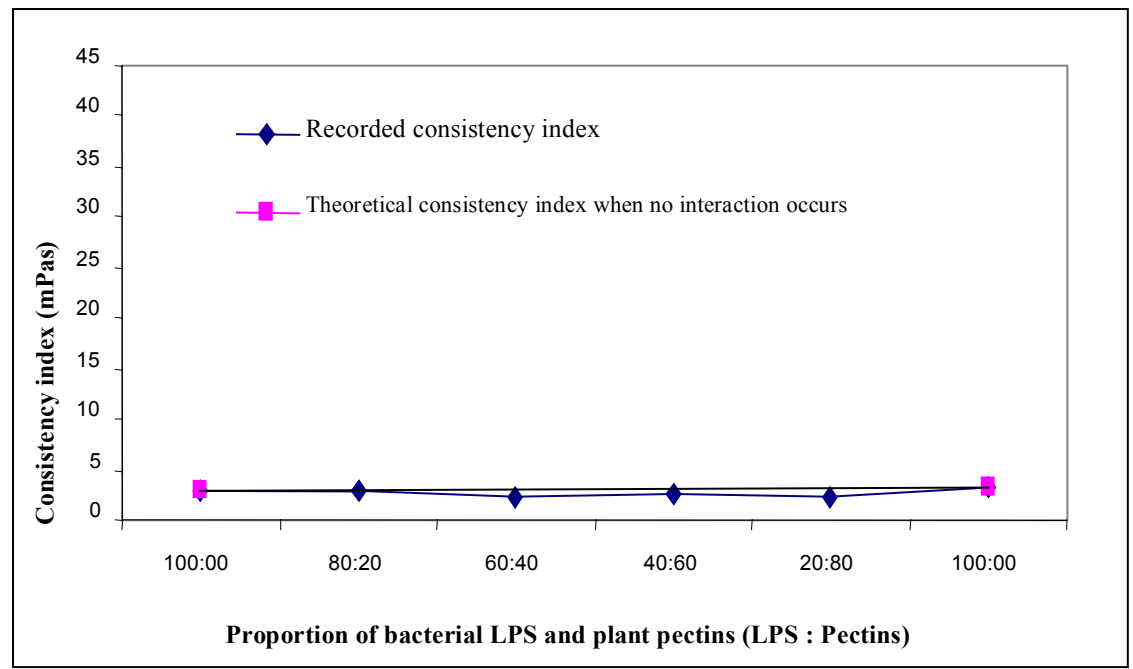

\section{B. Yield stress}

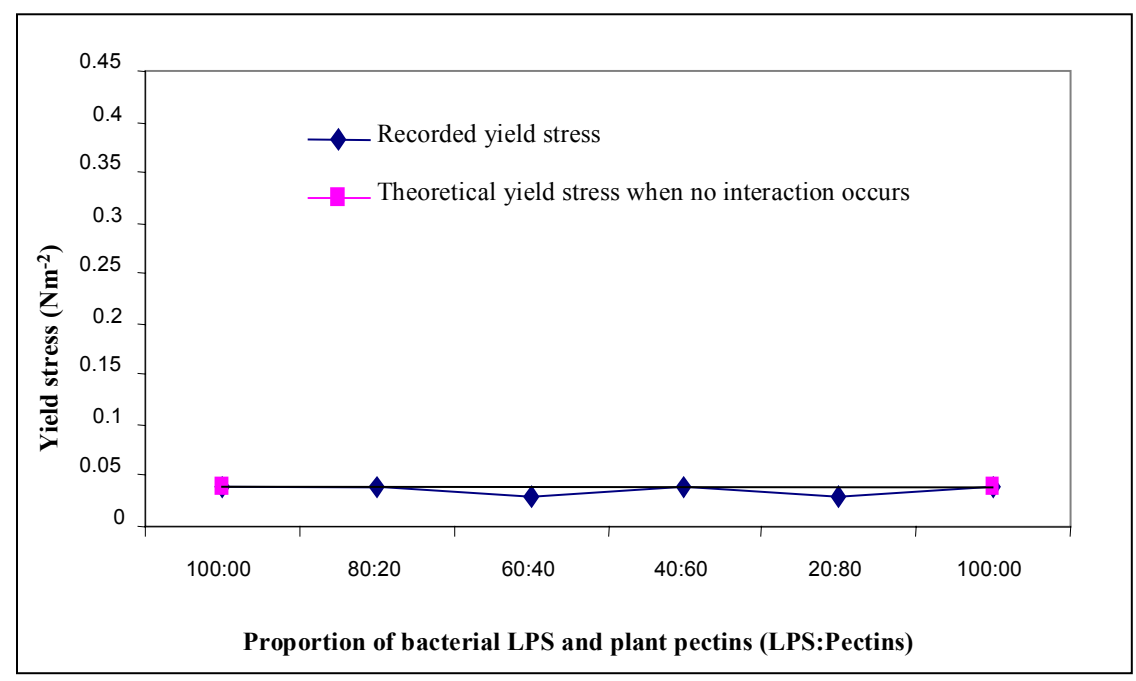


Fig. 2.3.5. Rheological properties of the interaction between LPS from $P$. $s$. pv. apii and pectins from the susceptible celery cv. Claret

\section{A. Consistency index}

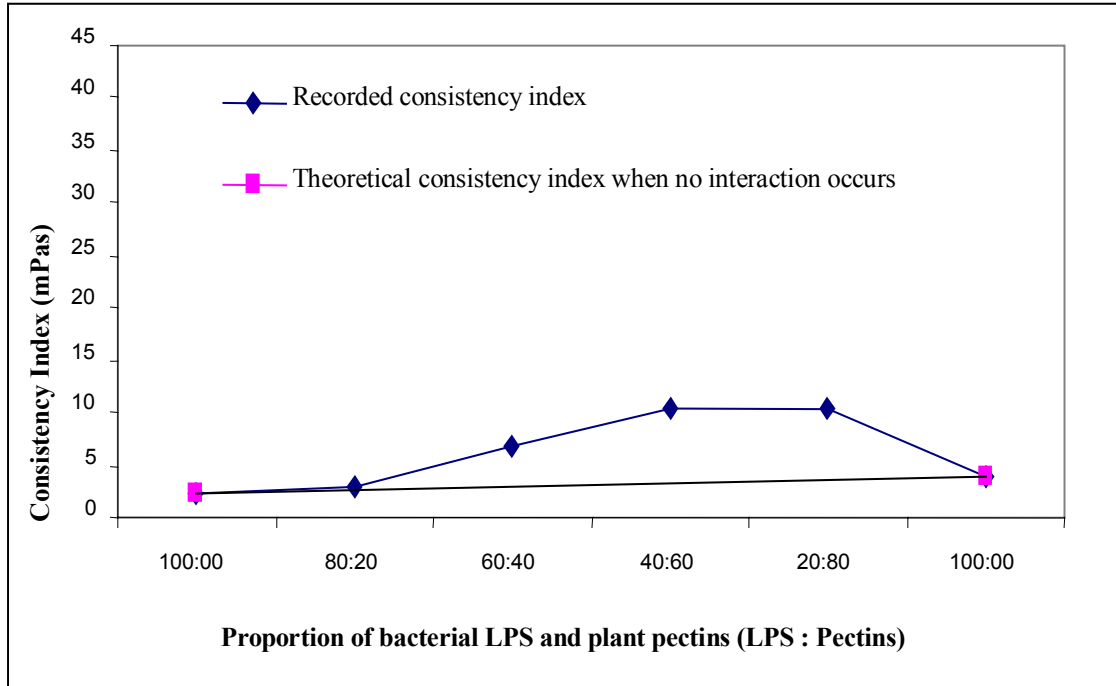

\section{B. Yield stress}

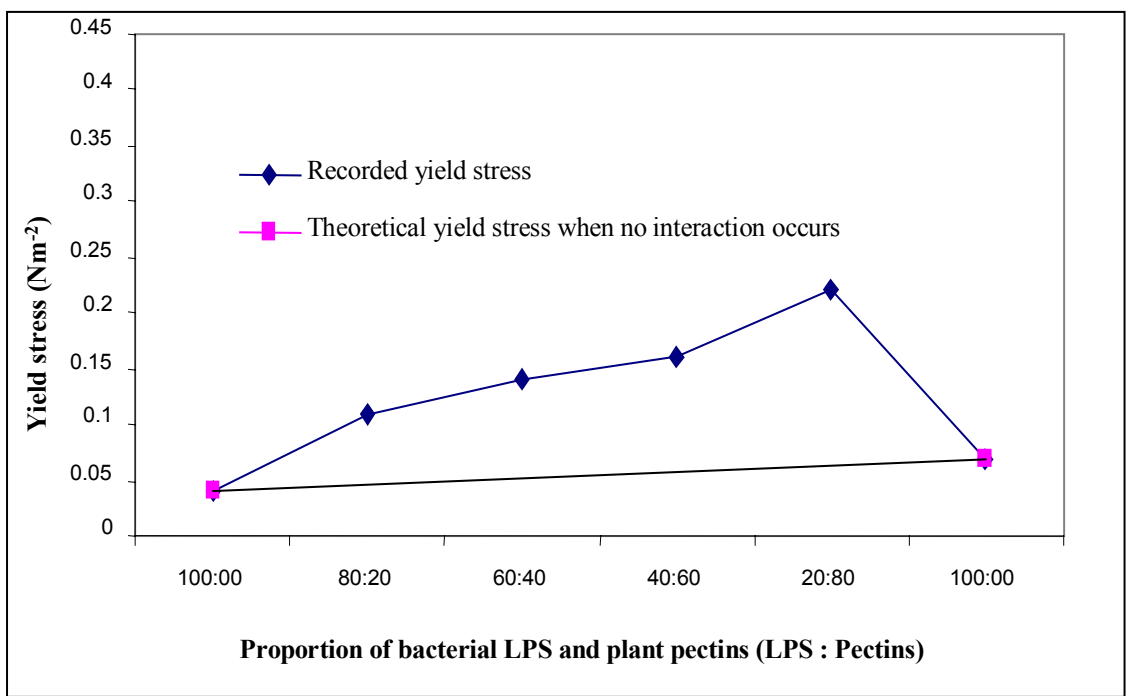


Fig. 2.3.6. Rheological properties of the interaction between LPS from $P$. $s$. pv. tomato race 0 and pectins from the susceptible celery cv. Claret

\section{A. Consistency index}

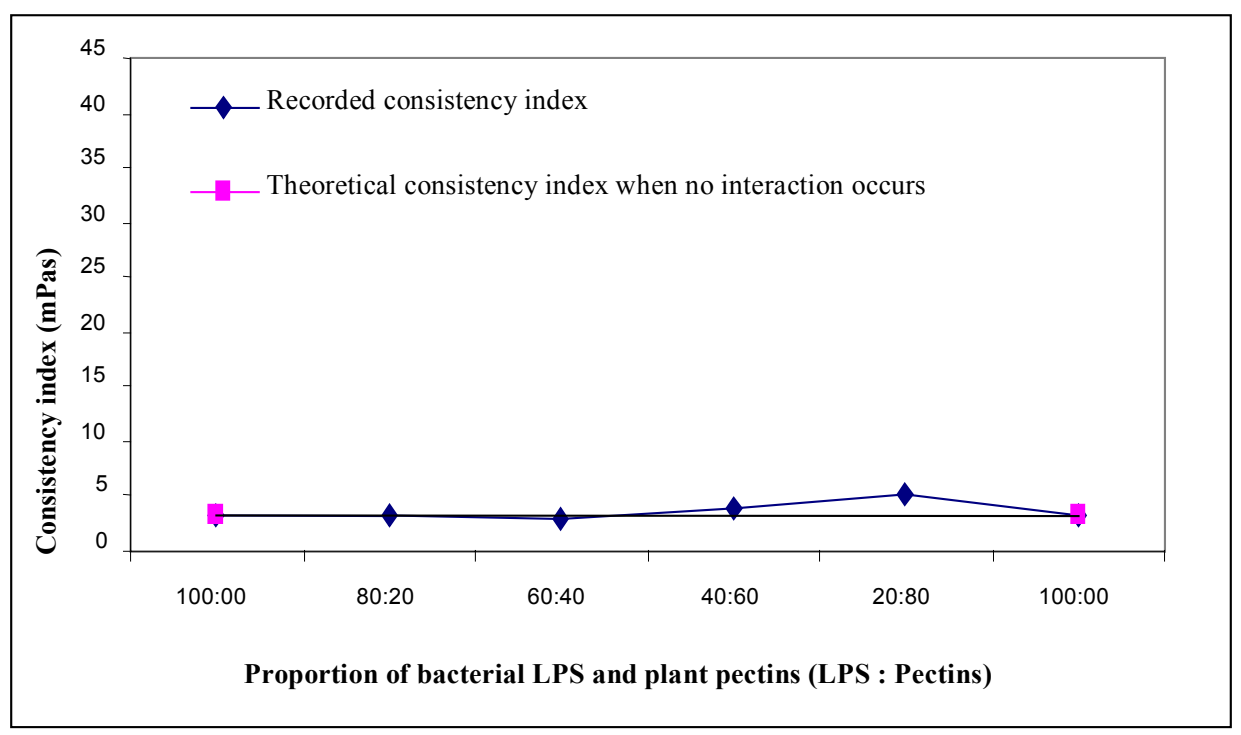

\section{B. Yield Stress}

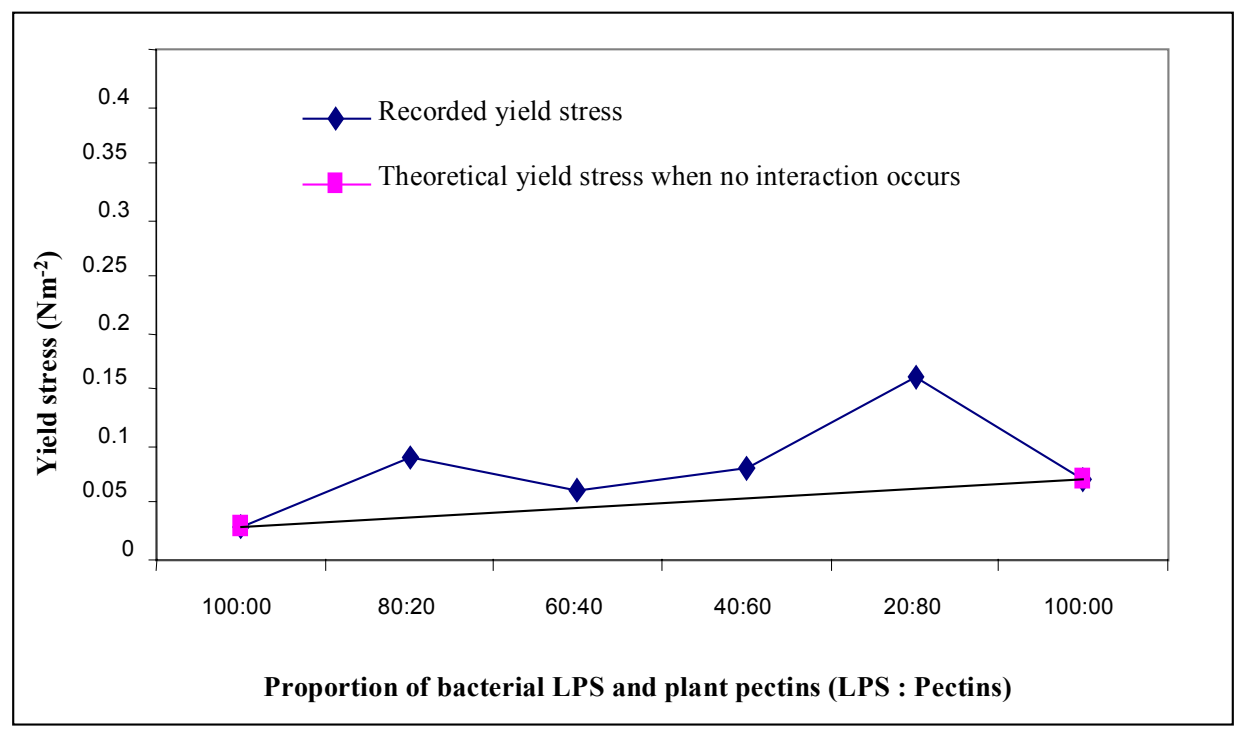


Fig. 2.3.7. Rheological properties of the interaction between LPS from $P$. $s$. pv. apii and pectins from the resistant celery $\mathrm{cv}$. Monarch

\section{A. Consistency index}

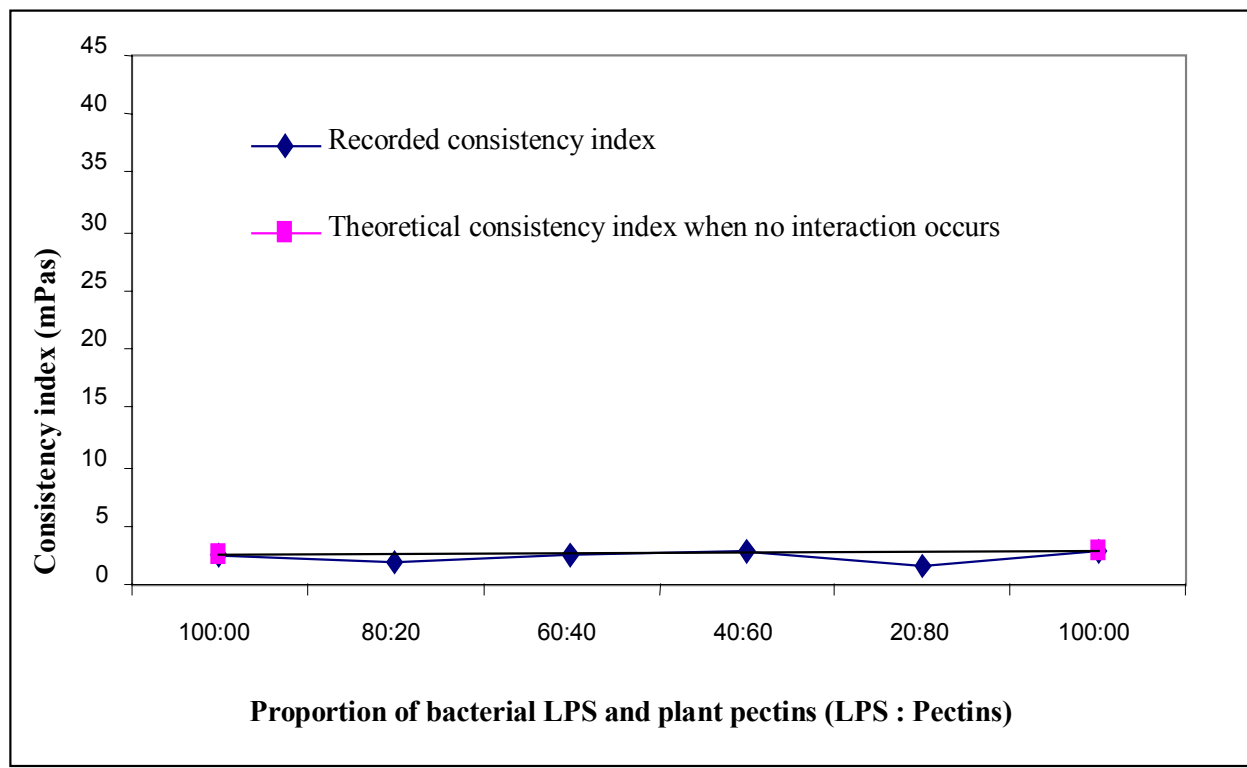

\section{B. Yield stress}

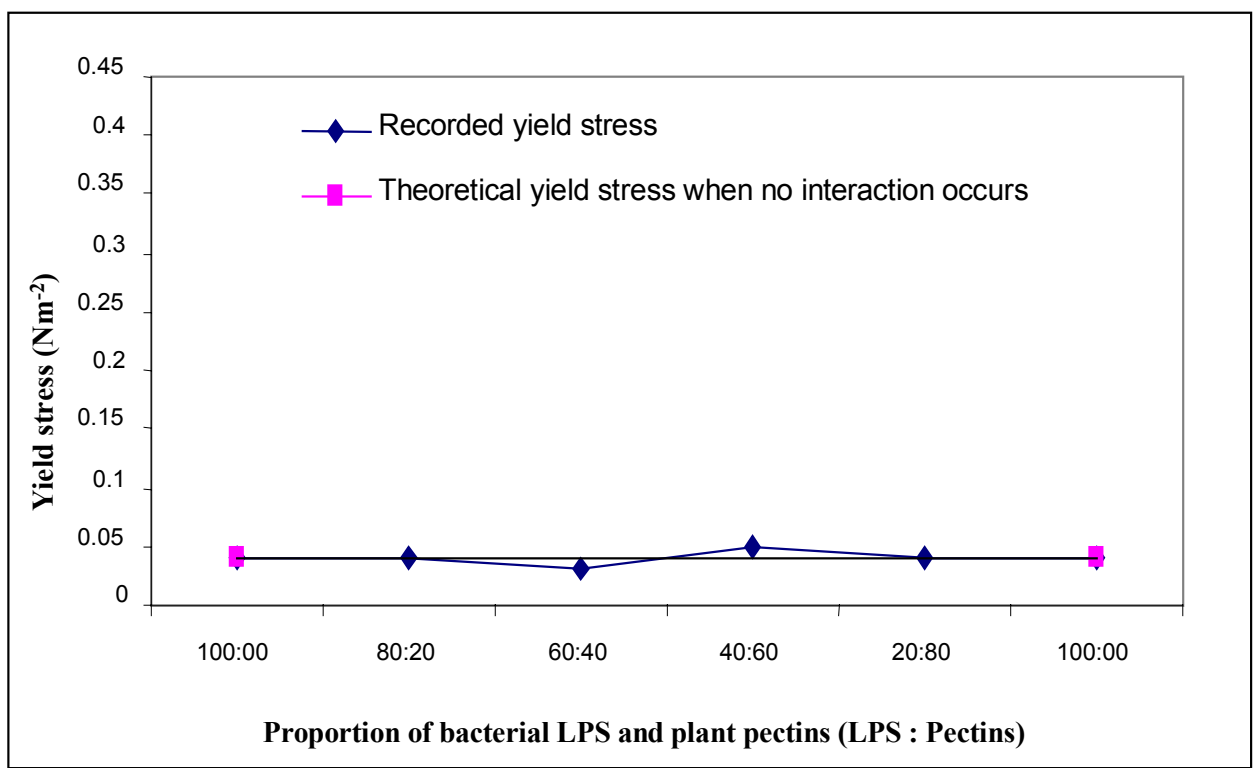


Fig. 2.3.8. Rheological properties of the interaction between LPS from $P$. s. pv. tomato race 0 and pectins from the resistant celery $\mathrm{cv}$. Monarch

\section{A. Consistency index}

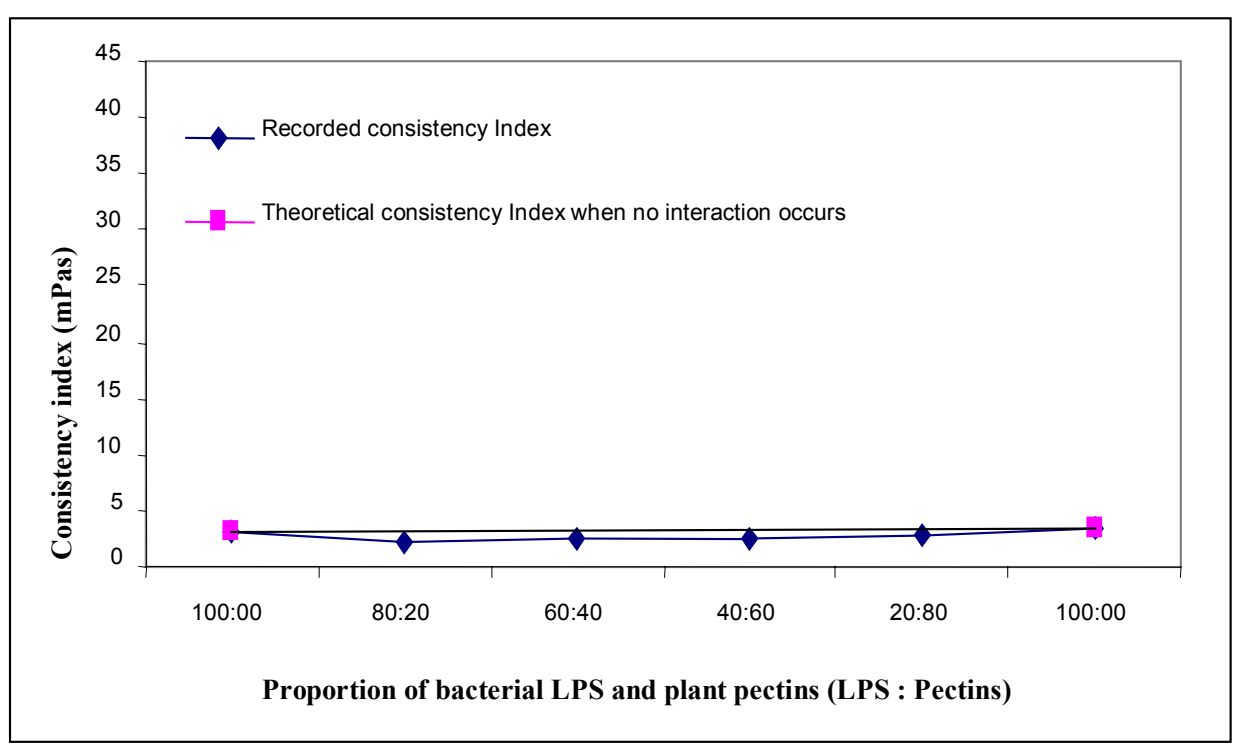

\section{B. Yield stress}

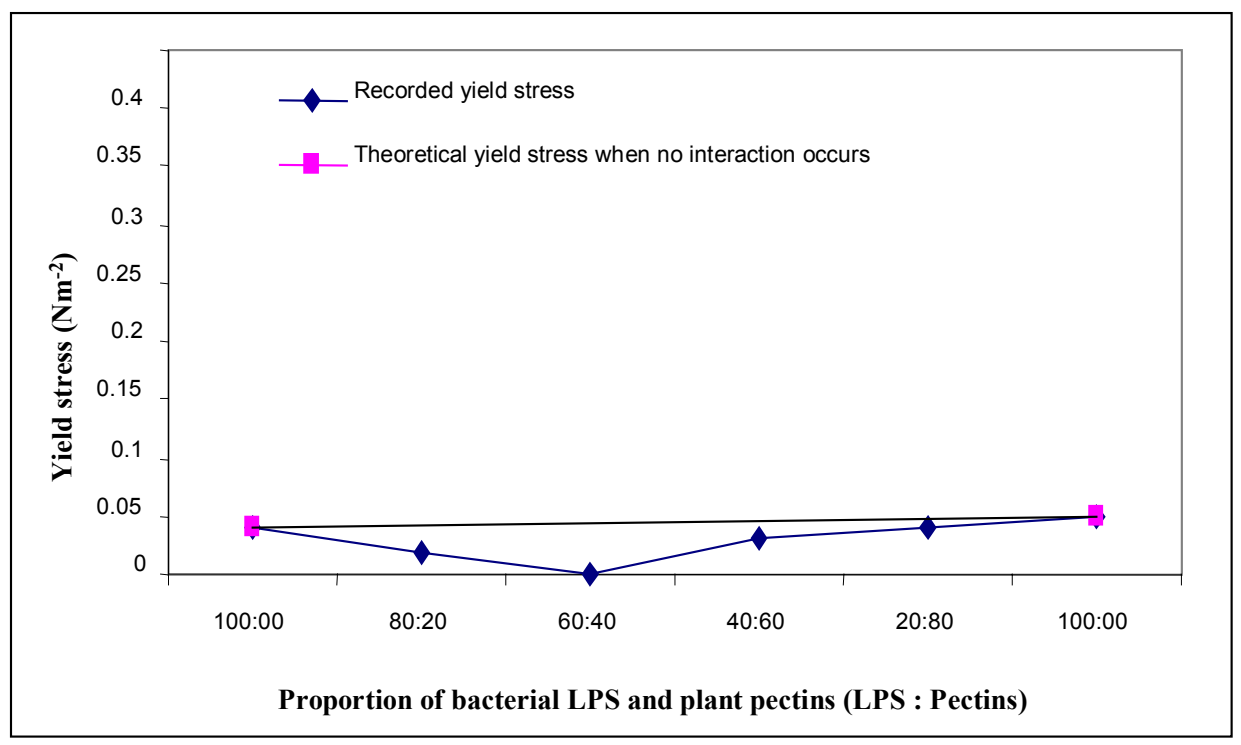




\subsection{Discussion}

All the experiments showed that bacterial LPS interacted synergistically with pectins from susceptible cultivars but not from resistant cultivars or non-host plants. In a synergistic interaction the physical properties of a mixed system have complex properties that often differ spectacularly from its constituents depending on a multitude of factors that includes polymer concentration, total and relative, solvent characteristics, temperature etc. Structural parameters such as the nature of side chains (Crescenzi et al., 1987), the degree of acetylation (Ojinnaka et al., 1997) and even the shapes of the hydrated molecules have implications in the interactions.

In this study, when bacterial LPS were combined with pectins of susceptible host plants (see table 2.3.1.) a synergistic interaction was demonstrated which was characterized by significant increase in viscosity and yield stress. This is in line with earlier results from Grolms (1996) in which synergistic interactions were observed in the interactions between LPS from $P$. s. pv. tomato with pectins from a tomato cultivar susceptible to $P$. s. pv. tomato race 0 and race 1 . Synergistic interactions have also been reported in compatible combinations of LPS from $P$. s. pv. phaseolicola and its susceptible host the bush bean cv. Red Kidney (Laux, 1998), P. s. pv. coriandricola and the susceptible coriander cv. Corry (Liehe, 1998) and more recently between LPS from Xanthomonas campestris pv. manihotis and the susceptible casava cv. Ben 86052 (Witt, pers. communication).

The ratio of LPS to pectins at which maximum synergism was recorded in the compatible combinations was 1:4. In earlier studies of Gromls and Rudolph (1997) this ratio has been reported to be either $2: 3$ or 1:4. This variation is thought to be due to the purity of the pectins and the method adopted for extraction.

No synergistic interactions are in general apparent in incompatible combinations. Even, significant decreases in viscosity and yield stress can be observed 
in some cases and this type of interaction has been referred to as "exclusion". In the present study, six incompatible combinations were studied (see table 2.3.1.). No noticeable changes were observed in three combinations (Figs. 2.3.7., 2.3.1., 2.3.6.) while exclusions were evident in the other three (Figs. 2.3.8, 2.3.4, 2.3.3.). Exclusions have been reported by Grolms (1996) in the interactions of LPS from P. s. pv. tomato with pectins from non-host plants and with pectins from tomato cv. Ontario no. 7710 which is resistant to $P$. s. pv. tomato race 0 .

In the assumed incompatible combinations when bacterial LPS were blended with pectins from non-host plants ( $P$. s. pv. apii vs. pectins from tomato plants and $P$. $s$. pv. tomato vs. pectins from celery plants) in vitro, increases in viscosity and yield stress (Figs. 2.3.1., 2.3.6.) were recorded. Thus, contrary to the widely established concept of synergistic interactions occurring exclusively in compatible combinations the study revealed a synergistic effect even in an assumed incompatible combination. The rheological reactions, however, reflect the antigenic identity of the O-chains present in the LPS of two pathovars (Ovod et al., 1997).

The rheological data, thus, indicated a compatible interaction between $P$. s. pv. apii and tomato and - to a weaker extent - between P. s. pv. tomato and celery. These indications were, indeed, confirmed by the inoculation experiments in the greenhouse (see chapter 1). Unexpectedly, P. s. pv. apii caused typical disease symptoms on tomato leaves, and P. s. pv. tomato caused slight symptoms on celery leaves.

A direct correlation between the magnitude of synergism and pathogenicity can be recognized from the greenhouse experiments carried out to test the ability of the strains to infect their assumed non-hosts ( $P . s$. pv. apii and $P . s$. pv. tomato (race 0$)$ on tomato and celery cultivars, respectively). P. s. pv. apii was able to successfully colonize the tomato cv. Ontario (S) on which symptoms of bacterial speck appeared from seven days after inoculation (Fig. 1.3.2.4.1a). Conversely, when P. s. pv. tomato was inoculated on celery plants the disease response could not be unambiguously determined. 
Chlorotic lesions appeared on leaves of the susceptible cv. Claret, however the lesions did not elaborate into characteristic disease symptoms (Fig. 1.3.2.4.1b).

Thus, the generally accepted assumption that the $P$. s. pathovars tomato and apii have a different host-range appears to be incorrect, and the hypothesis that a synergistic interaction between bacterial LPS and plant pectins can determine hostspecificity is confirmed by these experiments.

Nevertheless, the magnitude of synergism was observed to be less in the susceptible non-host combination (heterologous) of $P$. s. pv. tomato vs. the susceptible celery cv. Claret (Fig. 2.3.6.) than in the susceptible homologous combination P. s. pv. tomato versus the susceptible tomato cv. Ontario no. 7710 selectant (Fig. 2.3.2.).

The rheological experiments revealed a low magnitude of synergism between LPS of P. s. pv. tomato as well as apii with pectins from the susceptible celery cv. "Claret". Also, these data are in accordance with the inoculation experiments in the greenhouse as outlined in the subchapter 1.3.2. Celery plants in general, and even the only susceptible cv. "Claret" developed rather weak disease symptoms when compared to those on tomato leaves.

The reduced pathogenicity of certain pathovars of $P$. syringae on some of their susceptible assumed non-hosts in vitro has been extensively discussed by Little and Gilbertson (1997) who argue that in the light of the recent divergence of these pathovars from a common ancestor, the observed cross-infection may be due to residual ancestral traits and conclude that the reduced pathogenicity observed for heterologous combinations may reflect an effective limitation on the ability of these pathovars to naturally cross-infect heterologous hosts under field conditions.

It has been proposed that the bacterial cells become immobilized at their binding site through an envelopment process which involves an active restructuring of the plant cell wall surface (Goodman et al., 1976; Graham et al., 1977). This binding and encapsulating process has not been observed in a susceptible interaction, when the 
virulent bacteria remain free and multiply in the intercellular space (Anderson and Jasalavich, 1979; Rudolph and Mendgen, 1985). In light of the fact that bacterial LPS bind chemically to plant pectins via H-bonds or Van-der-Waals forces it has been speculated that the viscous gel that results from a compatible combination serves as a reservoir of water where the bacteria can survive, multiply and further the infection process. These observations lead to the hypothesis that bacterial LPS are actively involved in interactions with the important plant cell wall components- namely the pectins and these interactions manifest in certain physico-chemical modifications of their immediate environment. Such changes are vital for the determination of the fate of a host-pathogen interaction.

In conclusion, the biophysical studies reveal the role of specific structures of bacterial LPS-O-chain and pectins in host pathogen interaction, which is directly correlated to the inoculation experiments in the greenhouse. 


\subsection{Summary}

- LPS were extracted from two strains of the phytopathogenic bacteria Pseudomonas syringae pv. apii and $P$. s. pv. tomato race 0 .

- Pectins were extracted from the leaves of susceptible and resistant cultivars of celery and tomato plants.

- Combinations of LPS and pectins at different proportions were made in $\mathrm{Na}-\mathrm{K}$ phosphate buffer and rheological experiments were carried out using a Brookfield rheometer.

- All the compatible combinations, i.e., LPS mixed with pectins extracted from susceptible cultivars of tomato and celery plants showed a synergistic effect with an increase in viscosity and yield stress.

- In contrast, in incompatible combinations no synergistic effect was observed. There was a decrease in viscosity and yield stress when pectins extracted from the leaves of resistant cultivars combined with LPS from the respective bacteria.

- In a suspected incompatible combination, i.e., pectins from susceptible cultivars of celery and LPS from a non-host-pathogen $P$. s. pv. tomato, there was an increase in viscocity and yield stress indicating a synergistic interaction. But when pectins from susceptible tomato plants combined with LPS from $P$. s. pv. apii there was a weak interaction showing a partial synergistic interaction.

- Pectins from all the resistant cultivars used in this study showed a non-synergistic effect when combined with LPS from the two bacterial strains.

- All the mathematical calculations were done using Bingham's Law and Power law. There was clear indication that the maximum interaction occurs at a combination of $1: 4$

(LPS

Vs.

Pectins). 


\section{Chapter 3}

\section{Biochemical characterization of the lipopolysaccharide from Pseudomonas syringae pv. apii}

\subsection{Introduction}

The Pseudomonas syringae group of bacteria comprises various pathogens that cause disease on plants, predominantly on the leaves. This group is classified mainly on the basis of the host plants in which the bacteria can multiply and cause disease. In general, the pseudomonads possess an extremely narrow host range. Although numerous bacterial metabolites including toxins, extra-cellular polysaccharides and enzymes have been implicated in determining the host range, yet the precise mechanisms of host-specificity still remain unclear.

Fig. 3.1.1. General structure of bacterial lipopolysaccharide (Lüderitz et al., 1982)

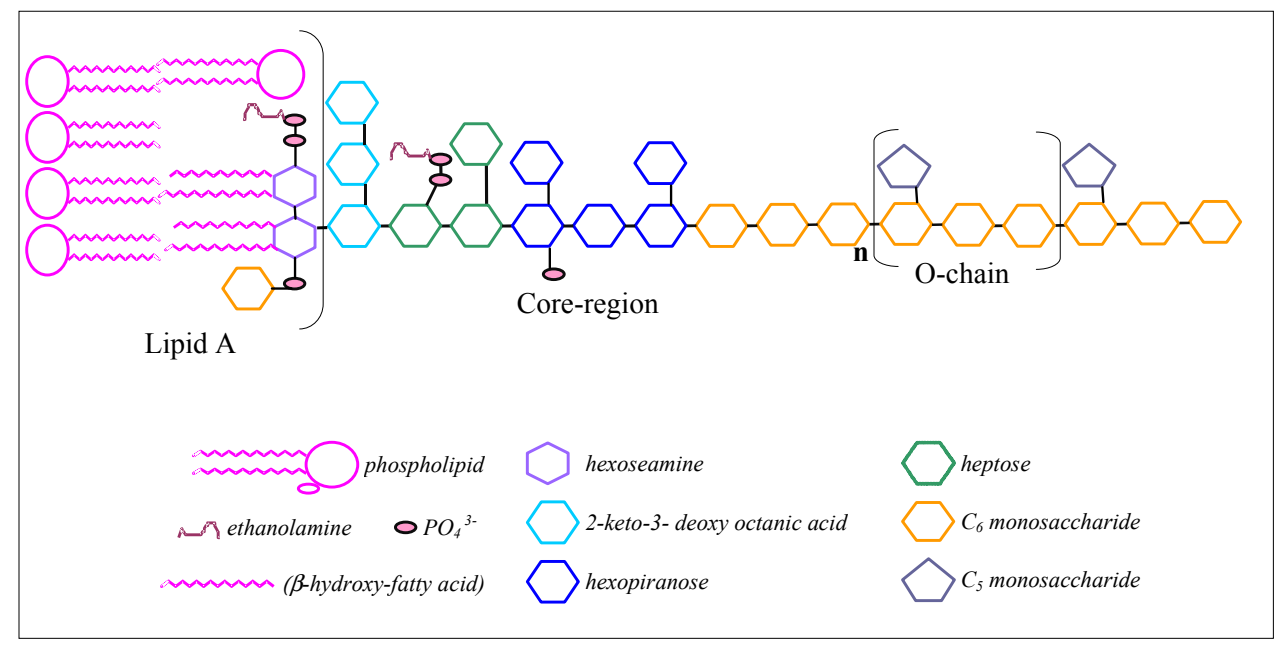

The pseudomonads, like all Gram-negative bacterial cells contain complex polymers called lipopolysaccharides (LPS) as their outermost layer. Besides providing an impermeable barrier against entry of harmful substances, LPS also interact with eukaryotic hosts. In plants, LPS appear to interact with cell wall substances by direct 
contact of the bacteria or by release of micelles containing LPS of the bacterial cell surface (Rudolph, 2001). Several data indicate that the LPS play a role in pathogenesis in susceptible hosts and in resistance induction in incompatible hosts (Laux et al., 1996, Müller et al., 1996). The effects of LPS on plant cells have recently been reviewed by Dow et al. (2000).

The genes for the synthesis of LPS are distributed throughout the bacterial chromosome and have been well characterized in Ralstonia solanacearum (Kao and Sequeria, 1991). Several LPS genes are clustered in loci, the predominant cluster has been shown to be $6.5 \mathrm{~kb}$ in length.

The LPS have a 'three in one'" type of architecture, viz., (1) lipid A, (2) an oligosaccharide core region and (3) a chain of repeating sugars or oligosaccharide units called O-chains or O-antigen (Fig. 3.1.1). Gram-negative bacteria that are mutated and lack O-chains are referred to as rough forms because of their appearance on agar plates; they are usually avirulent in nature.

The LPS molecules are anionic due to the presence of phospholipid groups and hence can bind to positively charged compounds (from hosts) to form aggregates. The interaction of bacterial LPS with plant pectins has been studied in several cases (Grolms, 1996; Liehe, 1998; Laux, 1998; Venkatesh and Rudolph, 2001b). The degree of interaction is influenced by various factors such as temperature, $\mathrm{pH}$ and the presence of divalent cations such as $\mathrm{Ca}^{2+}$ or $\mathrm{Mg}^{2+}$.

Bacterial LPS and plant pectins combine to exhibit two types of rheological behaviour synergistic and no synergistic interaction. A synergistic interaction is almost always synonymous with a compatible combination while no synergistic interaction accompanies an incompatible combination. A synergistic interaction in vitro can be directly related to conducive conditions in vivo in which the bacteria can multiply (Grolms and Rudolph, 1997; Laux et al. 1996). It seems possible that the bacterial LPS 
and plant pectins are involved in specific host-pathogen interactions. Graham (1983) suggested that the O-specific sugar moieties of LPS play a vital role in recognition by way of binding with a specific receptor on the host cell. Results of a study by Cody and Gross (1987) also lend support to the view that these biopolymers indeed play a governing role in early pathogenesis.

Ovod et al. (1997) made a systematic investigation and proposed a novel serological classification of Pseudomonas syringae pathovars based on the reaction of LPS O-chains and core moieties to monoclonal antibodies (MAbs). In general, many pathovars of $P$. syringae could be differentiated on the basis of their LPS-O-chain structure. However, in some cases, different $P$. syringae pathovars with identical LPSO-chains were listed by Ovod and co-workers (1997).

These findings appeared to contradict the hypothesis that host specificity of $P$. syringae pathovars is determined by a specific LPS-O-chain structure of each pathovar (Rudolph, 2001). To elucidate this phenomenon, we selected two P. syringae pathovars (tomato and apii) which apparently possess identical LPS-O-chains, but are recorded to infect different plant species (tomato or celery).

Therefore, partially purified LPS preparations were obtained from virulent strains of both pathovars and characterized biochemically. In parallel studies the interaction of these LPS-preparations with pectins from leaves of tomato and celery was investigated (Chapter 2). 


\subsection{Materials and Methods}

\subsubsection{Bacterial cultures}

The bacterial strains Pseudomonas syringae pv. apii GSPB 2548 and Pseudomonas syringae pv. tomato race 0 GSPB 2317 were obtained from the GSPB (Göttinger Sammlung Phytopathogener Bakterien). The strains were cultured on King's medium B agar and maintained on agar slants at $4{ }^{\circ} \mathrm{C}$. For obtaining LPS from a fermentor (see 3.2.4) King`s medium B was modified by adding $1 \%$ sodium gluconate (3.2.2)

All chemicals used in the study were purchased from Roth (Karlschule, Germany) and Merck (Darmstadt, Germany).

\subsubsection{Composition of the modified King's medium B (King et al. 1954)}

$$
g / l
$$

Proteose peptone

10. 0

Sucrose

10. 0

Sodium gluconate

10. 0

$\mathrm{KH}_{2} \mathrm{PO}_{4}$

1.5

$\mathrm{MgSO}_{4}$

1.5

to $1000 \mathrm{ml}$ with demineralized water

The $\mathrm{pH}$ of the medium was adjusted to 7.0 with $5 \mathrm{~N} \mathrm{HCl}$. Agar-agar was added to a final concentration of $0.15 \%(\mathrm{w} / \mathrm{v})$ and the medium was sterilized and stored at 4 ${ }^{\circ} \mathrm{C}$ for further use.

\subsubsection{Pre-culture}

Bacterial cultures were initiated from single colonies grown on King`s medium $\mathrm{B}$ agar and subsequently transferred to $25 \mathrm{ml}$ of nutrient broth. After $24 \mathrm{~h}$ of growth at 
$25^{\circ} \mathrm{C}, 1 \mathrm{ml}$ of the culture was transferred to 31 of nutrient broth to serve as the pre-culture.

\subsubsection{Extraction of bacterial lipopolysaccharides (LPS) from P. syringae pv. apii GSPB 2548 and P. s. pv. tomato GSPB 2317 race 0}

Seventy-five liters of nutrient broth supplemented with $1 \%(\mathrm{w} / \mathrm{v})$ proteose peptone were seeded with 31 of pre-culture in a 1001 fermentor (Model U 100, Bauner + Diesel GMBH, Germany) maintained at $25^{\circ} \mathrm{C}$ under aerobic conditions. The cells were harvested at mid-logarithmic phase by centrifugation at $12,000 \mathrm{~g}$ for 15 min. The pellets were suspended by swirling in a solution containing $\mathrm{NaCl}$ and EDTA $(0.1 \%(\mathrm{w} / \mathrm{v}) \mathrm{NaCl}, 10 \mathrm{mM}$ EDTA, $\mathrm{pH} 7.0)$ and centrifuged at 10,000 $\mathrm{g}$ for $20 \mathrm{~min}$ at 4 ${ }^{\circ} \mathrm{C}$. This process was repeated at least five times to remove the adsorbed exopolysaccharides (EPS) from the bacterial pellet. The washed pellets were then lyophilized.

LPS were extracted from the lyophilized bacterial pellets following the method of Westphal and Jann (1965). The lyophilized cells were suspended in water $(15 \mathrm{ml} / \mathrm{g}$ dry wt.). The slurry was warmed to $68{ }^{\circ} \mathrm{C}$ and admixed with an equal volume of $90 \%$ $(\mathrm{v} / \mathrm{v})$ pre-warmed phenol $\left(60{ }^{\circ} \mathrm{C}\right)$. The mixture was incubated at $68{ }^{\circ} \mathrm{C}$ in a water bath for $15 \mathrm{~min}$ with frequent stirring and cooled to $4{ }^{\circ} \mathrm{C}$ before centrifugation at $10,000 \mathrm{~g}$ for $20 \mathrm{~min}$ for phase separation. The upper aqueous phase containing LPS, polysaccharides, RNA and salts was carefully siphoned off and transferred to a sterile flask, and the lower organic phase containing proteins, lipids, phospholipids and DNA was discarded. The aqueous phase was then treated with RNAse followed by dialysis against demineralized water for $72 \mathrm{~h}$ at $4{ }^{\circ} \mathrm{C}$ to remove salts. The dialyzed sample was recovered by lyophilization.

\subsubsection{Purification of the LPS}

The lyophilized crude LPS were dissolved in sterile water $(5 \mathrm{mg} / \mathrm{ml})$ and clarified by centrifugation at $10,000 \mathrm{~g}$ for $20 \mathrm{~min}$ to remove insoluble materials. 
Protein and DNA contamination in the supernatant were determined spectrometrically

at $260 \mathrm{~nm}$ and $280 \mathrm{~nm}$. Contaminants, if present, were removed by treating the samples with proteinase $\mathrm{K}$ or DNAse. The purified LPS were then characterized biochemically.

\subsubsection{Biochemical analysis of LPS}

\subsubsection{Phosphate analysis}

Phosphate was determined by the modified method of Bartlett (1959) as described in Gross (1990).

\subsubsection{Analysis of KDO}

2-Keto-3-deoxy-octonate (KDO) was determined as described by Karkhanis et al. (1978). The LPS $(2-4 \mathrm{mg} / \mathrm{ml})$ were mixed with two volumes of $0.2 \mathrm{~N} \mathrm{H}_{2} \mathrm{SO}_{4}$, heated for $30 \mathrm{~min}$ at $100{ }^{\circ} \mathrm{C}$ and centrifuged at $10,000 \mathrm{~g}$ for $10 \mathrm{~min}$. Five hundred $\mu 1$ of the supernatant were transferred to a clean test tube into which $250 \mu 1$ of $\mathrm{HIO}_{4}(0.04 \mathrm{M}$ $\mathrm{HIO}_{4}$ in $\left.0.125 \%(\mathrm{v} / \mathrm{v}) \mathrm{H}_{2} \mathrm{SO}_{4}\right)$ were mixed. After $20 \mathrm{~min}$ of incubation at $25{ }^{\circ} \mathrm{C}, 250 \mu \mathrm{l}$ of $\mathrm{NaAsO}_{2}$ were added $\left(2.6 \% \mathrm{NaAsO}_{2}\right.$ in $\left.0.5 \mathrm{~N} \mathrm{HCl}\right)$. Immediately after the disappearance of brown color, $500 \mu 1$ of TBA $(0.6 \%$ thiobarbituric acid, dissolved in hot water) were mixed and the sample was incubated for $15 \mathrm{~min}$ at $100{ }^{\circ} \mathrm{C}$. While hot, $1 \mathrm{ml}$ of DMSO was added, and after cooling the OD was read at $548 \mathrm{~nm}$ against a suitable blank.

\subsubsection{Analysis of heptoses}

Heptoses were determined following the method of Wright and Rebers (1972). To $0.5 \mathrm{ml}$ of diluted LPS, $4.5 \mathrm{ml}$ of $\mathrm{H}_{2} \mathrm{SO}_{4}\left(1\right.$ vol. $\mathrm{H}_{2} \mathrm{O}$ plus 6 vol. conc. $\left.\mathrm{H}_{2} \mathrm{SO}_{4}\right)$ were added on an ice bath. The sample was first incubated for 3 to $10 \mathrm{~min}$ at $0{ }^{\circ} \mathrm{C}$ and again 
for $3 \mathrm{~min}$ at $25^{\circ} \mathrm{C}$. One hundred $\mu \mathrm{l}$ of L-cysteine- $\mathrm{HCl}[3 \%(\mathrm{w} / \mathrm{v})$ in water, (prepared fresh) were admixed and the sample was heated for $20 \mathrm{~min}$ at $100^{\circ} \mathrm{C}$. After incubating for $1 \mathrm{~h}$ at $25^{\circ} \mathrm{C}$, the absorbancies at $505 \mathrm{~nm}$ and $545 \mathrm{~nm}$ were read against a suitable blank. The difference in the absorptions (505 minus $545 \mathrm{~nm}$ ) was used to quantify heptoses.

\subsubsection{Analysis of fatty acids (Smith et al. , 1985)}

The organic extracts of acetic acid-degraded LPS were dried and their fatty acid methyl esters prepared with methanolic $\mathrm{HCl}$, methanol/BF3 or diazomethane and subjected to GLC in the usual manner. Ester-bound acids of the lipid A were preferentially converted to their methyl esters with sodium methoxide, while amidelinked fatty acids were liberated from the ether insoluble residue by subsequent treatment with $4 \mathrm{M} \mathrm{KOH}$ for $5 \mathrm{~h}$ at $100{ }^{\circ} \mathrm{C}$.

\subsubsection{Analysis of sugars}

LPS were hydrolyzed with 1-2 $\mathrm{N}$ trifluoroaceticacid $\left(4 \mathrm{~h} / 100{ }^{\circ} \mathrm{C}\right)$, the monosaccharides were analyzed on thin layer chromatography (TLC) and the alditol acetates of the carbohydrates were analyzed by gas liquid chromatography (GLC) (Gross, 1990). Amino compounds were quantified with an automated amino acid analyzer. 
3.2.7. Sodium dodecyl sulphate polyacrylamide gel electrophoresis (SDS-PAGE)

LPS were separated on a $1 \mathrm{~mm}$ thick $10 \%$ polyacrylamide gel using a minigel apparatus (10 x $10 \mathrm{~cm}$ Biometra Co., Göttingen, Germany)

\subsubsection{Buffers, chemicals and reagents used for SDS-PAGE}

Acrylamide stock

3 X Separating gel buffer

$3 \mathrm{X}$ Stacking gel buffer

TEMED

APS

Denaturing buffer $(5 \mathrm{X})$

Electrode buffer $(10 \mathrm{X})$

$$
\begin{aligned}
& 30 \%(\mathrm{w} / \mathrm{v}) \text { acrylamide, } \\
& 0.8 \%(\mathrm{w} / \mathrm{v}) \text { bisacrylamide }
\end{aligned}
$$

1 M Tris- $\mathrm{HCl}, \mathrm{pH} 8.8$

$0.3 \%(\mathrm{w} / \mathrm{v}) \mathrm{SDS}$

1 M Tris-HCl, pH 6.8

$0.3 \%(\mathrm{w} / \mathrm{v}) \mathrm{SDS}$

$10 \%(\mathrm{w} / \mathrm{v})$

$10 \%(\mathrm{w} / \mathrm{v})$

62.5 mM Tris-HCl, pH 6.8

$2 \%(\mathrm{w} / \mathrm{v}) \mathrm{SDS}$

$10 \%(\mathrm{v} / \mathrm{v})$ glycerol

$0.002 \%(\mathrm{w} / \mathrm{v})$ bromophenolblue

$400 \mathrm{mM}$ Tris $\mathrm{pH} 8.3$

$600 \mathrm{mM}$ glycine

$1 \%(w / v) \operatorname{SDS}$ 
Table 3.2.7.1. Formulation for preparing a $1 \mathrm{~mm}$-thick acrylamide gel

\begin{tabular}{|c|c|c|}
\hline Ingredients & eparating gel (10\%) & Stacking gel $(3 \%)$ \\
\hline Acrylamide stock solution & $2.0 \mathrm{ml}$ & $250.0 \mu 1$ \\
\hline Separating gel buffer & $2.0 \mathrm{ml}$ & - \\
\hline Stacking gel buffer & - & $500.0 \mu 1$ \\
\hline TEMED & $100.0 \mu 1$ & $50.0 \mu l$ \\
\hline APS & $15.0 \mu \mathrm{l}$ & $15.0 \mu l$ \\
\hline Double-distilled water & $3.0 \mathrm{ml}$ & $1.75 \mathrm{ml}$ \\
\hline
\end{tabular}

\subsubsection{Procedure for preparing the polyacrylamide gel}

The glass plates used for preparing the gels were cleaned with $70 \%$ ethanol and air-dried. A polymerization cassette was made using the two glass plates. All the constituents for the separating gel except ammoniumpersulphate (APS) and TEMED were added in a $10 \mathrm{ml}$ side arm Erlenmeyer flask. The flask was sealed with a rubber stopper and de-aerated. APS and TEMED were added to the mixture and dispensed between the sandwiched glass plates and overlaid with water-saturated iso-butanol or $\mathrm{H}_{2} \mathrm{O}$ and allowed to polymerize. A 3\% stacking gel was prepared as described above (see table 3.2.7.1.) and layered over the polymerized separating gel. A comb was fixed and the gel was allowed to set for at least $30 \mathrm{~min}$. 


\subsubsection{Preparation of LPS samples}

An aqueous suspension of LPS $(0.2-0.4 \mathrm{mg} / \mathrm{ml})$ was mixed with one fifth volume of $5 \mathrm{X}$ denaturing buffer (to a final concentration of $1 \mathrm{X}$ ) and incubated at 65 ${ }^{\circ} \mathrm{C}$ for $75 \mathrm{~min}$. Solubilization was carried out using DTE and the samples were kept on a heat block at $100{ }^{\circ} \mathrm{C}$ for $5 \mathrm{~min}$ (Müller, 1998).

\subsubsection{Electrophoresis conditions}

Ten $\mu \mathrm{l}(2-4 \mu \mathrm{g})$ of the LPS sample were loaded per well, and the gel was subjected to electrophoresis at $80 \mathrm{~V}$ for $30 \mathrm{~min}$ (stacking phase) and at $100 \mathrm{~V}$ for $1 \mathrm{~h}$ for separation.

\subsubsection{Visualization}

Following electrophoresis, the LPS were detected on the gel by silver staining as described by Heukeshoven and Dernick (1988).

Table 3.2.7.1. Silver staining method for LPS (Heukeshoven and Dernick, 1988).

\begin{tabular}{lll}
\hline & Steps & Solutions \\
\hline 1. & Fixing $(2 \mathrm{~h})$ & $30 \%(\mathrm{v} / \mathrm{v})$ ethanol \\
& & $10 \%(\mathrm{v} / \mathrm{v})$ acetic acid \\
2. & Incubation $(2 \mathrm{~h})$ & $30 \%(\mathrm{v} / \mathrm{v})$ ethanol \\
& & $0.5 \%(\mathrm{w} / \mathrm{v})$ sodium acetate \\
& & $0.5 \%(\mathrm{v} / \mathrm{v})$ glutardialdehyde \\
& & $0.2 \%(\mathrm{w} / \mathrm{v})$ sodium thiosulphate \\
& & double distilled water \\
3. & Washing $\left(\mathrm{H}_{2} \mathrm{O}, 3 \mathrm{x} 10 \mathrm{~min}\right)$ & $0.1 \%(\mathrm{w} / \mathrm{v}) \mathrm{AgNO}_{3}$ \\
4. & Staining $(45 \mathrm{~min})$ & $001 \%(\mathrm{v} / \mathrm{v})$ formaldehyde \\
& & $2.5 \%(\mathrm{w} / \mathrm{v}) \mathrm{Na}_{2} \mathrm{CO}_{3}$ \\
5. & Developing $(3-10 \mathrm{~min})$ & $500 \mathrm{mM} \mathrm{EDTA}$ \\
6. & Stopping $(5-10 \mathrm{~min})$ & double distilled water. \\
7. & Washing & \\
\hline
\end{tabular}




\subsection{Results}

\subsubsection{Biochemical Analysis}

The biochemical composition of the purified LPS from $P . s$. pv. apii is summarized in table 3.3.1.1.

Table 3.3.1.1. : Chemical composition of the lipopolysaccharide from Pseudomonas syringae pv. apii

\begin{tabular}{|c|c|c|c|c|c|c|}
\hline \multirow[t]{3}{*}{ Component } & \multicolumn{6}{|c|}{ Chemical composition of } \\
\hline & \multicolumn{2}{|c|}{ LPS } & \multicolumn{2}{|c|}{ Polysaccharide } & \multicolumn{2}{|c|}{ Lipid A } \\
\hline & $\mathrm{mol} / \mathrm{mol}$ & $\mathrm{nmol} / \mathrm{mg}$ & $\mathrm{mol} / \mathrm{mol}$ & $\mathrm{nmol} / \mathrm{mg}$ & $\mathrm{mol} / \mathrm{mol}$ & $\mathrm{nmol} / \mathrm{mg}$ \\
\hline $\mathrm{KDO}$ & 6.47 & 401 & & & & \\
\hline $\mathrm{PO}_{4}{ }^{3-}$ & 21.79 & 262 & & & & \\
\hline GlcN/ManN & 9.44 & 585 & & & & \\
\hline GalN & 5.47 & 339 & & & & \\
\hline GlcN & 1.00 & 62 & & & & \\
\hline $\operatorname{Etn} P_{\text {tot }}$ & 4.23 & 262 & & & & \\
\hline Glucose & & & 18.35 & 1138 & & \\
\hline Rhamnose & & & 8.23 & 510 & & \\
\hline Ribose & & & 0.39 & 24 & & \\
\hline Heptose & & & 2.85 & 177 & & \\
\hline 3-OH-C10:0 & & & & & 2.03 & 126 \\
\hline $\mathrm{C} 12: 0$ & & & & & 2.73 & 169 \\
\hline 2-OH-C12:0 & & & & & 1.48 & 92 \\
\hline 3-OH-C12:0 & & & & & 3.40 & 211 \\
\hline Alanine & 2.90 & 180 & & & & \\
\hline
\end{tabular}

KDO: 3- deoxy-D-manno-octulosonic acid, $\mathrm{PO}_{4}{ }^{3-}$ : phosphate, GlcN/ManN: N-acetylglucosamine / N-acetylmannosamine, GalN: N-acetylgalactosamine, GlcN: N-acetylglucosamine, Etn $P_{\text {tot }}$ : ethanalamine phosphate, 3-OH-C10:0: 3-hydroxydecanoic acid, C12:0: dodecanoic acid, 2-OH-C12:0: 2-hydroxy-dodecanoic acid, 3-OH-C12:0: 3-hydroxy-dodecanoic acid 
The total phosphate content in the lipid A and the core region taken together was $1351 \mathrm{nmol} / \mathrm{mg}$ of LPS. Analysis of the core region showed the presence of 401 nmol of KDO per mg of LPS. The heptose content was $177 \mathrm{nmol} / \mathrm{mg}$ LPS.

Among monosaccharides glucose was the most prominent followed by rhamnose. Their amounts were $18.35 \mathrm{~mol} / \mathrm{mol}$ LPS and $8.23 \mathrm{~mol} / \mathrm{mol} \mathrm{LPS}$ respectively. A dimer of acetylated amino sugars $\mathrm{N}$-acetylglucosamine/mannosamine was detected in high quantity, while $\mathrm{N}$-acetylgalactosamine was the other amino sugar detected.

Analysis of fatty acids showed the presence of 3-hydroxy-decanoic acid (3-OHC10:0), dodecanoic acid (C12:0), 2-hydroxy-dodecanoic acid (2-OH-C12:0) and 3hydroxy-dodecanoic acid (3-OH-C12:0) in the ratio 2:3:2:3. The amino acid alanine was present at $180 \mathrm{nmol} / \mathrm{mg}$ of LPS. 


\subsubsection{SDS-PAGE}

The LPS extracted from P. s. pv. apii were characterized by SDS PAGE. After staining with silver a characteristic ladder like pattern (Fig. 3.3.2.1.) was obtained. The highest mobility bands of LPS from P. s. pv. apii (lanes $3 \& 4$ ) differed from those of the standards used (lanes $1 \& 2$ ).

Fig. 3.3.2.1. Silver stained $P$. syringae pv. apii LPS after SDS-PAGE

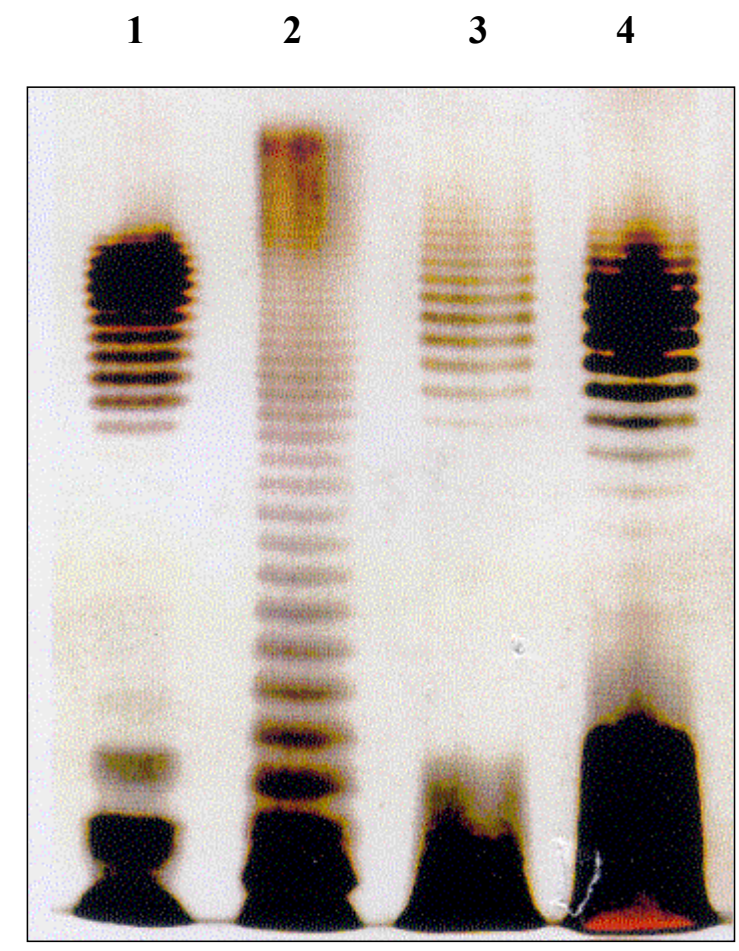

LPS were extracted by the hot phenol-water method of Westphal and Jann (1965) and resolved on a $10 \%$ polyacrylamide gel and visualized by silver staining. Lane 1: Escherichia coli $(1.0 \mu \mathrm{g})$, lane 2: Pseudomonas aeruginosa $(0.5 \mu \mathrm{g})$, lane 3: Pseudomonas syringae pv. apii $(2.0 \mu \mathrm{g})$, lane 4: Pseudomonas syringae pv. apii (4.0 $\mu \mathrm{g})$. A characteristic ladder like pattern was obtained for LPS of $P$. $s$. pv. apii which differs from LPS of E. coli and P. aeruginosa. 


\subsection{Discussion}

Lipopolysaccharides are ubiquitous components of the outer membrane of all Gram-negative bacteria. They are comprised of three regions, viz., lipid A, the core region and a highly heterogeneous region comprised of repeating units of oligosaccharides (O- chain). Strains that lack O-chains are referred to as rough strains. In addition to the involvement in the direct interaction of a bacterial cell with its immediate environment the LPS has also been acknowledged as an element of virulence that plays a vital role in host-pathogen interactions (Rudolph, 2001). Phytopathogenic pseudomonads are generally considered to be highly adapted pathogens with a narrow range of target hosts, and their host specificity is governed by number of factors which remain unravelled. It was suggested that the specificity of the P. syringae pathovars is due to specific LPS structures, especially of the LPS O-chain (Laux et al. 1996). However, Ovod et al. (1997) reported that some strains of $P$. syringae have identical O-chain repeats (for eg., P. s. pv. apii and P. s. pv. tomato or P. s. pv. cannabina and P. s. pv. maculicola). If the LPS O-chains are the primary, if not the sole, determinants of host specificity, strains that possess an identical O-chain pattern must also have the same host range. In fact, during preliminary screening experiments, it was noticed that the two $P$. s. pathovars tomato and apii have the ability to cross-infect their assumed non-hosts (Venkatesh and Rudolph, 2001b). In this context, however, the fact that the two P. s. pathovars tomato and apii have been so classified based on their ability to infect different hosts appears contradictory. The present study was aimed to further clarify this issue.

The LPS from $P$. s. pv. apii was therefore characterized biochemically and compared to LPS from P. s. pv. tomato (see table 3.3.1, studied previously by Müller, 1998) to determine the extent of similarity between them. The typical components of the LPS core from pseudomonads such as glucose, rhamnose, L-glycero Dmannoheptose, glucosamine, galactosamine, 2-keto 3-deoxy-D manno-octonic acid (KDO), alanine and phosphate could be all detected in the LPS from P. syringae pv. apii by biochemical analyses. The molar ratio of the two most abundant neutral sugars 
was 2:1, glucose being present twice as much as rhamnose. In this aspect LPS from $P$. s. pv. apii appears to be similar to that of $P$. s. pv. tomato race 0 (Müller 1998). By contrast the predominant hexose sugar is rhamnose in some strains of Pseudomonas syringae pv. phaseolicola and P. s. pv. syringae (Laux, 1998; Müller, 1998). In P. s. pv. coriandericola, the molar ratio of L-rhamnose to $3 \mathrm{~N}$-acetyl-3-deoxy-D-fucose was reported to be 4:1 (Das et al. , 1994).

In $P . \quad s$. pv. atrofaciens, the molar ratio of L-rhamnose to N-acetyl Dglucosamine was 4:1 (Zdorovenko et al. , 2001). Thus the LPS from P. s. pv. apii and $P$. S. pv. tomato appear to have similar neutral sugar composition which differs significantly from that of other pathovars of $P$. syringae. KDO and heptose analyses are routine tests for LPS since these compounds serve as valuable markers for LPS.

The molar ratio of phosphate to glucosamine is approximately 21 and that of ethanolamine to phosphate is ca. 4. This indicates that the lipid A preparations are highly phosphorylated. Some strains of $P$. s. pv. tomato were reported to contain highly phosphorylated lipid A cores (Das et al. , 1994). A possible role of the degree of phosphorylation of LPS in modulating the function of the outer membrane as a permeability barrier has been discussed by Ray et al. (1994). The detection of dimers of galactosamine and mannosamine are thought to be the result of the incomplete hydrolysis of the LPS.

The component analyses of the hydrophobic fraction of lipid A showed the presence of the 2-hydroxy-dodecanoic acid, 3-hydroxy-decanoic acid, decanoic acid, 3 -hydroxy-dodecanoic acid in the ratio of approximately $2: 2: 1: 3$. Thus dodecanoic acid seems to be a distinguishing feature of the lipid A fraction from $P$. s. pv. apii as is the case with other pseudomonads such as P. s. pv. tomato (Muller, 1998), $P$. aeruginosa, $P$. acidovorans, $P$. syncyanea, $P$. putida and $P$. aminovorans (Das et al., 1994, Wilkinson, 1977). In P. s. pv. syringae, P. s. pv. phaseolicola and P. s. pv. atrofaciens, $\mathrm{C} 16: \mathrm{O}, \mathrm{C} 18: \mathrm{O}, \mathrm{C} 16: 1$ and $\mathrm{C} 18: \mathrm{O}$ were detected in addition to the four fatty acids mentioned above (Zdorovenko et al. , 2001). Again, LPS from P. s. pv. apii seems to 
possess a fatty acid profile that is similar to that of $P$. $s$. pv. tomato but different from that of $P$. s. pv. phaseolicola or P. s. pv. atrofaciens.

Table 3.3.1 : Chemical composition of lipopolysaccharides from Pseudomonas syringae pvs. apii and tomato (the data for $P$. s. pv. tomato are from Müller, 1998).

\begin{tabular}{|c|c|c|c|c|c|c|}
\hline \multirow[t]{3}{*}{ Component } & \multicolumn{6}{|c|}{ Chemical composition of } \\
\hline & \multicolumn{2}{|c|}{ LPS } & \multicolumn{2}{|c|}{ Polysaccharide } & \multicolumn{2}{|c|}{ Lipid A } \\
\hline & $\begin{array}{c}P . s . \mathrm{pv} . \\
\text { tomato } \\
\text { race } 0 \\
\mathrm{nmol} / \mathrm{mg}\end{array}$ & $\begin{array}{c}P . s . \mathrm{pv} . \\
\text { apii } \\
\mathrm{nmol} / \mathrm{mg}\end{array}$ & $\begin{array}{c}P . s . \mathrm{pv} . \\
\text { tomato } \\
\text { race } 0 \\
\mathrm{nmol} / \mathrm{mg}\end{array}$ & $\begin{array}{c}\text { P. s. pv. } \\
\text { apii } \\
\mathrm{nmol} / \mathrm{mg}\end{array}$ & $\begin{array}{c}P . s . \mathrm{pv} . \\
\text { tomato } \\
\text { race } 0 \\
\mathrm{nmol} / \mathrm{mg}\end{array}$ & $\begin{array}{c}\text { P.s. pv. } \\
\text { apii } \\
\mathrm{nmol} / \mathrm{mg}\end{array}$ \\
\hline $\mathrm{KDO}$ & 48 & 401 & & & & \\
\hline $\mathrm{PO}_{4}{ }^{3-}$ & 225 & 262 & & & & \\
\hline GlcN/ManN & nd & 585 & & & & \\
\hline GalN & nd & 339 & & & & \\
\hline GlcN & nd & 62 & & & & \\
\hline $\operatorname{Etn} P_{\text {tot }}$ & nd & 262 & & & & \\
\hline$P_{\text {tot }}$ & nd & 1351 & & & & \\
\hline Glucose & & & 1440 & 1138 & & \\
\hline Rhamnose & & & 1007 & 510 & & \\
\hline Ribose & & & 25 & 24 & & \\
\hline Heptose & & & nd & 177 & & \\
\hline 3-OH-C10:0 & & & & & 180 & 126 \\
\hline $12: 0$ & & & & & 110 & 169 \\
\hline 2-OH-C12:0 & & & & & 87 & 92 \\
\hline 3-OH-C12:0 & & & & & 207 & 211 \\
\hline Alanine & nd & 180 & & & & \\
\hline
\end{tabular}

KDO: 3-deoxy-D-manno-octulosonic acid, $\mathrm{PO}_{4}{ }^{3--}$ Phosphate,

GlcN/ManN: N-acetylglucosamine, N-acetylmanosamine, GalN : N-acetygalacosamine, GlcN :N-acetylglucosamine, Etn $P_{\text {tot }}$ Ethonalamine Phosphate, $P_{\text {tot }}$ : Total phosphate, 3-OH-C10:0: 3-hydroxydecanoic acid, C12:0: dodecanoic acid, 2-OH-C12:0: 2-hydroxydodecanoic acid, 3-OH-C12:0; 3-hydroxy-dodecanoic acid. nd- not detected 
Alanine, cystein and glycine have been reported as typical amino acid components of LPS from the pseudomonads (Das et al. , 1994). However, the LPS of P. s. pv. apii differed from that of the other pseudomonads as only alanine was detected.

LPS from $P$. s. pv. apii were characterized on a SDS-PAGE and visualized by silver staining. The differences in the electrophoretic pattern between lanes 3 and 4 is a concentration dependent effect since the number of bands visualized is influenced by loading and staining efficiencies. The form of LPS as revealed by gel electrophoresis was the smooth (S) type. The electrophoretic behavior of LPS in the presence of SDS reflects its basic structure. A ladder like pattern was obtained on the gel (Fig. 3.3.2.1) due to the heterogeneity of the antigenic-side-chain length in the LPS molecules (Goldman and Leive, 1980; Palva and Makela, 1980). It appears that the major form of LPS in P. s. pv. apii has a large number of O-antigen units attached, since a gap is seen in the ladder at higher mobilities (Dooley et al. , 1985). This type of pattern has also been reported for Pseudomonas syringae pv. atrofaciens (Ovod et al. , 1991), P. s. pv. aeruginosa, and some fluorescent strains of pseudomonads (Rivera et al. , 1988) as well as for other enteric bacteria such as Erwinia amylovora. The distinct patterns of LPS on SDS-PAGE have been utilized to identify serogroups of Erwinia strains (Murray et al. , 1990).

Based on the biochemical composition and SDS-PAGE analysis of LPS from $P$. s. pv. apii it can be concluded that the pathovar is very closely related to $P$. $s$. pv. tomato and that these two are distinct from several other pathovars that comprise the Pseudomonas syringae group of pseudomonads. However the analyses do not allow to unequivocally ascertain the differentiation of these two pathovars in to the distinct taxonomic groups as has been presently done. Additional experiments that further critically dissect the pathovars at the molecular and structural levels are required to fortify their respective positions in the taxonomic hierarchy. 


\subsection{Summary}

- Bacterial strains were cultivated on King's medium B in a 1001 fermentor. The bacterial pellets were collected by centrifugation and freeze dried.

- LPS were extracted from Pseudomonas syringae pv. apii strain GSPB 2548 using the hot phenol-water method (Westphal and Jann, 1965).

- Biochemical analysis was carried out using the purified LPS.

- Phosphate analysis indicated the presence of $\mathrm{PO}_{4}{ }^{3-}$ to be $21.79 \mathrm{~mol} / \mathrm{mol}$ of LPS.

- Analysis of 2-keto-3-deoxy-octonate (KDO) revealed the presence of $6.47 \mathrm{~mol} / \mathrm{mol}$ of $\mathrm{KDO}$ and the heptose content was $2.85 \mathrm{~mol} / \mathrm{mol}$.

- The amount of the amino sugars $\mathrm{N}$-acetyl glucosamine and N-acetyl galactosamine was found to be $5.47 \mathrm{~mol} / \mathrm{mol}$ and $1.00 \mathrm{~mol} / \mathrm{mol}$, respectively.

- Sugar analysis revealed the presence of glucose, rhamnose and ribose. Among the sugars glucose was predominant followed by rhamnose and ribose.

- The fatty acid profile indicated the presence of 3-hydroxy-decanoic acid, dodecanoic acid, 2-hydroxy-dodecanoic acid and 3-hydroxy dodecanoic acid in the ratio of $2: 3: 2: 3$.

- Alanine content was detected at $2.90 \mathrm{~mol} / \mathrm{mol}$.

- The LPS were characterized by SDS-PAGE and visualised by the silver staining method. A characteristic ladder like pattern was observed for the LPS from P. s. pv. apii. 
- The biochemical analysis revealed that the LPS from P. s. pv. apii was similar in composition to that of $P$. s. pv. tomato with respect to the neutral sugar content but differed in fatty acid contents.

\section{$\bullet$}




\section{Chapter 4}

\section{Biochemical characterization of pectins from cultivars of celery and tomato resistant or susceptible to Pseudomonas syringae pvs. tomato and apii and isolation and characterization of putative carbohydrate binding proteins from P. s. pvs. tomato and apii by haemagglutination inhibition studies}

\subsection{Introduction}

\subsubsection{Pectins}

Pectins constitute a diverse family of complex anionic polysaccharides that are found in the middle lamella and in the intercellular spaces of all higher plants. The pectic polysaccharides account for nearly $30 \%$ of the primary plant cell walls. Pectins contribute to some important physical and sensorial properties of fresh fruits and vegetables such as ripeness, texture and are widely used as stabilizing agents in food industry (Rollin and De Vries, 1990).

Pectins are structurally extremely complex. The principal building block of pectins is galacturonic acid (GalA). Besides, they always contain large quantities of other sugars rhamnose, arabinose, glucose and galactose being the most abundant. The regions of the pectin molecule that comprise linear chains of .1-4) linked D-galacturonic acid units are referred to as "smooth" regions and the blocks of highly substituted rhamnogalacturonans that interrupt the homogalacturonan backbone are known as "hairy" regions. The GalA moiety of the pectin molecule can be methyl-esterified at the C-6 position and acetylated at positions 2 or 3 (Fig. 4.1.1.1.). The degree and distribution of esterified regions differ between plant species and also at different developmental stages of growth during the life cycle of a plant. Liners and van Cutsem (1992) reported that pectins extracted from tightly attached young calli of carrot have higher amounts of methyl-esterified galacturonic acid residues when compared to that of loosely attached old calli which have a significant amount of nonmethyl esterified regions. The amount of neutral sugars, on the other hand were shown to determine intercellular attachment (Kikuchi et al., 1996). 
The structure of pectins is further characterized by cross-linkages with divalent cations and with possible esterification to other cell wall polymers. The candidates for interaction between pectins and other polysaccharides in the plant cell were proposed to be phenolic acids mediated molecular linkages. However, the exact nature of the cross links still remains largely speculative (Darvill et al., 1978).

The functional properties of pectins reside primarily in their chemical structure and composition. Quite rightly, therefore, elucidation of its structure has been at the epicentre of pectin research over several years. Conventional chemical analyses have greatly aided our understanding of the chemistry of pectins and recent technological advances such as spectroscopy (De Vries et al., 1982, Schols and Voragen, 1996, Daas et al., 1999), HPAEC (Kravtchenko et al., 1993), atomic force microscopy (Round et al., 2001), and immunoprofiling (Willats and Knox, 1999) have expanded our knowledge about the architecture of pectins.

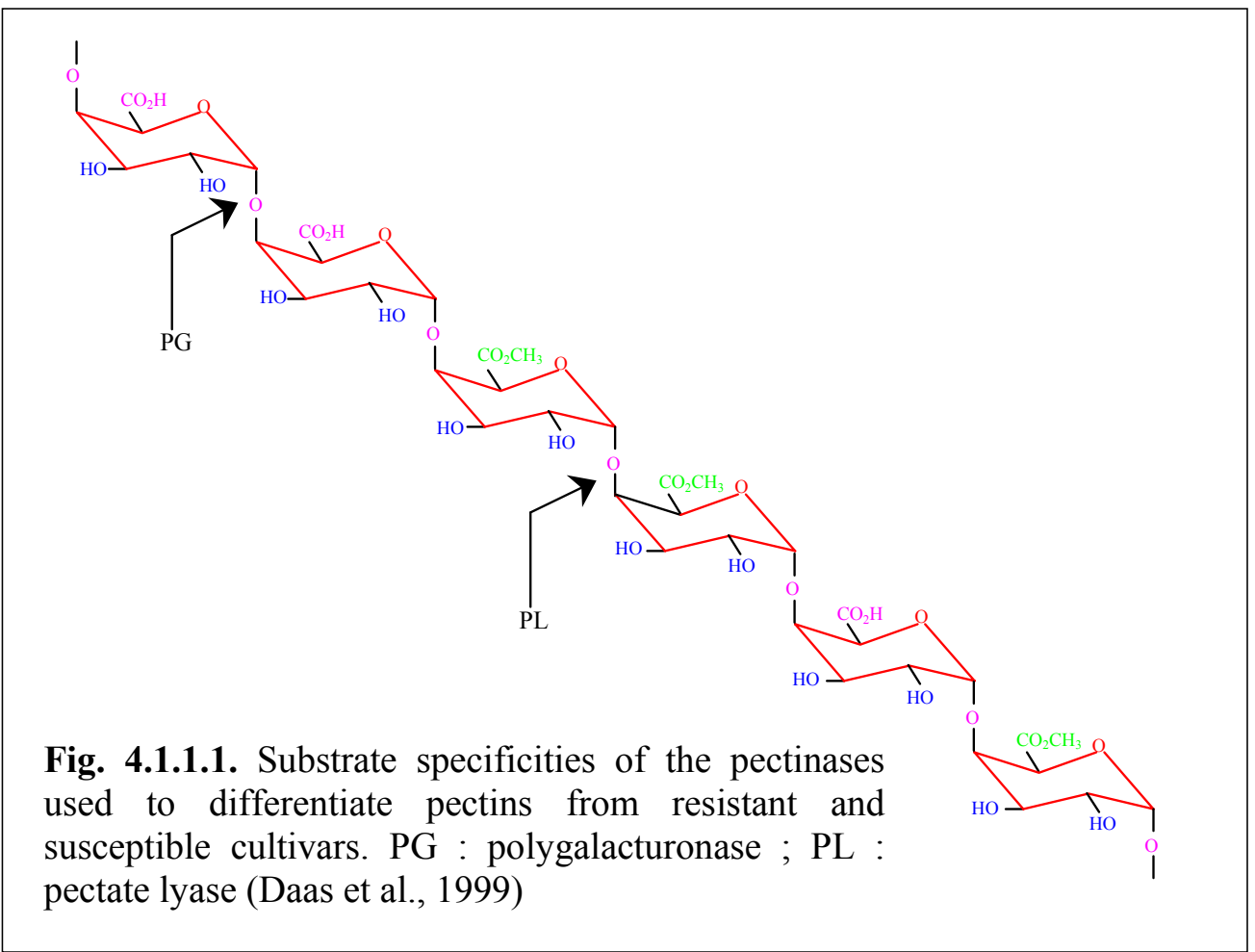


In addition, the availability of pectin-degrading enzymes has led to the emergence of a new approach known as enzymatic fingerprinting to broaden our understanding of the structural diversity of pectins (Limberg et al., 2000). The most commonly used enzymes for the purpose are the exo and endo polygalacturonases (PG), pectate lyase (PAL), pectin methylesterase (PE), pectin lyase (PL) and -galactosidase (De Veau et al., 1993).

The complex structural composition of pectins reflects perhaps their functional diversity. It is not surprising therefore that pectins play multifaceted roles during the life cycle of a plant. The unique gelling properties of pectins has found many commercial applications. Interestingly, this property is also one of the factors that determines the fate of a hostpathogen interaction. For instance, in host-pathogen interactions pectins act as defence barriers against the invasion of microorganisms. The resistance of primary cell walls to enzyme digestion has been suggested to be the result of the formation of calcium bridges between pectin chains (Ferguson, 1984). On the other hand, Rao et al. (1982) indicated that pectins of plant cell walls play a critical role in adherence of bacterial cells to the host surface. That pectins interact with bacterial lipopolysaccharides was also demonstrated through rheological investigations by Grolms (1996), Liehe (1998) and Laux (1998). Additionally, in chapter 2, the differential rheological behaviour of pectins from resistant and susceptible cultivars of tomato and celery with bacterial LPS is discussed.

The role of pectins in induction of pathogenesis related genes has been studied in the past. However the elucidation of the role of the structural composition of pectins in hostpathogen interaction is a topic that has received scant attention, and this very aspect is the focus of the present investigation. Pectins were extracted from resistant and susceptible cultivars of tomato and celery leaves and partial characterization of the extracted pectins was carried out by chemical and enzymatic hydrolysis in order to differentiate them. The current study is one of the very few undertaken to date in order to differentiate pectins from resistant and susceptible cultivars on the basis of their chemical and structural characteristics. Both conventional and advanced methods were followed to characterize the pectins obtained from resistant and susceptible cultivars of tomato and celery plants. Preliminary results point towards a correlation between the degree of esterification of plant pectins and susceptibility to bacterial infection. 


\subsubsection{Carbohydrate binding proteins}

Carbohydrate binding proteins of non-immune origin with no-catalytic activities are ubiquitous in nature and are known to play an important role in cell recognition (Goldstein et al., 1980). Bacterial cell surface proteins and small appendages such as pili are involved in the adhesion of bacterial cells to eukaryotic cell surfaces (Sharon, 1987). Several bacteria produce lectins and lectin-like proteins that are involved in microbial pathogenicity and play a key role in infection in animals and humans. However, the physiological role of bacterial lectins in plant pathogenesis is not clearly known.

Very few reports are available that deal with lectins produced by plant pathogenic microorganisms of which only a handful point to a possible role for the proteins in hostpathogen interactions. The role of lectins present on the root surfaces in legume-rhizobium symbiosis is perhaps better known. For instance, the symbiotic relationship between soybean roots and Bradyrhizobium japonicum was shown to involve a lectin produced by the bacteria with a carbohydrate from plants (Loh et al., 1993). Sequeira et al. (1977) suggested that lectins produced by phytopathogenic bacteria recognize specific carbohydrates present on the cell surface of plants and thereby give an opportunity for subsequent interactions. Joshi et al. (1995) characterized a carbohydrate binding protein from the phytopathogen Xanthomonas campestris. According to Stadnik et al. (2001) a cell surface lectin from Xanthomonas, presumably, plays a role in the contact interactions between bacteria and plants. Some bacterial lectins recognize certain mono- and polysaccharides in plants. The lectins from Erwinia were reported to specifically bind to N-acetyl lactosamine (Romantshuk et al., 1994). In addition to lectins from bacteria there are also reports on the cell surface proteins from Saccharomyces cereviseae that are specific to mannose (Javadekar et al., 2000).

Lectins are generally classified on the basis of their blood group specificity and subsequently on the potency with which a monosaccharide can inhibit their agglutination and glycoconjugate precipitating activity (Sharma and Surolia, 1997). Several specificity groups including mannose, glucose, galactose, N-acetylglucosamine, N-acetylgalactosamine, Lfucose and $\mathrm{N}$-acetylneuraminic acid have been studied (Goldstein and Hayes, 1978; Sharon and Lis, 1990). Lectins in general have relatively low affinity to monosaccharides and high affinity to oligosaccharides (Rini, 1995; Weis and Drickamer, 1996). 
In the present study, carbohydrate binding proteins were extracted from the phytopathogenic bacteria Pseudomonas syringae pv. tomato and Pseudomonas syringae pv. apii. These strains were previously shown to posses an identical O-chain pattern in their LPS. The proteins were characterized based on their haemagglutination and inhibition properties with pectins extracted from resistant and susceptible cultivars of tomato and celery plants. Similar properties were also studied for the proteins against different sugars. The carbohydrate binding proteins seem to possess certain unique properties that are involved in interactions with specific sugars from the host. Thus, these proteins may play a role in determining the host-range of a pathogen. 


\subsection{Materials and Methods}

\subsubsection{Extraction of Pectins (Sonnenberg, 1994)}

Pectins were extracted from juvenile leaves of eight-week-old plants from resistant and susceptible cultivars of tomato and celery. Five hundred grams of frozen leaves were homogenized in a blender (Ultra-Turrax T2) for $30 \mathrm{~min}$ at 12,000 rpm/min with 1.51 of $100 \mathrm{mM}$ sodium potassium phosphate buffer ( $\mathrm{pH} \mathrm{5.5)}$ containing 4\% (w/v) PVPP, $20 \mathrm{mM}$ EDTA and 2\% (w/v) sodium ascorbate. The homogenate was left overnight at $4{ }^{\circ} \mathrm{C}$ and later centrifuged at $10,000 \mathrm{~g}$ for $20 \mathrm{~min}$. The supernatant was filtered through a Whatman filter paper. Further, the volume was condensed to one fifth of the initial volume using a rotary evaporator.

Scheme for the extraction of pectins from plant leaves (Sonnenberg, 1994)

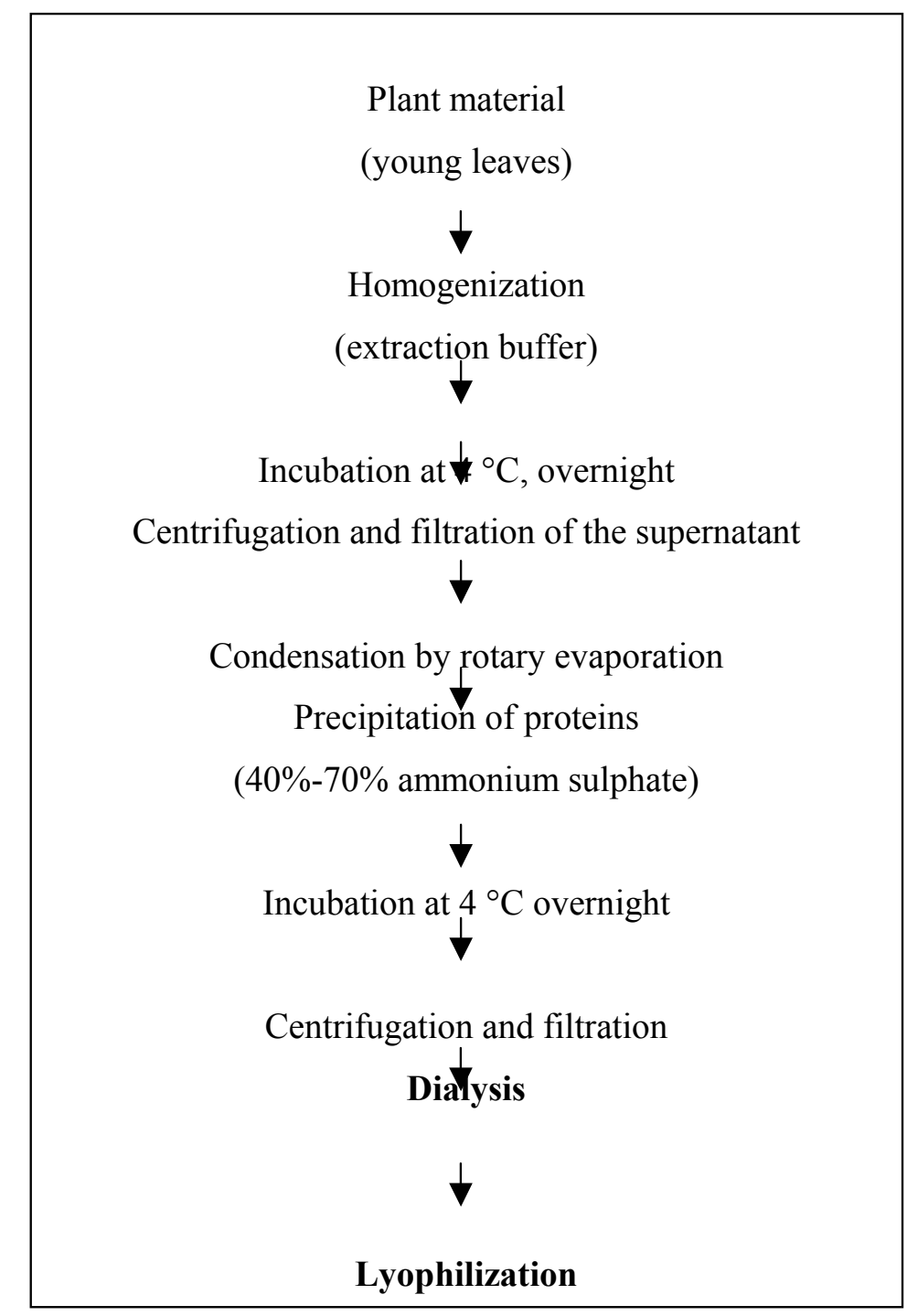


Proteins were precipitated from the supernatant using ammonium sulphate (40\%-70\%) and kept at $4{ }^{\circ} \mathrm{C}$ overnight. Centrifugation was carried out at $10,000 \mathrm{~g}$ for $20 \mathrm{~min}$ to remove the proteins and the supernatant containing pectins was filtered using a Whatman filter paper and dialyzed against demineralized (dm) water for $72 \mathrm{~h}$. Crude pectins were recovered by lyophilization.

\subsubsection{Analysis and characterization of pectins (Owens et al. , 1952)}

\subsubsection{Volumetric Analysis}

\subsubsection{Determination of equivalent weight}

The equivalent weight of crude pectins was determined by weighing in $10 \mathrm{mg}$ of moisture free pectins to a $25 \mathrm{ml}$ flask pre-moistened with $200 \mu \mathrm{l}$ of $70 \%$ ethanol. Five $\mathrm{mg}$ of sodium chloride were added to sharpen the end point during the titration. Two milliliters of carbon dioxide free $\mathrm{dm}$ water and 2 drops of the indicator phenol red were added to the flask. The pectic substances were stirred in rapidly to dissolve completely and titrated slowly against $0.1 \mathrm{~N} \mathrm{NaOH}$ until the colour of the indicator changed from pink to yellow and persisted for at least $30 \mathrm{sec}$. The neutralized solution was saved for the methoxyl determination.

\subsection{Estimation of methoxyl content}

The methoxyl content was determined by adding $2.5 \mathrm{ml}$ of $0.25 \mathrm{~N} \mathrm{NaOH}$ to neutralize the earlier solution obtained from equivalent weight determination. The neutralized solution was incubated at room temperature for $30 \mathrm{~min}$ followed by the addition of $2.5 \mathrm{ml}$ of $0.25 \mathrm{~N} \mathrm{HCl}$ and titrated against $0.1 \mathrm{~N} \mathrm{NaOH}$ to the same end point as before.

The methoxyl content can be calculated as follows:

$$
\mathrm{MeO} \%=\frac{\text { milliequalence of sodium hydroxide } \times 31 \times 100}{\text { Weight of sample }(\mathrm{mg})}
$$

where 31 is the molecular weight of methoxyl 
Anhydrouronic acid (AUA) content

The amount of anhydrouronic acid (AUA) can be calculated if the equivalent weight and methoxyl content of the pectins are known

$$
\% \mathrm{AUA}=\frac{176 \times 100}{\mathrm{Z}}
$$

where 176 is the molecular weight of AUA and

$$
\mathrm{Z}=\frac{\text { weight of the sample in } \mathrm{mg}}{\text { meq. of alkali for free acid }+ \text { meq. of alkali for methoxyl }}
$$

\subsection{Determination of the degree of esterification (DE)}

The degree of estertification can be calculated according to the formula developed by Schultz (1976).

$$
\% \mathrm{DE}=\frac{176 \times \mathrm{CH}_{3} \mathrm{O} \% \times 100}{31 \times \mathrm{AUA} \%}
$$

where $\mathrm{CH}_{3} \mathrm{O} \%$ is the $\%$ of methoxyl content

\subsubsection{Acid hydrolysis of pectins}

Five milligrams of crude pectins were dissolved in $2 \mathrm{ml}$ of $4 \mathrm{M}$ trifluoroacetic acid (TFA) in a clean test tube and flushed with nitrogen to avoid oxidation. The tubes were 
sealed using a gas flame and incubated at $121^{\circ} \mathrm{C}$ for $4 \mathrm{~h}$. The acid was removed by evaporation under vacuum and the dried samples were dissolved in $1 \mathrm{ml}$ of dm water for further analysis.

\subsubsection{Thin layer chromatography (TLC)}

Thin layer chromatography was performed on pre-coated cellulose plates $(20 \mathrm{~cm} \mathrm{x}$ $20 \mathrm{~cm}$ ). The hydrolyzed samples of pectins were dissolved in $100 \mu 1$ of demineralized water. Ten microliters of the samples and standard sugars were spotted on the plates and placed in a chamber containing the solvent and allowed to run for $6 \mathrm{~h}$. The plates were dried for few minutes under a fume hood and sprayed with naphthoresorcin-phosphoric acid followed by incubation at $100{ }^{\circ} \mathrm{C}$ for $30 \mathrm{~min}$ to visualize the spots.

Solvent Mixture - APEW (Schramek and Mayer, 1982)

Acetic acid (99.8\%) : Pyridine : Ethylacetate : Water : : $1: 5: 5: 3$

\section{Spraying reagent - Naphthoresorcin - phosphoric acid (Stahl, 1967)}

Ten volumes of $0.2 \%(\mathrm{v} / \mathrm{v})$ naphthoresorcin dissolved in absolute ethanol and 1 volume of $85 \%(\mathrm{v} / \mathrm{v})$ of phosphoric acid.

\subsubsection{Gas chromatography}

Five milligrams of crude pectins were hydrolyzed using $4 \mathrm{M}$ TFA and recovered as described earlier. About $200 \mu \mathrm{g}$ of crude pectins were placed in Teflon-capped vials to which $200 \mu \mathrm{l}$ of pyridine and $100 \mu \mathrm{l}$ of trimethylsilyl acetamine (TMSI) were serially added. The mixture was vortexed for $2 \mathrm{~min}$ and incubated at $70{ }^{\circ} \mathrm{C}$ for $10 \mathrm{~min}$ on a heat block and cooled to room temperature.

The samples were analyzed on a GC Schamdzu 14 A / FID using supelco SPB1 (30 m; ID $0.32 \mu \mathrm{m}$; Film $0.25 \mu \mathrm{m}$ ) column with $\mathrm{N}_{2}$ as a carrier gas with a linear velocity of $5 \mathrm{~cm} / \mathrm{sec}$; and a split ratio of $50: 1$. The injector temperature was $280{ }^{\circ} \mathrm{C}$. The temperature conditions during the analysis were as follows: initial temp: $130{ }^{\circ} \mathrm{C}$, ramp at $20{ }^{\circ} \mathrm{C} / \mathrm{min}$ to $290^{\circ} \mathrm{C}$ with a hold up for $9 \mathrm{~min}$, detector temperature: $300{ }^{\circ} \mathrm{C}$. 


\subsubsection{Enzymatic digestion of pectins (Koerner et al. , 1999)}

Five milligrams of crude pectin samples from leaves of resistant and susceptible cultivars of celery plants were dissolved in $1 \mathrm{ml}$ of $50 \mathrm{mM}$ sodium acetate buffer adjusted to $\mathrm{pH}$ 4.5. The enzymes pectate lyase and polygalacturonase (gift from Dr. A. Pant, National Chemical Laboratories (NCL), Pune, India) were dissolved in $50 \mathrm{mM}$ acetate buffer to a final concentration of $5 \mathrm{U} / \mathrm{ml}$. One unit of each enzyme was added to $1 \mathrm{ml}$ aliquots of the pectin solution separately and incubated at $37^{\circ} \mathrm{C}$ for $48 \mathrm{~h}, 100 \mu \mathrm{l}$ aliquots were taken at different time intervals and the digestion was arrested by heating the aliquots at $100{ }^{\circ} \mathrm{C}$ for $10 \mathrm{~min}$. The samples were then filter purified using a $4 \mu \mathrm{m}$ filter (Sartorius) and dried in a speed vac prior to analyses on a glyco column, Waters HPLC. The analyses were done at NCL, Pune, India.

\subsubsection{Carbohydrate binding proteins from phytopathogenic Pseudomonas spp.}

\subsection{Extraction of carbohydrate binding proteins (haemagglutinins)}

The bacteria (P. s. pv. apii GSPB 2548 and P. s. pv. tomato GSPB 2317) were grown in nutrient broth at $27{ }^{\circ} \mathrm{C}$ for $48 \mathrm{~h}$. The cells were harvested by centrifugation at $10,000 \mathrm{xg}$ for $20 \mathrm{~min}$ and suspended in $50 \mathrm{mM}$ acetate buffer $(\mathrm{pH} \mathrm{6.0)} \mathrm{containing} 2 \mathrm{M}$ urea, $5 \mathrm{mM}$ EDTA and $1 \mathrm{mM}$ PMSF. The suspension was stirred for $12 \mathrm{~h}$ at $4{ }^{\circ} \mathrm{C}$ and the cells were separated by centrifugation at $10,000 \mathrm{xg}$ for $20 \mathrm{~min}$ and the supernatant was subjected to $90 \%(\mathrm{w} / \mathrm{v})$ saturation with ammonium sulphate to precipitate proteins. The precipitate was separated by centrifugation at $10,000 \mathrm{xg}$ for $30 \mathrm{~min}$ and later dialyzed for $72 \mathrm{~h}$ against $20 \mathrm{mM}$ Tris-HCl buffer (pH 7.2) containing $2 \mathrm{mM}$ EDTA.

The dialyzed product was loaded onto a column of DEAE-Sephadex, pre-equilibrated with $20 \mathrm{mM}$ Tris buffer ( $\mathrm{pH}$ 7.2) containing $2 \mathrm{mM}$ EDTA. The ion exchange column was washed with the same buffer and the unbound protein was eluted using a linear gradient of $0-0.5 \mathrm{M} \mathrm{NaCl}$ in $20 \mathrm{mM}$ Tris- $\mathrm{HCl}$ buffer with $2 \mathrm{mM}$ EDTA. The fractions showing haemagglutination were pooled, lyophilized, dialyzed and loaded onto 
phenyl Sepharose pre-equilibrated with Tris buffered saline (TBS $10 \mathrm{mM}$ Tris- $\mathrm{HCl} \mathrm{pH}$ 7.2, $4 \mathrm{M} \mathrm{NaCl}$ ). The unbound carbohydrate binding protein was eluted with a gradient of ethylene glycol in $10 \mathrm{mM}$ Tris- $\mathrm{HCl}(\mathrm{pH}$ 7.2), and the active fractions were pooled and dialyzed against TBS and lyophilized. The protein was quantified following the method of Lowry et al. (1951).

\subsection{Characterization of the proteins by native $P A G E$}

All chemicals used for performing electrophoresis were purchased from Roth (Karlschule, Germany) and Merck (Darmstadt, Germany).

\subsection{Native polyacrylamide gel electrophoresis (Schröder, 2000)}

Carbohydrate binding proteins were separated on a $1 \mathrm{~mm}$ thick polyacrylamide gel using a mini gel apparatus (10 x $10 \mathrm{~cm}$ Biometra Co., Göttingen, Germany). The glass plates used for preparing the gels were cleaned with 70\% ethanol and air-dried. All the constituents, except ammoniumpersulphate (APS) were added in a $10 \mathrm{ml}$ side arm Erlenmeyer flask. The flask was sealed with a rubber stopper and the contents were deaerated. APS was added to the mixture and dispensed between the glass plates and overlaid with iso-butanol or $\mathrm{H}_{2} \mathrm{O}$ and allowed to polymerize. The stacking gel was prepared as described above but with a lower concentration of acrylamide (see table 4.2.2.1.).

\subsection{Buffers, chemicals and reagents used for native-PAGE}

Acrylamide stock solution

Running gel buffer (3 X)

Stacking gel buffer (3 X)

TEMED

APS

Electrode buffer $(10 \mathrm{X})$
$30 \%(\mathrm{w} / \mathrm{v})$ acrylamide , $0.8 \%(\mathrm{w} / \mathrm{v})$ bisacrylamide

$3 \mathrm{M}$ Tris- $\mathrm{HCl}, \mathrm{pH} 8.8$

0.5 M Tris- $\mathrm{HCl}, \mathrm{pH} 6.8$

$10 \%(\mathrm{w} / \mathrm{v})$

$10 \%(\mathrm{w} / \mathrm{v})$

$400 \mathrm{mM}$ Tris $\mathrm{pH} 8.3$

$600 \mathrm{mM}$ glycine 
Table 4.2.2.1. Formulation for preparing 2 mini gels for native PAGE

\begin{tabular}{lcc}
\hline Ingredients & Separating gel (10\%) & Stacking gel (3\%) \\
\hline Acrylamide stock solution & $9.4 \mathrm{ml}$ & $1.0 \mathrm{ml}$ \\
Separating gel buffer & $3.6 \mathrm{ml}$ & - \\
Stacking gel buffer & - & $2.0 \mathrm{ml}$ \\
TEMED & $17.0 \mu \mathrm{l}$ & $8.0 \mu \mathrm{l}$ \\
APS & $145.0 \mu \mathrm{l}$ & $40.0 \mu \mathrm{l}$ \\
Double-distilled water & $18.8 \mathrm{ml}$ & $5.0 \mathrm{ml}$ \\
& & \\
\hline
\end{tabular}

\subsection{Electrophoresis conditions}

The gel was run at $100 \mathrm{~V}$ for $30 \mathrm{~min}$ (stacking phase) and at $200 \mathrm{~V}$ for $2 \mathrm{~h}$ for separation.

\subsection{Sodium dodecyl sulphate polyacrylamide gel electrophoresis (SDS-PAGE)}

Carbohydrate binding proteins were separated on a $1 \mathrm{~mm}$ thick polyacrylamide gel using a mini gel apparatus (10 x $10 \mathrm{~cm}$ Biometra Co., Göttingen). The gels were prepared as described earlier.

\subsection{1. Buffers, chemicals and reagents used for SDS-PAGE}

Acrylamide stock solution $\quad 30 \%(\mathrm{w} / \mathrm{v})$ acrylamide , $0.8 \%(\mathrm{w} / \mathrm{v})$ bisacrylamide

Running gel buffer (3 X) $1 \mathrm{M}$ Tris-HCl, $\mathrm{pH} 8.8$

$$
0.3 \%(\mathrm{w} / \mathrm{v}) \mathrm{SDS}
$$

Stacking gel buffer (3 X) $1 \mathrm{M}$ Tris-HCl, $\mathrm{pH} 6.8$

TEMED $\quad 10 \%(\mathrm{w} / \mathrm{v})$

APS $10 \%(\mathrm{w} / \mathrm{v})$ 


$\begin{array}{ll}\text { Electrode buffer }(10 \mathrm{X}) & 400 \mathrm{mM} \text { Tris } \mathrm{pH} 8.3 \\ & 600 \mathrm{mM} \text { glycine } \\ & 1 \%(\mathrm{w} / \mathrm{v}) \mathrm{SDS} \\ & 0.0625 \mathrm{M} \text { Tris-HCl, } \mathrm{pH} 6.8 \\ & 2 \%(\mathrm{w} / \mathrm{v}) \mathrm{SDS} \\ & 10 \%(\mathrm{v} / \mathrm{v}) \text { glycerol } \\ & 0.002 \%(\mathrm{w} / \mathrm{v}) \text { bromophenolblue }\end{array}$

\subsection{2. Preparation of protein samples}

Proteins were quantified according to Lowry et al. (1951). Twelve microliters of the protein samples were suspended in denaturing buffer for SDS-PAGE kept on a heat block at $100{ }^{\circ} \mathrm{C}$ for $5 \mathrm{~min}$. For native PAGE the samples were suspended in a buffer without SDS and DTE.

\subsection{3. Electrophoresis conditions}

The gel was run at $80 \mathrm{~V}$ for 30 min (stacking phase) and at $100 \mathrm{~V}$ for $1 \mathrm{~h}$ for separation.

Table 4.2.2.2. Formulation for preparing 2 mini gels for SDS-PAGE

\begin{tabular}{|c|c|c|}
\hline Ingredients & Separating gel $(10 \%)$ & Stacking gel (3\%) \\
\hline Acrylamide stock solution & $2.0 \mathrm{ml}$ & $250.0 \mu 1$ \\
\hline Separating gel buffer & $2.0 \mathrm{ml}$ & - \\
\hline Stacking gel buffer & - & $500.0 \mu 1$ \\
\hline TEMED & $100.0 \mu 1$ & $50.0 \mu 1$ \\
\hline APS & $15.0 \mu \mathrm{l}$ & $15.0 \mu \mathrm{l}$ \\
\hline Double-distilled water & $3.0 \mathrm{ml}$ & $1.75 \mathrm{ml}$ \\
\hline
\end{tabular}




\subsection{4. Detection of proteins after SDS-PAGE gel by Coomassie staining}

After the completion of electrophoresis, the gel was carefully separated from the glass plates and left in Coomassie blue staining solution for atleast $2 \mathrm{~h}$. The gel was then transferred to the destaining solution, and destained until the desired contrast was reached.

\subsection{5. Detection of proteins after SDS-PAGE gel by silver staining}

(Heukeshoven and Dernick, 1988)

\begin{tabular}{lll}
\hline & Steps & Solutions \\
\hline 1. & Fixing $(2 \mathrm{~h})$ & $30 \%$ ethanol \\
& & $10 \%$ acetic acid \\
2. & Incubation $(2 \mathrm{~h})$ & $30 \%$ ethanol \\
& & $0.5 \%$ sodium acetate \\
& & $0.5 \%$ glutardialdehyde \\
& & $0.2 \%$ sodium thiosulphate \\
3. & Washing with double distilled $\mathrm{H}_{2} \mathrm{O}(3 \times 10$ min $)$ \\
4. & Staining (45 min) & $0.1 \% \mathrm{AgNO}_{3}$. \\
& & $001 \%$ formaldehyde \\
5. & Developing (3-10 min) & $2.5 \% \mathrm{Na}_{2} \mathrm{CO}_{3}$ \\
6. & Stopping (5-10 min) & $0.5 \mathrm{M} \mathrm{EDTA}^{2}$ \\
7. & Washing with double distilled water.
\end{tabular}

\subsection{Haemagglutination and inhibition assays}

The partially purified proteins were serially diluted from a starting concentration of $0.5 \mu \mathrm{g} / \mathrm{ml}$ with Tris buffered saline $(20 \mathrm{mM}$ Tris- $\mathrm{HCl} \mathrm{pH} 7.2,150$ $\mathrm{mM} \mathrm{NaCl}$ ) in a microtitre plate and incubated for $1 \mathrm{~h}$ at $20^{\circ} \mathrm{C}$ with an equal volume of $3 \%(\mathrm{v} / \mathrm{v})$ suspension of rabbit erythrocytes (obtained from Max Planck Institute for Experimental Medicine, Göttingen, Germany) in TBS and incubated at room 
temperature for $1 \mathrm{~h}$ and observed for agglutinations. The activity was calculated by the reciprocal of the highest dilution of the agglutinin that gave complete agglutination. Inhibition assays were carried out with crude pectins obtained from leaves of resistant and susceptible cultivars of tomato and celery plants along with commercial pectins (from apple and citrus) and sugars. The assays were performed essentially as described above. Dilutions of sugars starting from $1 \mathrm{M}$ were incubated with the protein $(0.025$ $\mu \mathrm{g})$ suspension with an equal volume of rabbit erythrocytes (3\%). The wells were observed after $1 \mathrm{~h}$ for inhibition of haemagglutination. 


\subsection{Results}

\subsubsection{Extraction of pectins}

Pectins were extracted from leaves of resistant and susceptible cultivars of tomato and celery plants. The extraction was carried out according to the method described by Sonnenberg, 1994. The colour of the pectins varied from light brown to yellow. The yield of pectins was ca. $1 \mathrm{~g}$ per $\mathrm{kg}$ of fresh weight of leaves.

\subsubsection{Characterization of pectins}

\subsubsection{Volumetric analysis}

Volumetric analyses were performed to determine the equivalent weight for the different pectin samples from which their methoxyl content and the degree of esterification were estimated. The results are presented in table 4.4.2.1. All data provided in the table were averaged from at least three independent experiments for each of three different batches of pectins obtained from resistant and susceptible cultivars of tomato and celery plants.

\subsubsection{Determination of equivalent weight}

The equivalent weight of each of the pectins was calculated following the method of Owens (1952). The susceptible cultivars of both tomato and celery plants had almost similar equivalent weights of 1100 , whereas the pectins from the resistant cultivars appeared to have higher equivalent weights, especially those from the resistant tomato cultivar (1666) (table 4.4.2.1).

\subsection{Estimation of methoxyl content}

The methoxyl content estimated on the basis of the corresponding equivalent weights was $1.86 \%$ and $3.1 \%$ respectively for pectins from resistant and susceptible cultivars of tomato. For celery pectins the methoxyl content was $2.4 \%$ and $2.7 \%$ in susceptible and resistant cultivars respectively. 


\subsection{Determination of the degree of esterification (DE)}

The degree of esterification was significantly higher for pectins from resistant cultivars of both tomato (69\%) and celery (77\%) as compared to those from susceptible cultivars ( $33 \%$ in tomato and $39.6 \%$ in celery).

\subsubsection{Thin layer chromatography (TLC)}

Pectins obtained from the resistant and susceptible cultivars of tomato and celery plants were subjected to complete hydrolysis with 4 M TFA as described in methods and analyzed by TLC on cellulose plates using a solvent mixture of acetic acid, ethyl acetate, pyridine and water. The solute fronts were visualized after spraying with naphthoresorcin - phosphoric acid reagent. The pectin samples were run in lane 1-4. Lanes 5- 9 show the solute fronts of the standard sugars mannuronic acid, rhamnose, arabinose, galacturonic acid and galactose respectively. The sugars present in the pectins were detected based on comparsions to standard sugars. Arabinose, rhamnose, galactose and a small amount of galacturonic acid were detected in pectins from the susceptible cultivars of tomato and celery plants. Arabinose, rhamnose and traces of galacturonic acid were detected also in the samples from resistant cultivars while galactose was not detected. Mannuronic acid was not detected in any of the samples.

Fig. 4.4.3.1. Detection of sugars by Thin layer chromatography
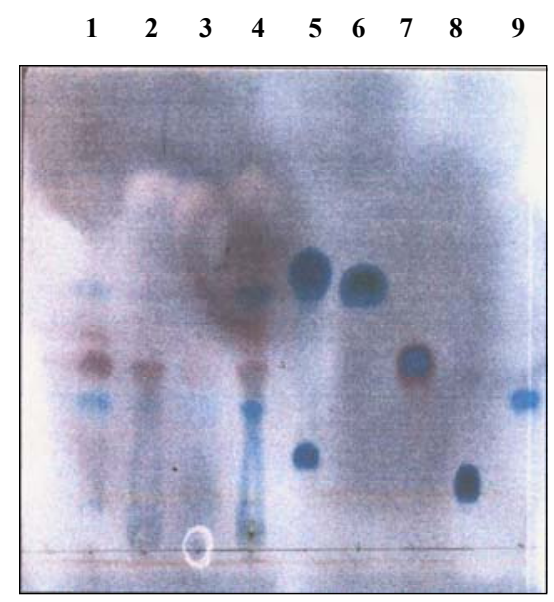

Lanes: 1 : Pectins (Celery-susceptible); 2 : Pectins (Celery-resistant); $3:$ Pectins (Tomatoresistant); 4 : Pectins (Tomato-susceptible); 5 : Mannuronic acid; $6:$ Rhamnose ; 7 : Arabinose; $8:$ Galacturonic acid ; 9 : Galactose. 


\subsubsection{Gas chromatography}

Pectins extracted from leaves of resistant and susceptible cultivars of tomato and celery plants were hydrolyzed using $4 \mathrm{M} \mathrm{TFA}$ at $121^{\circ} \mathrm{C}$ for $12 \mathrm{~h}$. Gas chromatographic analysis of the hydrolysate was carried out in a GC Shimnadz 14A/FID supelco column, (injector temp. $280^{\circ} \mathrm{C}$ ) in order to quantify the sugars that are most commonly found in pectins.

Fig. 4.4.4.1. GC analysis of pectins from susceptible and resistant cultivars of tomato and celery plants

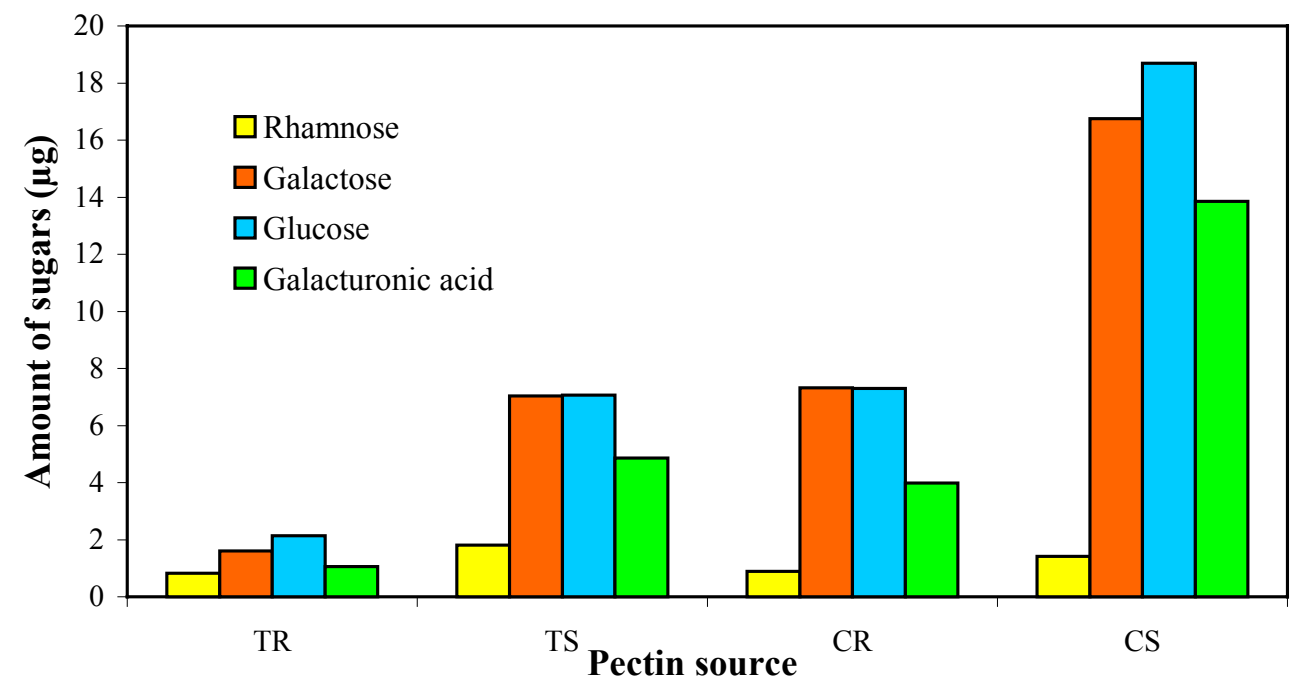

The different standard sugars used were glucose, galactose, rhamnose, arabinose ribose, mannose, xylose and galacturonic acid. Myo-inositol was used as the internal standard for calibration. The sugars detected are summarized in table 4.4.2.1. Rhamnose, galactose, glucose and galacturonic acid were detected in all the pectin samples. The amounts of each of the sugars are given in table 4.4.2.1. Among the sugars, glucose and galactose were abundant, followed by galacturonic acid and a low content of rhamnose.

Quantitative differences were observed in the sugar composition of resistant and susceptible cultivars of the same plant species. The galacturonic acid content was at least three fold higher in the resistant cultivars as compared to their susceptible 
counterparts. The rhamnose content in the susceptible celery cultivar was drastically higher than in the other three samples. The galactose and glucose contents were also the highest in the pectins from susceptible celery cultivars. The galactose to glucose ratio in all the pectin samples was nearly 1:1. 
Table 4.4.2.1. Characterization of pectic polysaccharides from tomato and celery cultivars resistant or susceptible to Pseudomonas

\begin{tabular}{|c|c|c|c|c|c|c|c|c|c|c|c|c|c|c|c|c|}
\hline \multirow[t]{2}{*}{$\begin{array}{c}\text { Sampl } \\
\text { eNo. }\end{array}$} & \multirow[t]{2}{*}{ Cultivar } & \multirow[t]{2}{*}{ Plant } & \multirow[t]{2}{*}{ Pathogen } & \multirow{2}{*}{$\begin{array}{l}\text { Reac } \\
\text { tion } \\
\text { to } \\
\text { path } \\
\text { ogen }\end{array}$} & \multirow{2}{*}{$\begin{array}{c}\text { Co } \\
\text { lou } \\
\mathbf{r}\end{array}$} & \multicolumn{4}{|c|}{$\begin{array}{c}\text { Thin Layer } \\
\text { Chromatography }\end{array}$} & \multicolumn{3}{|c|}{$\begin{array}{c}\text { Volumetric } \\
\text { analysis }\end{array}$} & \multicolumn{4}{|c|}{ Gas chromatography } \\
\hline & & & & & & $\begin{array}{l}A \\
r a\end{array}$ & & & Gal A & $\begin{array}{c}\mathrm{MeO} \\
(\%)\end{array}$ & Eq.wt & $\begin{array}{l}\text { D.E } \\
\text { (\%) }\end{array}$ & $\begin{array}{c}\text { Gal } \\
\left(\text { g.geq }^{-1}\right)\end{array}$ & $\underset{\left(\mathrm{g} . \mathrm{geq}^{-1}\right)}{\text { Rha }}$ & $\underset{\left(\text { g.geq }^{-1}\right)}{\text { GalA }}$ & $\begin{array}{c}\text { Glu } \\
\left(\text { g.geq }^{-1}\right)\end{array}$ \\
\hline 1 & $\begin{array}{l}\text { Ontario } \\
7710\end{array}$ & Tomato & $\begin{array}{l}\text { P.s. pv. } \\
\text { tomato }\end{array}$ & $\mathrm{R}$ & $\begin{array}{c}\text { Lig } \\
\text { ht } \\
\text { bro } \\
\text { wn }\end{array}$ & + & + & - & +- & 1.9 & 1666 & 66 & 14.4 & 6.9 & 8.8 & 17.9 \\
\hline 2 & $\begin{array}{l}\text { Ontario } \\
\text { Selectant } \\
7710\end{array}$ & Tomato & $\begin{array}{l}\text { P.s. pv. } \\
\text { tomato }\end{array}$ & $\mathrm{S}$ & $\begin{array}{c}\text { Pal } \\
\text { e } \\
\text { yell } \\
\text { ow }\end{array}$ & + & + & + & +- & 3.1 & 1100 & 33 & 38.7 & 10.8 & 26.8 & 38.8 \\
\hline 3 & Monarch & Celery & P.s. pv. apii & $\mathrm{R}$ & $\begin{array}{l}\text { Bro } \\
\text { wn }\end{array}$ & + & + & - & +- & 2.4 & 1250 & 77 & 45.8 & 5.6 & 24.9 & 45.6 \\
\hline 4 & Claret & Celery & P.s. pv. apii & $\mathrm{S}$ & $\begin{array}{l}\text { Bro } \\
\text { wn }\end{array}$ & + & + & + & + & 2.7 & 1111 & 40 & 93.1 & 78.3 & 76.9 & 103.9 \\
\hline
\end{tabular}

$\mathrm{R}$ : Resistant, S : Susceptible

+ : Present, - : Absent, +- : trace Ara : Arabinose, Gal : Galactose, Rha : Rhamnose, GalA : Galacturonic acid, Glu : Glucose $M e O$ : Methoxyl content, Eq.wt. : Equivalent weight, D.E. : Degree of Esterification 


\subsubsection{Enzymatic Digestion of Pectins by Pectate lyase and Polygalacturonic acid}

The pectins extracted from leaves of susceptible and resistant cultivars of tomato and celery plants were digested with two enzymes pectate lyase (PL) and polygalacturonase. The elution profiles were compared between the susceptible and resistant cultivars of celery and was used to infer possible differences in the composition of pectins in resistant and susceptible cultivars. The relative amount of galacturonic acid released upon hydrolysis was also determined in a time course experiment.

The elution profile of the charged oligomers differed between the two forms of pectins after digestion with pectate lyase. Only two charged oligomers were generated from pectins of the resistant cultivar. The retention time of these oligomers was 15 and 17 min respectively. In the susceptible cultivar on the other hand, a larger number of oligomers were detected in addition to the two predominant ones that were also detected in the resistant cultivar. Further, the enzyme pectate lyase generated more galacturonic acid with pectins from the resistant celery cultivar than with that from the susceptible cultivar. In the susceptible cultivar the amount of galacturonic acid was about 5 a.u. in comparison with the resistant cultivars in which the amount of galA generated was 10 a.u. The differences were evident in the 24 and $36 \mathrm{~h}$ digests although no significant differences were apparent in the amounts of galacturonic acid released at the two time intervals.

The elution profiles of pectins digested with polygalactruronase did not show any significant differences between the resistant and susceptible pectins during any of the different time intervals tested. 
Fig. 4.4.5.1. Analysis of standard sugars by HPLC

A- Galacturonic acid

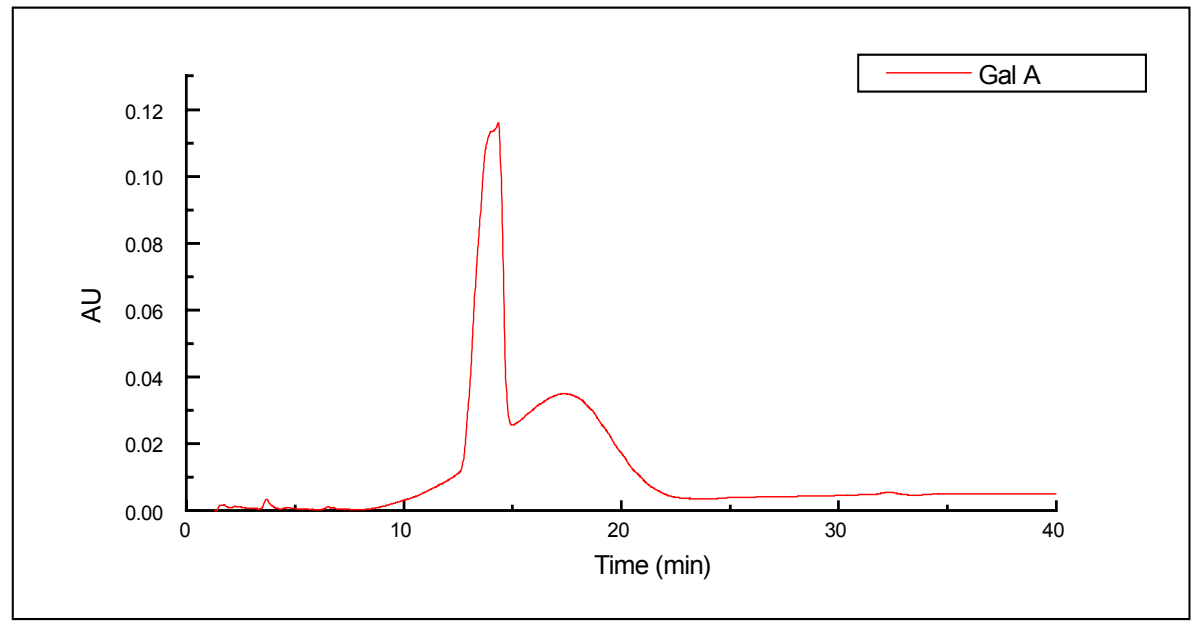

B- Polygalacturonic acid

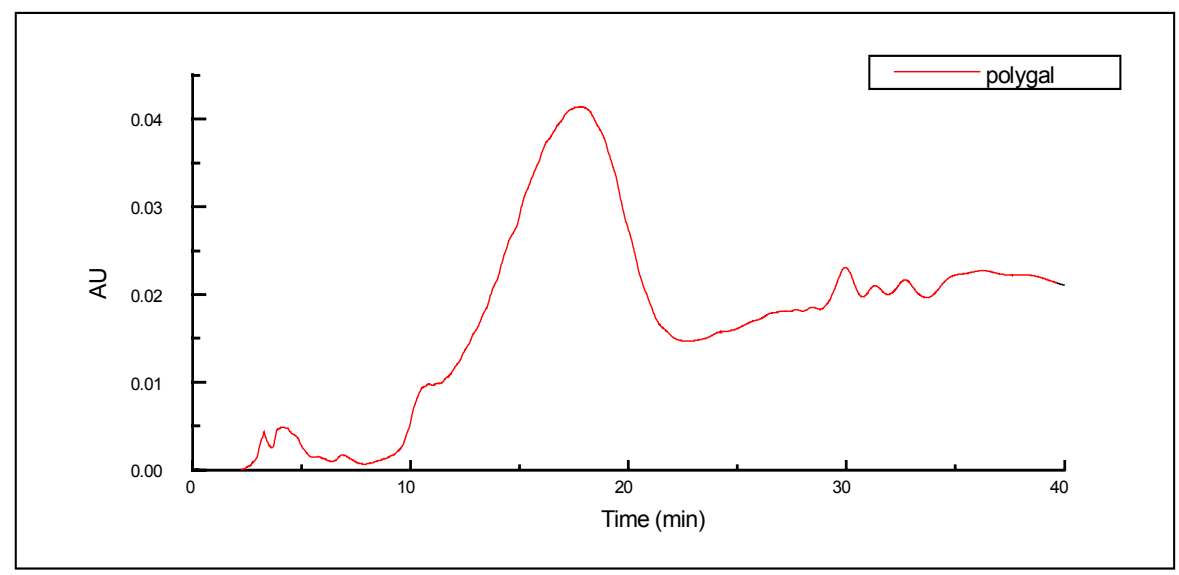

Chromatograms of standard sugars obtained after analysis on a HPLC glycopack column, (Waters Inc., The Netherlands). The retention time is $16.12 \mathrm{~min}$ for galacturonic acid and $17.15 \mathrm{~min}$ for polygalacturonic acid. 
Fig. 4.4.5.2. Chromatograms of pectins extracted from susceptible and resistant cultivars of celery plants, digested with pectate lyase for $24 \mathrm{~h}$.

A-Pectate lyase digests of pectins from the susceptible celery cv. Claret

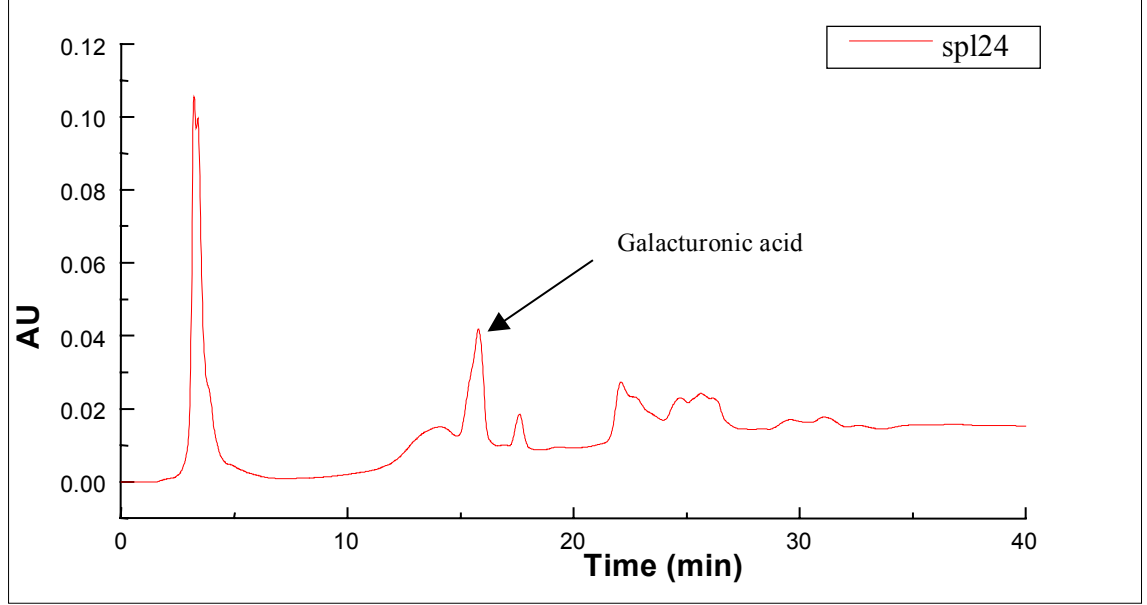

B-Pectate lyase digests of pectins from the resistant celery cv. Monarch

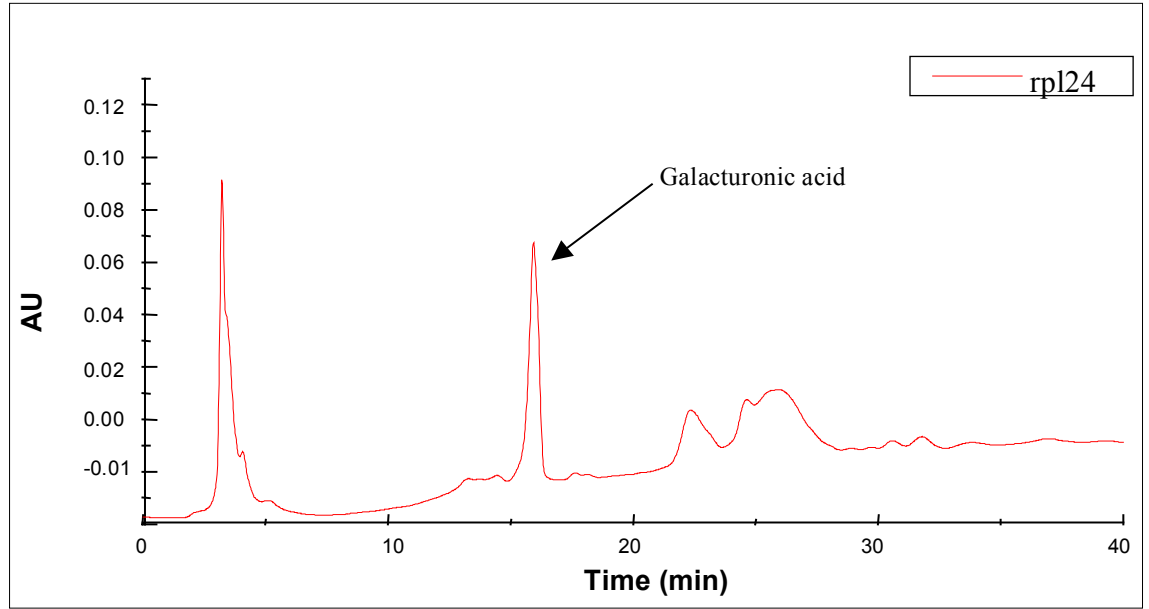

Pectins were extracted from resistant and susceptible cultivars of celery plants and digested with pectate lyase. The reaction was arrested at $24 \mathrm{~h}$ and the samples were analyzed by HPLC. The amount of galacturonic acid was slightly higher in the resistant cultivar. 
Fig. 4.4.5.4. Chromatograms of pectins extracted from susceptible and resistant cultivars of celery plants, digested with polygalacturonase for $\mathbf{2 4} \mathbf{h}$.

A- Polygalacturonase digests of pectins from the susceptible celery cv. Claret

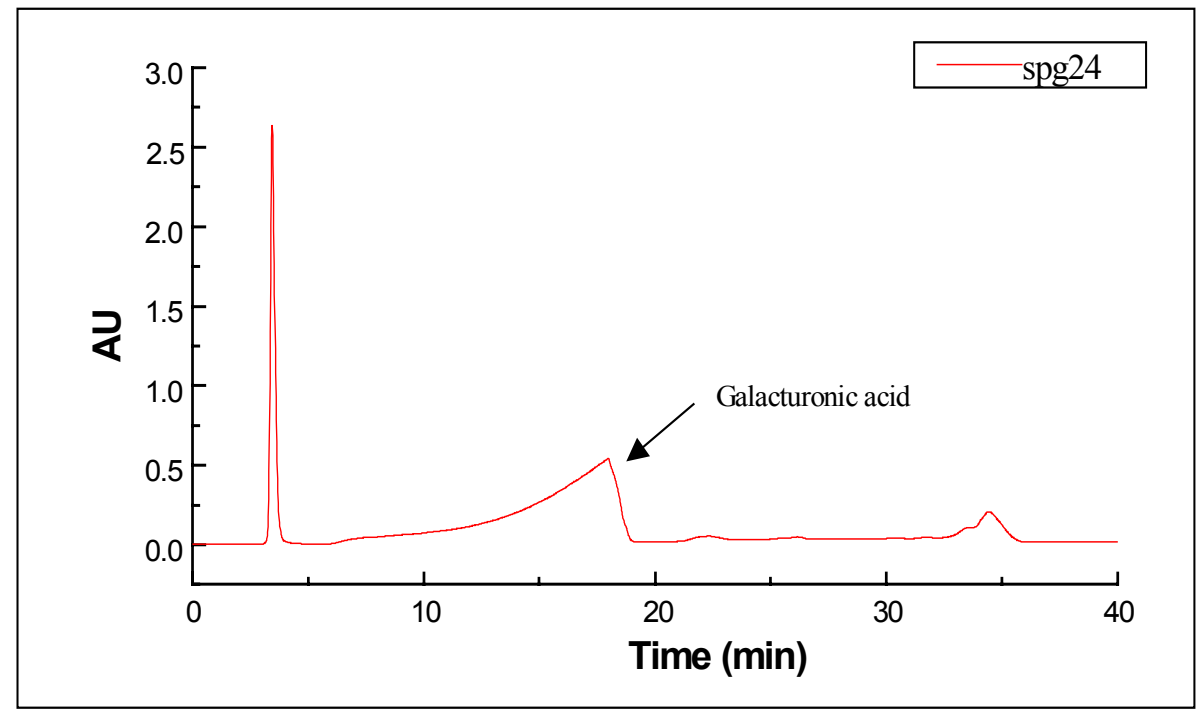

B- Polygalacturonase digests of pectins from the resistant celery cv. Monarch

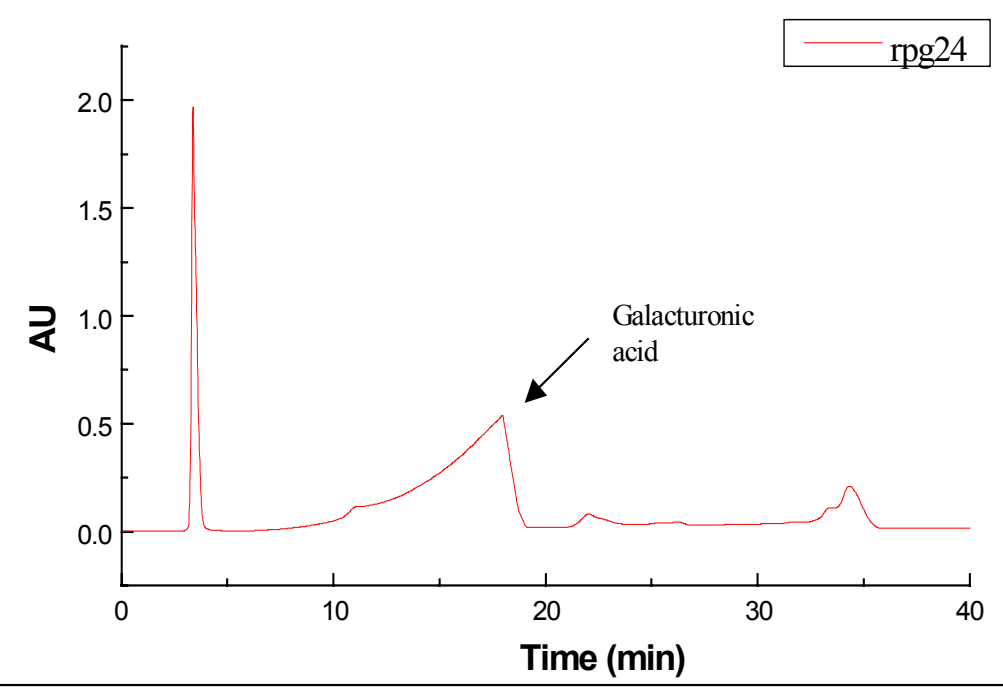

Pectins were extracted from resistant and susceptible cultivars of celery plants and digested with polygalacturonase. The reaction was arrested at $24 \mathrm{~h}$ and the samples were analyzed by HPLC. No significant differences were observed in the amount of galacturonic acid residues released. 
Fig. 4.4.5.4. Chromatograms of pectins extracted from susceptible and resistant cultivars of celery plants, digested with polygalacturonase for $24 \mathrm{~h}$.

A- Polygalacturonase digests of pectins from the susceptible celery cv. Claret

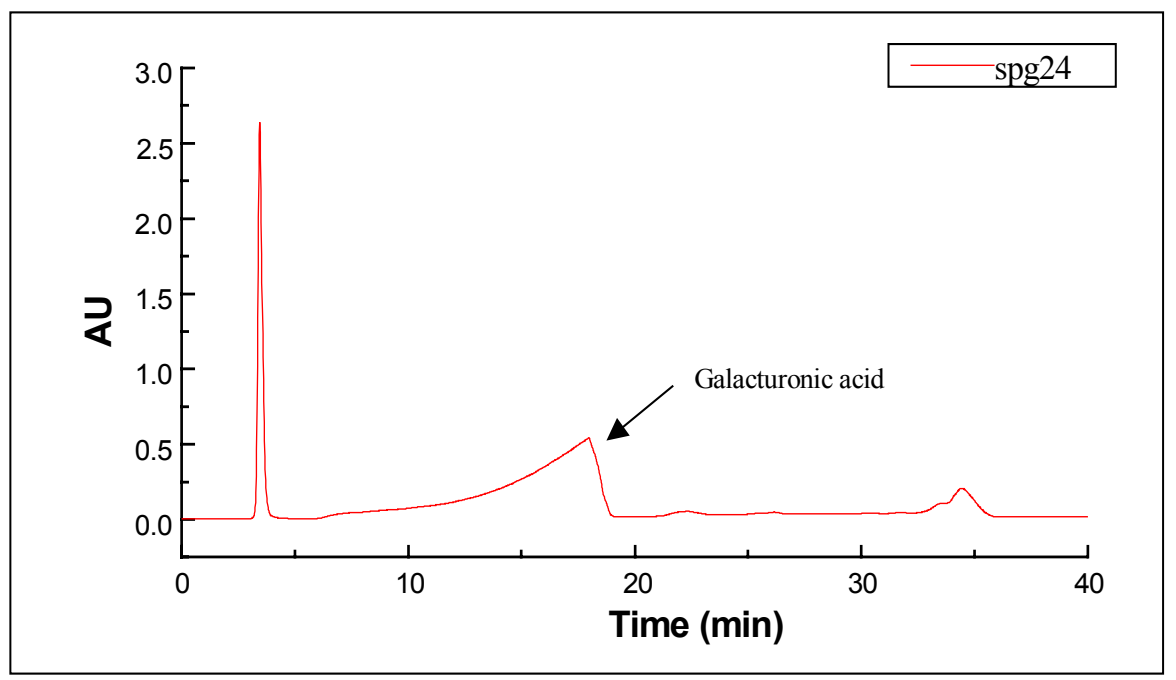

B- Polygalacturonase digests of pectins from the resistant celery cv. Monarch

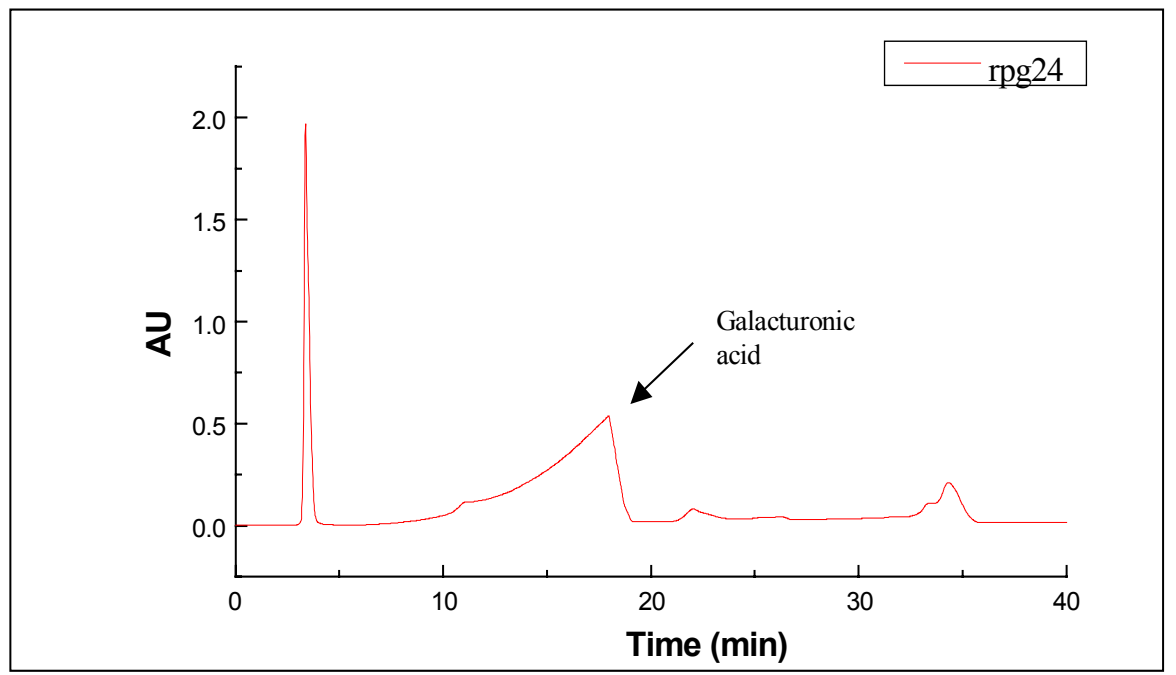

Pectins were extracted from resistant and susceptible cultivars of celery plants and digested with polygalacturonase. The reaction was arrested at $24 \mathrm{~h}$ and the samples were analyzed by HPLC. No significant differences were observed in the amount of galacturonic acid residues released. 
Fig. 4.4.5.4. Chromatograms of pectins extracted from susceptible and resistant cultivars of celery plants, digested with polygalacturonase for $24 \mathrm{~h}$.

A- Polygalacturonase digests of pectins from the susceptible celery cv. Claret

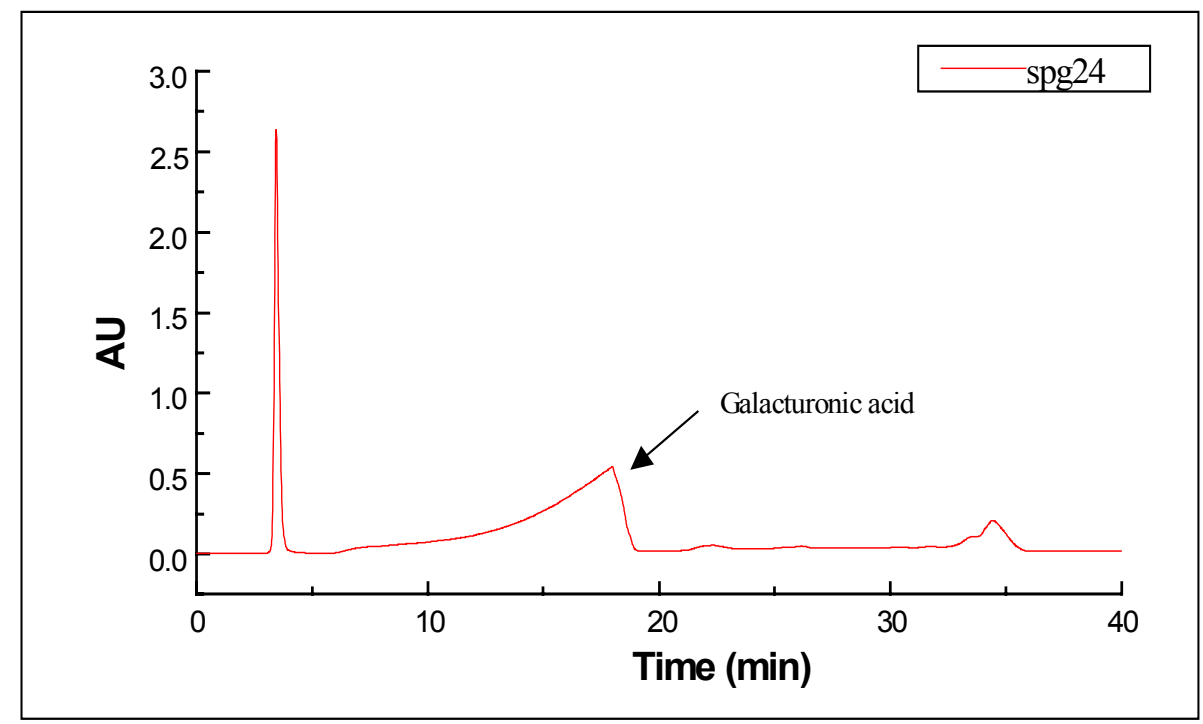

B- Polygalacturonase digests of pectins from the resistant celery $\mathrm{cv}$. Monarch

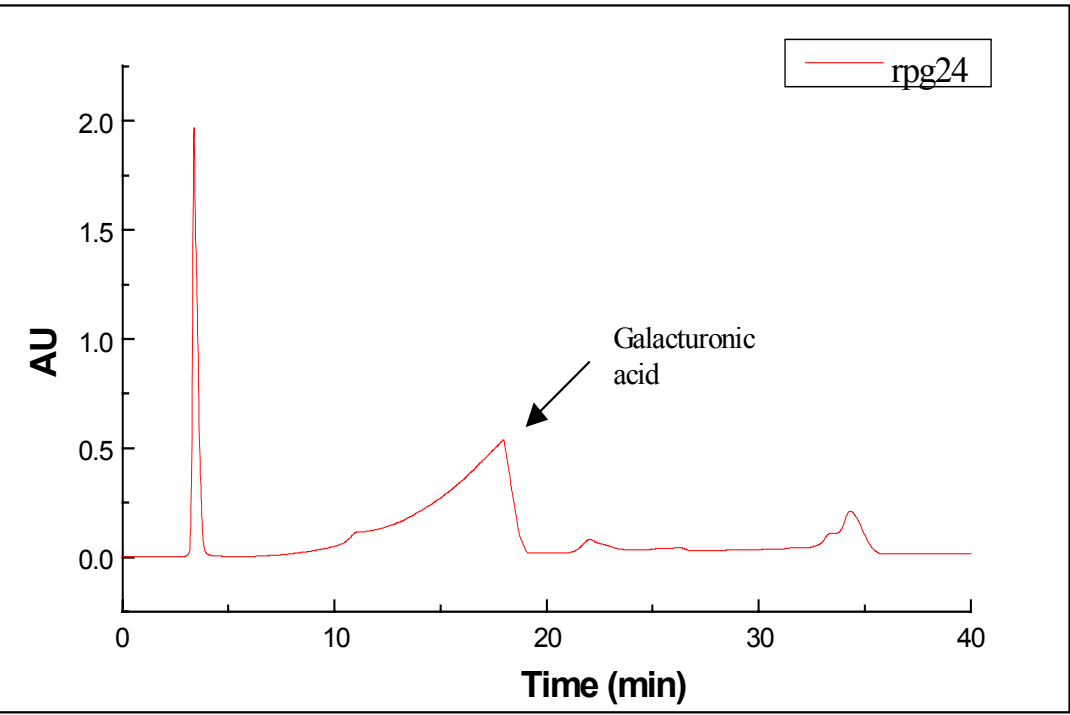

Pectins were extracted from resistant and susceptible cultivars of celery plants and digested with polygalacturonase. The reaction was arrested at $24 \mathrm{~h}$ and the samples were analyzed by HPLC. No significant differences were observed in the amount of galacturonic acid residues released. 


\subsubsection{Carbohydrate binding proteins from two Pseudomonas syringae pathovars}

4.4.6.1 Isolation of a carbohydrate binding protein from $P$. s. pv. apii and $P$. s. pv. tomato

A carbohydrate binding protein was extracted from two pathovars of the phytopathogenic bacterium Pseudomonas syringae namely $P$. s. pv. tomato and $P$. s. pv. apii. Ion exchange and hydrophobic chromatographies were performed to purify the proteins. The procedures followed for purification of the protein are elaborated under methods in this chapter. The proteins were quantified according to the method of Lowry et al. (1951) and used for analyses.

\subsubsection{Characterization of the carbohydrate binding protein by native polyacrylamide gel electrophoresis}

The partially purified proteins from the two pathovars of $P$. syringae were characterized by native polyacrylamide gel electrophoresis. The apparent molecular weight of the protein was between 90 and $70 \mathrm{kDa}$ in both the bacteria. (fig. 4.4.6.2)

\subsubsection{Characterization of the carbohydrate binding protein by sodium dodecyl} sulphate polyacrylamide gel electrophoresis

The partially purified proteins were characterized by sodium dodecyl sulphate polyacrylamide gel electrophoresis. Several fragments ranging in mol. wt. from 60 $\mathrm{kDa}-20 \mathrm{kDa}$ were detected by Coomassie as well as silver staining (refer figs. 4.4.6.3a and 4.4.6.3.6). 
Fig. 4.4.6.2. Characterization of a putative carbohydrate binding protein from the phytopathogenic bacteria $P$. s. pv. tomato and $P$. s. pv. apii by native PAGE

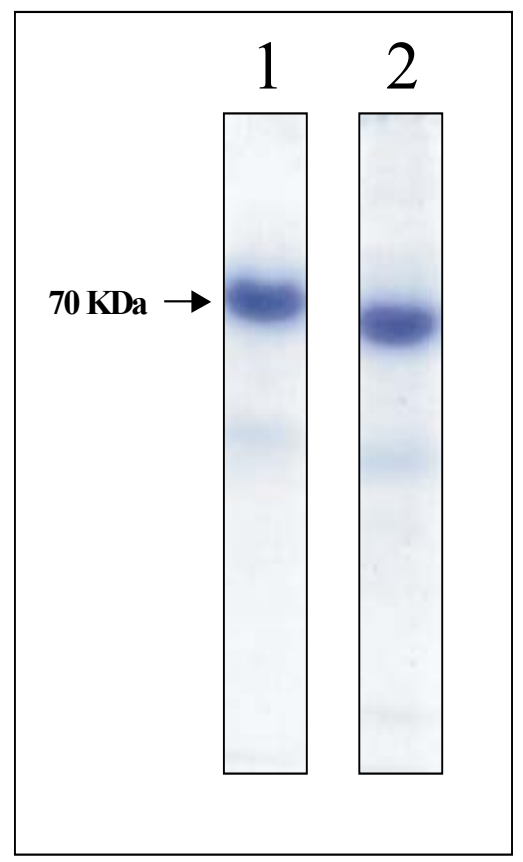

Carbohydrate binding proteins were extracted from $P$. s. pv. tomato and $P$. s. pv. apii and purified by ammonium sulphate precipitation. The proteins were partially purified on a DEAE cellulose column and further on a phenyl Sepharose column. Twelve $\mu$ g protein each were loaded per lane (lane 1: $\boldsymbol{P}$. s. pv. tomato, lane 2: $\boldsymbol{P} . \boldsymbol{s} . \mathbf{p v}$. apii) and the proteins were characterized by native PAGE. 
Fig. 4.4.6.3a. Characterization of a putative carbohydrate binding protein from the phytopathogenic bacteria $P$. s. pv. tomato and $P$. $s$. pv. apii by SDS-PAGE

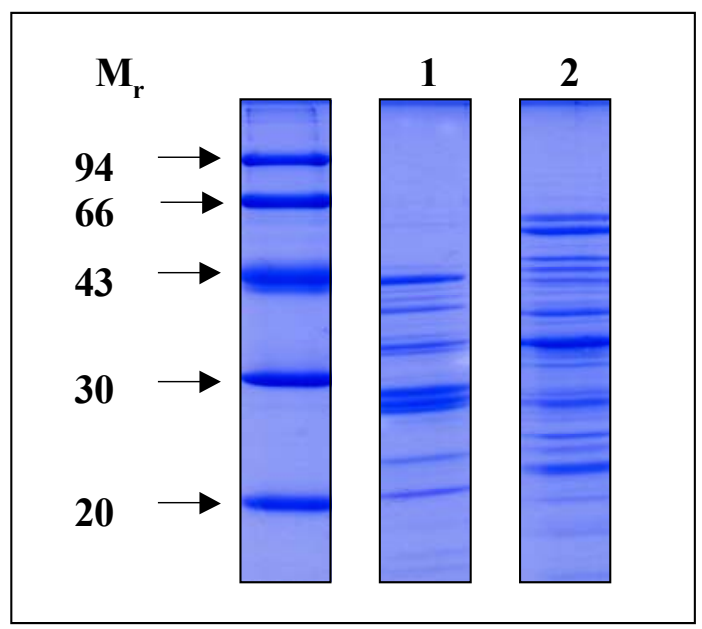

Carbohydrate binding proteins were extracted from $P$. s. pv. tomato and $P$. s. pv. apii and purified by ammonium sulphate precipitation. The proteins were partially purified on a DEAE cellulose column and further on a phenyl Sepharose column. Sixteen $\mu \mathrm{g}$ protein were loaded per lane (lane 1: $\boldsymbol{P}$. $\boldsymbol{s}$. pv. tomato, lane 2: $\boldsymbol{P}$. $\boldsymbol{s}$. pv. apii) and the proteins were characterized by SDS-PAGE and visualized by Coomassie staining.

Fig. 4.4.6.3b. Characterization of a putative carbohydrate binding protein from the phytopathogenic bacteria $P$. s. pv. tomato and $P$. s. pv. apii by SDS-PAGE

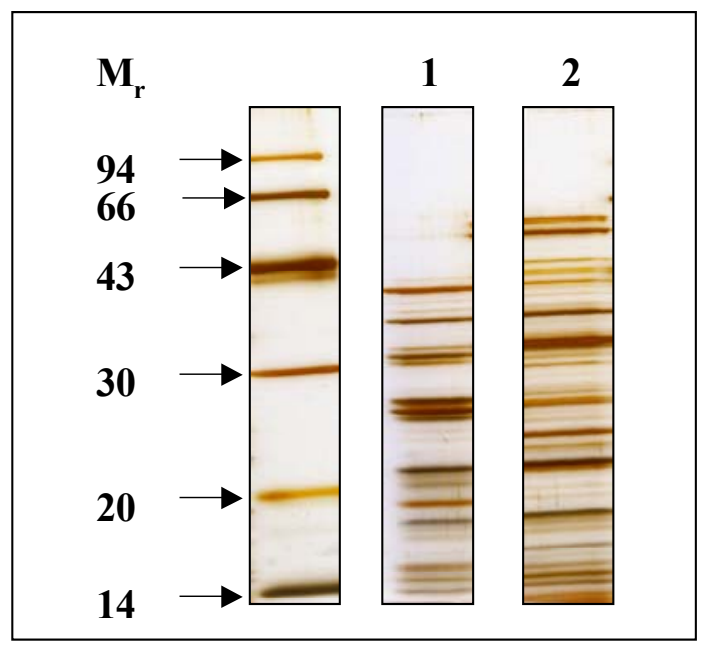

Carbohydrate binding proteins were extracted from P. s. pv. tomato and P. s. pv. apii and purified by ammonium sulphate precipitation. The proteins were partially purified on a DEAE cellulose column and further on a phenyl Sepharose column. Eight $\mu \mathrm{g}$ protein each were loaded per lane (lane 1: $\boldsymbol{P}$. s. pv. tomato, lane 2: $\boldsymbol{P}$. $\boldsymbol{s}$. pv. apii) and the proteins were characterized by SDS-PAGE and visualized by silver staining. 


\subsubsection{Haemagglutination Inhibition Studies}

A cell surface protein was isolated from two pathovars of the phytopathogenic bacterium Pseudomonas syringae namely P. s. pv. tomato and P. s. pv. apii. The proteins were partially purified. The sugar specificities of the proteins from the two bacteria were determined by haemagglutination inhibition assays. The specifities of the protein for the pectins extracted from tomato and celery plant that were either resistant or susceptible to the pathogens were also tested.

The haemagglutination activity of the protein from $P$. s. pv. apii was inhibited by three of the 14 sugar and sugar derivatives tested. Rhamnose and the gluconic acid (the acid derivative of glucose) were equally effective in inhibition of haemagglutination, the minimum inhibitory concentration for each of the two sugars was $62.5 \mathrm{mM}$. Another inhibitory compound was D- galacturonic acid which inhibited the haemagglutination at a concentration of $125 \mathrm{mM}$. Sugars such as D-mannose, Dxylose N-acetyl D-glucosamine, D-lyxose, L-arabinose, D-arabinose, D-fucose were non-inhibitory to the haemagglutination activity at the highest concentration tested.

The haemagglutination activity of the protein from P. s. pv. tomato was also inhibited by D-gluconic acid and D-galacturonic acid. The former was effective at as low a concentration as $8 \mathrm{mM}$ while the latter was effective at a concentration of 62.5 $\mathrm{mM}$. The amino derivative of glucose, namely D-glucosamine was inhibitory to the haemagglutinating activity of the protein from $P$. s. pv. tomato but not from $P$. s. pv. apii. All the other compounds used in the assay were non inhibitory to the haemagglutinating activity even at the highest concentration tested (Table 4.2.2.2). 
Results

Fig. 4.4.6.4a. Haemagglutination assay for carbohydrate binding proteins from Pseudomonas syringae pv. tomato and $P$. s. pv. apii

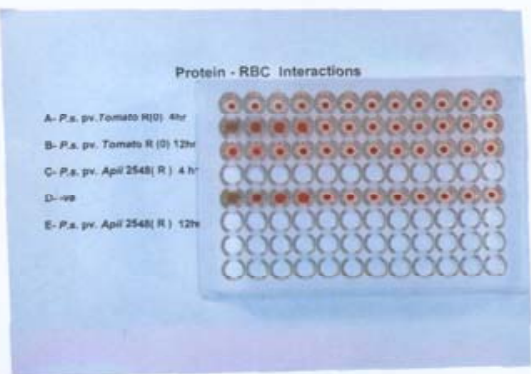




\section{Results}

Fig. 4.4.6.4b. Haemagglutination inhibition assay of a carbohydrate binding protein from P. s. pv. tomato

Plate I

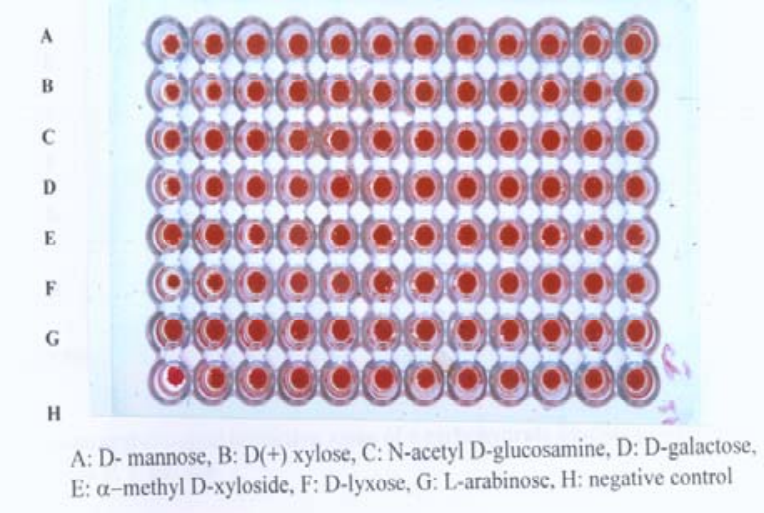

Plate II

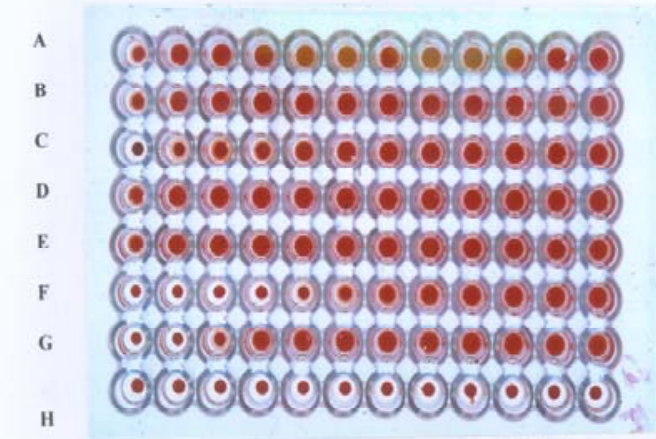

A: D-arabinose, B: D-fucose, C: D-glucosamine, D: D-ribose,

E: D-rhamnose, F: gluconic acid, G: D-galacturonic acid 
Results

Plate III

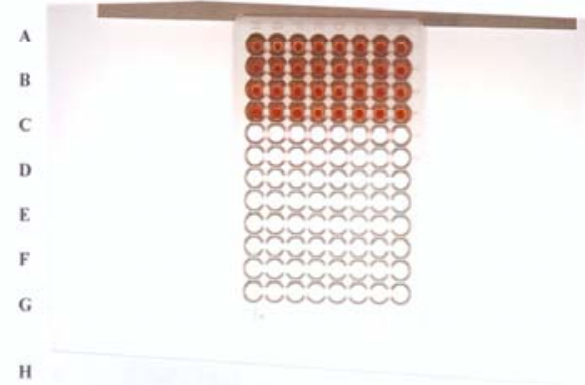

A: Tomato susceptible, B: Tomato resistant,C: Celery susceptible, D: Celery resistant

Fig, 4.4.6.4c. Haemagglutination inhibition assay of a carbohydrate binding protein from P. s. pv. apii

Plate I

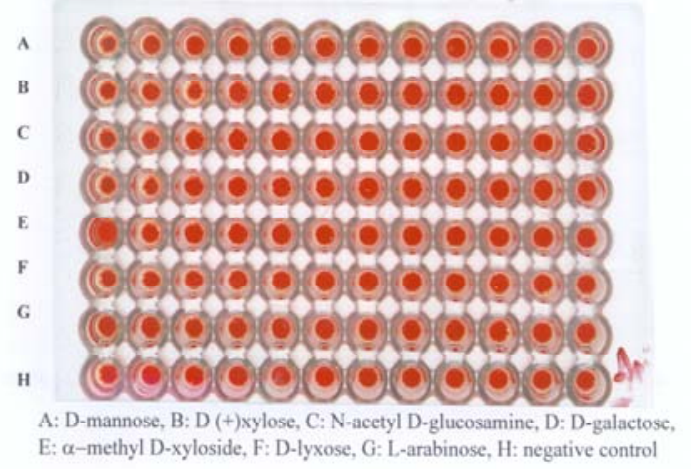


Plate II

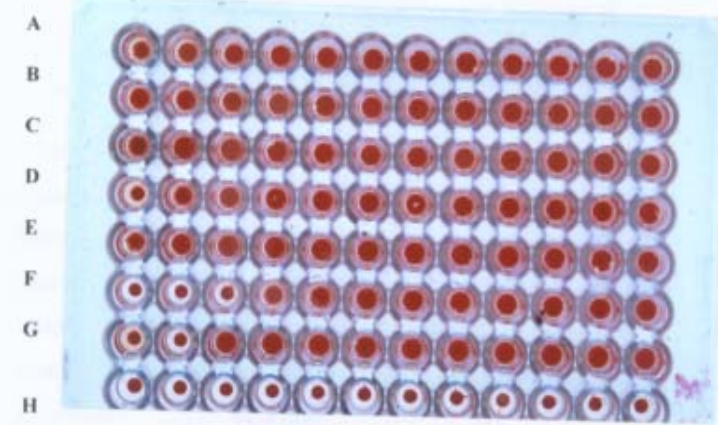

A: D-arabinose, B: D-fucose, C: D-glucosamine, D: D-ribose,

E: D-rhamnose, F: gluconic acid, G: D-galacturonic acid

Plate III

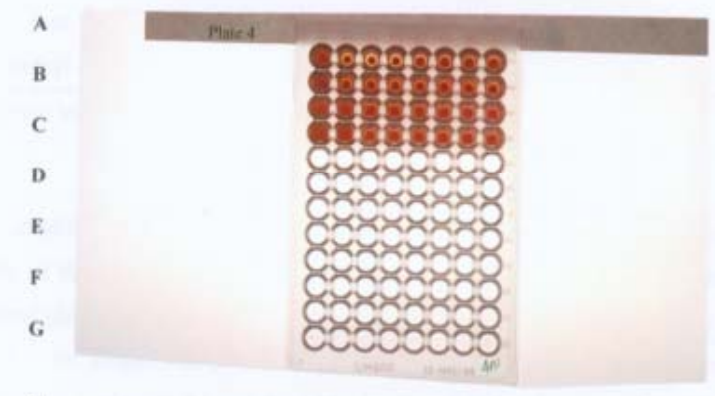

H

A: Tomato susceptible, B: Tomato resistant, C: Celery susceptible, D: Celery resistant 
Table 4.4.2.2. Haemagglutination inhibition of the haemagglutinins from Pseudomonas syringae pv. tomato and $P$. s. pv. apii by some sugars

\begin{tabular}{|c|c|c|}
\hline \multirow[t]{2}{*}{ Sugars } & \multicolumn{2}{|c|}{$\begin{array}{l}\text { Iinimum inhibitory concentration (MIC) required } \\
\text { to inhibit heamagglutinins of }\end{array}$} \\
\hline & P. s. pv. tomato race 0 & P. s. pv. apii \\
\hline D-Galacturonic acid & $62.5 \mathrm{mM}$ & $125 \mathrm{mM}$ \\
\hline D-Arabinose & NI & NI \\
\hline L-Arabinose & NI & NI \\
\hline $\begin{array}{l}\text { D-Fucose } \\
\text { D-Galactose }\end{array}$ & $\begin{array}{l}N I \\
\mathrm{NI}\end{array}$ & $\begin{array}{l}N I \\
\mathrm{NI}\end{array}$ \\
\hline D-Gluconic acid & $8 \mathrm{mM}$ & $62.5 \mathrm{mM}$ \\
\hline D-Glucosamine & $62.5 \mathrm{mM}$ & NI \\
\hline $\mathrm{N}$-acetyl D- glucosamine & NI & NI \\
\hline D-Lyxose & NI & NI \\
\hline D-Mannose & NI & NI \\
\hline D-Rhamnose & NI & $62.5 \mathrm{mM}$ \\
\hline D-Ribose & NI & NI \\
\hline D-Xylose & NI & NI \\
\hline$\alpha$-Methyl D-xyloside & NI & NI \\
\hline
\end{tabular}

NI- not inhibitory at highest concentration tested

Assays were performed in order to test if the haemagglutination activity of the cell surface proteins isolated from the bacteria was inhibited by pectins isolated from their host plants. The haemagglutinating activity of the proteins from P. s. pv. tomato was inhibited by pectins isolated from all the four cultivars (see table 4.4.2.3.). The activity of the haemagglutinins from $P$. s. pv. apii was however not inhibited by pectins from any of the cultivars even at the highest concentration tested. 
Table 4.4.2.3. Haemagglutination-Inhibition of the Haemagglutinins from Pseudomonas syringae pv. tomato and $P$. s. pv. apii by pectins

\begin{tabular}{|c|c|c|}
\hline \multirow[t]{2}{*}{ Pectins } & \multicolumn{2}{|c|}{$\begin{array}{c}\text { Minimum inhibitory concentration (MIC) required } \\
\text { to inhibit heamagglutinins of }\end{array}$} \\
\hline & P. s. pv. tomato race 0 & P.s.pv. apii \\
\hline Tomato (susceptible) & $62.5 \mu \mathrm{g}$ & NI \\
\hline Tomato (resistant) & $62.5 \mu \mathrm{g}$ & NI \\
\hline Celery (susceptible) & $62.5 \mu \mathrm{g}$ & NI \\
\hline Celery (resistant) & $62.5 \mu \mathrm{g}$ & NI \\
\hline
\end{tabular}

NI- not inhibitory at highest concentration tested 


\subsection{Discussion}

Plant cells have a rigid cell structure owing to the presence of a cell wall. Among various components of the cell wall are pectins found in the middle lamella of all higher plants. In a pectin molecule, neutral sugars are concentrated in blocks of highly substituted rhamnogalacturonans separated by regions containing Dgalacturonic acid residues. Recent technological advancements (Round et al., 2001; Daas et al., 1999) have shed considerable light on the structure and chemical composition of pectins and continue to further our understanding of the functional significance of the pectic polysaccharides.

The present study is an attempt to characterize the variations in the chemical and structural composition of pectins from resistant and susceptible cultivars of two plant species, namely tomato and celery, and to relate the differences to the nature of interaction to their pathogens, Pseudomonas syringae pv. tomato and Pseudomonas syringae pv. apii, respectively.

Pectins were extracted from the leaves of susceptible and resistant cultivars of tomato and celery plants following a slightly modified method of Sonnenberg (1994). The modification yielded a purer sample with significantly lower levels of protein contamination. The yield of pectins was ca. $1 \mathrm{~g}$ for every kilogram of fresh weight. Different methods have been adopted in the past for the extraction of pectins. The method used in the present study is relatively simple and cost effective. The colour of the pectins varied from pale yellow to brown, a less significant observation, indicative more of the different plant sources than the purity of the preparation.

The equivalent weight of the pectins was determined by volumetric analysis from which the degree of esterification (DE) was calculated using standard mathematical formulae. An interesting correlation was observed between the degree of esterification and the nature of the host response against pathogen attack. The degree of esterification was at least two fold higher in the resistant cultivars (tomato and celery) than in the susceptible cultivars. The DE of pectins is inversely related to the rapidity of gel formation, those below $50 \%$ formed gels more rapidly than those with a 
DE between 50 and 70\% (Owens, 1952). In the light of the hypothesis that the formation of a gel aids in the survival and multiplication of bacterial cells within the intercellular leaf spaces (Laux, 1998), the ease with which the gel can be formed in the microcosm constituting a plant and its potential pathogen assumes special significance. It is worth pointing out here that in the rheological investigations an increase in viscosity and yield stress that accompanies the formation of a gel was demonstrated in interactions of pectins from susceptible cultivars and bacterial LPS and not in the interactions of pectins with resistant cultivars (Laux, 1998; Grolms 1996; Venkatesh and Rudolph, 2001a).

The methoxyl content was estimated for pectins from the susceptible and resistant cultivars of tomato and celery plants. The methoxyl content of pectins in the resistant cultivars and in the susceptible cultivars were almost similar within each of the plant species and varied marginally between the different plants. It is inferred that direct estimation of methyl content as was carried out in the present study cannot detect within-cultivar variations in the degree of methylation of their cell wall pectins. More sensitive analyses such as HPLC can perhaps better resolve such subtle differences. Consistent with the postulate of Yabusaki et al. (1979) that the role of methylation is to stabilize the conformation of the polymethyl polysaccharides, a higher degree of methylation, could, well serve to impart a stable conformation to the pectic components as well.

Preliminary characterization of pectins was carried out by TLC analysis and the sugars rhamnose, arabinose and galactose were detected. Surprisingly, galacturonic acid was barely detectable in the samples as was also the case in an earlier study (Grolms, 1996). This might be due to incomplete hydrolysis of pectins with trifluoroacetic acid (TFA).

The pectic sugars were further analyzed by gas chromatography. The content of sugars was two fold higher in pectins obtained from susceptible cultivars than in pectins from resistant cultivars. The results suggest that the pectins of susceptible cultivars contain a larger number of branched side-chains as compared to their resistant counterparts. The presence of branched side chains may be significant for the 
interactions with other macromolecules (for instance, bacterial LPS). This view, however, needs to be substantiated with adequate experimental evidence at the molecular and structural levels.

Two enzymes, namely pectate lyase (PL) and polygalacturonase (PG), in combination with chromatographic techniques (HPLC) were used as analytical tools for the analysis of structural and/or compositional variations between pectins extracted from leaves of susceptible and resistant cultivars of tomato and celery plants. The pectins were extensively digested with the afore mentioned enzymes and the time dependent hydrolysis was analyzed by HPLC (glycopack coloumn, WATERS. Inc., The Netherlands). The elution profiles of the products during the early, intermediate and late stages of the enzymatic reaction were compared. The results indicated that differences were indeed evident between the pectins extracted from resistant and suseptible cultivars (refer figs. 4.4.5.2., 4.4.5.3.).

It is widely known that the enzyme pectate lyase has the highest specificity for highly methyl esterified homogalacturonan and that the cleavage process results in the release of unsaturated oligomers carrying double bonds at the non-reducing end. Recently, it was shown (Daas et al., 1999) that pectate lyase can cleave not only between two methyl esterified residues but also between an esterified and a nonesterified galacturonic acid and thus exhibits a lower specificity in the substrate binding site. Prolonged hydrolysis of the pectin as well as the initial product of hydrolysis by pectate lyase show the predominant formation of two types of oligosaccharides for resistant pectins whereas variable size oligomers are formed with susceptible pectins. The generation of only two oligomers (retention time 15 and 17 min) indicates that the pectins are evenly methyl esterified. The pectins of the susceptible cultivars are more heterogeneous in charged residue distribution along the polygalacturonic acid backbone.

When endo polygalacturonase digests of the pectins were analysed by HPLC, no significant differences were observed between the resistant and susceptible cultivars. The enzyme polygalacturonase has a more restricted substrate specificity than pectate lyase and can differentiate pectins with similar degree of methylation but 
a distinct methyl ester distribution pattern. The lack of differentiation by PG suggests that the distribution of methylated groups does not vary considerably between the two forms of pectins. However, in the light of the differences in elution pattern obtained with pectate lyase digests it is inferred that although the pectins of resistant and susceptible cultivars are homogenously esterified, yet differences exist between them which may be characterized by more specific methods.

However, the investigations reported here on the chemical composition and structure of plant pectins do not allow any insights into the mechanism of specific interactions between bacterial LPS and plant pectins. We only know of specific structure of the bacterial LPS, residing in their O-chain. The nature of specific pectin structures can only be speculated upon. Therefore, although differences were evident in the composition of pectins from susceptible and resistant cultivars, elucidation of the exact mechanism of their interactions with macromolecules of pathogens still remain unclear. The nature of pectic polysaccharides in higher plants is sufficiently diverse; the differences exist to a major extent, in their neutral sugar content. There have been reports to suggest that pectic components of plant cell walls, particularly, the neutral sugars can interact with several other carbohydrates which result in the formation of cell clusters (Kikuchi et al., 1996). In the present study, sufficient differences were found in the composition of sugars between the susceptible and resistant cultivars of tomato and celery plants (results of GC analyses, table 4.4.2.1.). Further, haemagglutination inhibition studies strongly indicated that the presence of certain sugars is obligatory for the interactions of pectins with other macromolecules. Based on these observations it can be hypothesized that the differences in composition of neutral sugars may play a more direct role in host-pathogen interactions. However, more direct evidence would be necessary to conclusively ascertain the involvement of specific components of pectins in interactions with bacterial LPS.

The finding that leaf pectins of plants reacting susceptible to bacteria causing leaf spots were less esterified appears very interesting. This aspect should be analyzed in several other plant/bacteria-interactions to find out whether it is a generally occurring difference between pectins from susceptible and resistant plants. This would further consolidate the hypothesis that the structure of pectins has a functional significance in host-pathogen interactions. 
The cell surface proteins extracted from $P$. s. pv. tomato and $P$. s. pv. apii were characterized by native PAGE. The native molecular mass of the protein from both the bacteria was around 70 . When the proteins were characterized on a denaturing SDS polyacrylamide gel, several fragments were detected. The relative molecular masses of the fragments ranged from about 65 to less than 20. The detection of low molecular mass bands $\left(M_{r}<14\right)$ on the SDS polyacrylamide gels suggests a certain level of proteolytic activity. The occurrence of multiple bands might indicate that the protein is multimeric or that it is part of a protein complex. It must also be added that the protein was only partially purified and some of the fragments on the SDS PAGE may belong to proteins other than the one with the haemagglutinating activity. On the other hand, the detection of a single band on a native gel suggests that the proteins have, indeed, been sufficiently purified. Additional experiments are therefore necessary to resolve the exact nature of the protein.

The resolution of the proteins on the denaturing gels revealed sufficient differences between the haemagglutinins of the two bacteria. The protein from $P$. $s$. pv. tomato had 3 prominent bands one of mol. wt. ca. $43 \mathrm{kDa}$ and the other two of less than $30 \mathrm{kDa}$. The protein from P. s. pv. apii has atleast two prominent bands of mol. wt. ca. $35 \mathrm{kDa}$ and ca. $50 \mathrm{kDa}$. It can be inferred that although the haemagglutinins from $P$. s. pv. tomato and $P$. s. pv. apii appear to have a similar native molecular weight, yet, their compositions are different. These differences could be important determinants of the nature of interactions that a pathogen develops with its hosts.

The haemagglutination of rabbit erythrocytes by proteins from $P$. s. pv. apii and P. s. pv. tomato was inhibited by certain sugars and pectins (Tables 4.4.2.2. and 4.4.2.3.). This is positive evidence for the interaction of a bacterial component with plant pectins. The fact that both proteins were inhibited by D-gluconic acid and Dgalacturonic acid, albeit at different concentrations, further supports this since the latter forms the major component of plant pectins. Some sugars, for instance, Dmannose, D-xylose, N-acetyl D-glucosamine, D-lyxose, L-arabinose, D-arabinose and D-fucose did not inhibit haemagglutination suggesting that the presence of the interaction is specific in nature. On the other hand, the presence of some of these 
sugars in plant pectins may provide the necessary secondary structure for the interactions.

The differences in the inhibition observed in the sugars isolated from the host indicates that the haemaglutinin from $P$. s. pv. apii and $P$. s. pv. tomato recognize different epitopes of the same polysaccharide (pectin) receptor of the host plants. The pectin from celery probably does not have the epitope that is recognized by the haemagglutinin from $P . s$. pv. apii and $P . s$. pv. tomato. It is speculated that preliminary binding of the bacterial cells to plant cell walls is initiated by the pectin component and subsequent secondary events determine whether or not the bacterial cells remain attached to the cell surface of the host and thereby further the infection process. This explains the similar inhibition pattern of the haemagglutinating activity of proteins from $P$. s. pv. tomato by tomato and celery cultivars irrespective of whether they are resistant or susceptible in nature.

The finding that the pectins from celery did not interact with the isolated haemagglutinins from $P$. s. pvs. tomato or apii may also explain why it was rather difficult to induce typical disease symptoms with both bacterial pathogens on celery (see chapter 1). Thus, the interactions between the bacterial carbohydrate binding proteins and plant pectins will provide new insights towards host-pathogen interactions. 


\subsection{Summary}

- Pectins were extracted from juvenile leaves of 8-week-old plants of susceptible and resistant cultivars of tomato and celery plants. Pectins were extracted according to the method described by Sonnenberg (1994).

- The pectins were partially characterised by volumetric analysis for the determination of equivalent weight, methoxyl content and the degree of esterification.

- The equivalent weight of pectins extracted from susceptible and resistant cultivars of tomato plants was 1100 and 1666 respectively and 1111 and 1250 respectively, for the pectins from susceptible and resistant celery plants.

- The methoxyl content of the pectins from susceptible cultivars of tomato and celery plants was $3.1 \%$ and $2.7 \%$ and only $1.9 \%$ and $2.4 \%$ from the resistant cultivars.

- A comparison of the degree of pectin esterification between the susceptible and resistant cultivars revealed significant differences. The pectins from the resistant cultivars were always two fold more esterified than those from the susceptible cultivars.

- The colour of the pectins varied from light brown to pale yellow.

- The pectins were hydrolysed with TFA and initially analysed by thin layer chromatography which showed the presence of sugars, such as rhamnose, arabinose, galactose with strong spots and a weak spot for galacturonic acid.

- Gas chromatography of the hydrolysates revealed the presence of galactose, rhamnose, glucose and galacturonic acid.

- The difference in the amount of sugars detected by gas chromatography between the pectins extracted from resistant and susceptible cultivars was significant, the susceptible cultivars showed a higher amount of sugars as compared to the resistant cultivars. 
- Enzymatic digestion of the pectins was carried out with two different enzymes, pectate lyase and polygalacturonase.

- The pectins hydrolysed with pectate lyase had a different elution profile for the resistant and susceptible cultivars.

- The amount of galacturonic acid released in resistant cultivars was high in comparison to the susceptible cultivars, indicating that the pectins extracted from the resistant cultivars had more esterified groups when compared to the pectins from suceptible cultivars of celery.

- The enzymatic digestion of pectins by polygalacturonase did not reveal differences between the pectins from susceptible and resistant cultivars.

- Haemgglutination studies were carried out with the proteins extracted from the phytopathogens Pseudomonas syringae pv. apii strain GSPB 2548 and Pseudomonas syringae pv. tomato strain GSPB 2317.

- The proteins were partially purified and characterized by polyacrylamide gel electrophoresis on a native gel where only a single band appeared for each protein (molecular weight between 70-90 kDa).

- When proteins were characterized on a SDS-PAGE multiple bands were visualized.

- Haemagglutination inhibiton studies were carried out with commercial sugars and pectins extracted from susceptible and resistant cultivars of tomato and celery.

- Both proteins were inhibited by D-galacturonic acid and D-gluconic acid at different concentrations; $62.5 \mathrm{mM}$ and $125 \mathrm{mM}$, respectively, for the proteins from $P$. s. pv. tomato and $8 \mathrm{mM}$ and $62.5 \mathrm{mM}$, respectively, for the proteins from $P$. s. pv. apii.

- In addition, the agglutinating activity of the protein from P. s. pv. apii was inhibited by D-rhamnose, but not by pectins from either the suceptible or the resistant cultivars. 
- On the other hand, the protein from P. s. pv. tomato was also inhibited by glucosamine, but not by D-rhamnose. In addition, the agglutinating activity was inhibited by pectins extracted from the susceptible and resistant cultivars. 


\section{Literature cited}

\section{Literature cited :}

Ausubel, F., Brent, R., Kingston, R. E., Moore, D. D., Seidman, J. G., Smith, J. A. and Struhl, K. (1987). Short Protocols in Molecular Biology- A Compendium of Methods from Current Protocols in Molecular Biology. ( $3^{\text {rd }}$ ed.), J. Wiley and Sons, New York.

Anderson, A. J. and C. Jasalavich, (1979). Agglutination of Pseudomonad cells by plant products. Physiol. Plant Pathol., 15: 149-159.

Bartlett, G. R. (1959). Phosphorus assay in column chromatography. J. Biol. Chem., 234: 446-468.

Bashan, Y., Sharon, E., Okon, Y. and Henis, Y., (1981). Scanning electron and light microscopy of infection and symptom development in tomato leaves infected with Pseudomonas tomato. Physiol. Mol. Plant Pathol., 19: 1319-144.

Bender, C. L., Stone, H. E., Sims, J. J. and Cooksey, D. A. (1987). Reduced pathogen fitness of Pseudomonas syringae pv. tomato Tn5 mutants defective in coronatine production. Physiol. Mol. Plant Pathol., 30: 273-283.

Bereswill, S., Bugert, P., Voelksch, B., Ulrich, M., Bender, C. and Geider, K. (1994). Identification and relatedness of coronatine-producing Pseudomonas syringae pathovars by PCR analysis and sequence determination of the amplification products. Appl. Environ. Microbiol., 60: 2924-2930.

Cairns, P., Miles, M. J., Morris, V. J. and Brownsky, G. J. (1997). X-ray fiber diffraction studies of synergistic, binary polysaccharides gels. Carbohydr. Res., 160: 411423.

Cody, Y. S. and Gross, D. C. (1987) Outer membrane protein mediating iron uptake via pyoverdinpss, the fluorescent siderophore produced by Pseudomonas syringae pv. syringae. J. Bacteriol., 169: 2207-2214. 
Copetti, G., Grassi, M., Lapasin, R. and Pricl, S. (1997). Synergistic gelation of xanthan gum with locust bean gum: a rheological investigation. Glycoconjugate J., 14: 951-961.

Crescenzi, V. and Dentini, M. (1987). The influence of side-chains on the dilutesolution properties of three structurally related, bacterial anionic polysaccharides. Carbohydr. Res., 160: 283-302.

Daas, P. J. H., Hansen, K. M., Schols, H. A., De Ruiter, G. A. and Voragen, A. G. J. (1999). Investigation of non-esterifed galacturonic acid distribution in pectin with endopolygalacturonase. Carbohydr. Res., 318: 135-145.

Darvill, A. G., McNeil, M. and Albersheim, P. (1978). Structure of plant cell walls. VIII. A new pectic polysaccharide. Plant Physiol., 62: 418-422.

Das, S., Ramm, M., Kochanowski, H. and Basu, S. (1994). Structural studies of the side chain of outer membrane lipopolysaccharide from Pseudomonas syringae pv. coriandricola W-43. J. Bacteriol., 176:6550-6557.

De Veau E. J. I., Gross, K. C., Huber, D. J. and Watada, A. E. (1993). Degradation and solubilization of pectin by $\beta$-galactosidases purified from avocado mesocarp. Physiol. Plant, 87: 279-285.

De Vries, J. A., Rombouts, F. M., Voragen, A. G. J. and Pilnik, W. (1982). Enzymatic degradation of apple pectins. Carbohydr. Polym., 2: 25-34.

Dice, L. R. (1945). Measures of the amount of ecologic association between species. Ecology, 26: 297-302.

Dooley, J. S. G., Lalier, R., Shaw, D. H. and Trust, T. J. (1985). Electrophoretic and immunochemical analyses of the lipopolysaccharides from various strains of Aeromonas hydrophilia. J. Bacteriol., 164: 263-269. 
Dow, M., Newman, M. A. and von Roepenack, E., (2000). The induction and modulation of plant defense responses by bacterial lipopolysaccharides. Annu. Rev. Phytopathol., 38: 241-261.

Ferguson, J. (1984). Calcium in plant senescence and fruit ripening. Plant Cell Environ., 7: 477-489.

Gilson, E., Clement, J-M., Brutlag, D. and Hofnung, M. (1984). A family of dispersed repetitive extragenic palindromic DNA sequences in bacteria. Trends Gen., 3: 226-230.

Goebel, B. M. and Stackebrandt, E. (1994). Cultural and phylogenetic analysis of mixed microbial populations found in natural and commercial bioleaching environments. Appl. Environ. Microbiol., 60: 1614 - 1621.

Goldman, R.C. and Leive, L. (1980). Heterogeneity of antigenic-side-chain length in lipopolysaccharides from Escherichia coli 0111 and Salmonella typhimurium. Eur. J. Biochem., 107: 145-153.

Goldstein, I. J. and Hayes, C. E. (1978). The lectins: carbohydrate-binding proteins of plants and animals. Advan. Carbohydr. Chem. Biochem., 35: 127-340.

Goldstein, I. J., Hughes, R. C., Monsigny, M., Osawa, T. and Sharon, N. (1980). What should be called a lectin? Nature (Lond), 285: 66.

Goodfellow, M. and O'Donnell, A. G. (1993). Handbook of New Bacterial Systematics. Academic Press, London, 560 pp.

Goodman, R. N., Huang, P. Y. and White, J. A. (1976). Ultrastructural evidence for immobilization of an incompatible bacterium, Pseudomonas pisi, in tobacco leaf tissue. Phytopathology, 66: 754-764.

Graham, T. L ., Sequeira, L. and Huang, T. S. R. (1977). Bacterial lipopolysaccharides as inducers of disease resistance in tobacco. Appl. Environ. Microbiol., 33: 424-432. 
Graham, T. L. (1983). Role of lipopolysaccharide in recognition and induced disease resistance in plant host of Pseudomonas solanacearum, In: A. Nowotny (ed.), Beneficial effects of endotoxins. Plenum Press, New York, pp. 555-568.

Grolms, U. (1996). Rheologie der Interaktion zwischen bakteriellen Lipopolysacchariden (LPS) und pflanzlichen Polymeren und Resistenzinduktion durch LPS. Ph. D. Dissertation, University of Göttingen, Göttingen, Germany.

Grolms, U. and Rudolph, K. (1997). Rheological interactions between lipopolysaccharides of Pseudomonas syringae pathovars and plant polysaccharides. In Developments in Plant Pathology, Vol. 9, Pseudomonas syringae Pathovars and Related Pathogens, K. Rudolph, T. J. Burr, J.W. Mansfield, D. Stead, A. Vivian and J. V.Kietzell, (eds.), Kluwer Academic Publishers, Dordrecht, pp. 364-369.

Gross, M. (1990). Factors for virulence of bacteria, Lipolysaccharides, In: Z. Klement, K. Rudolph and D. C. Sands (eds.). Methods in Phytobacteriology, Akademiai Kiado, Budapest, pp. 423-428.

Heukeshoven, J. and Dernick, R. (1988). Improved silver staining procedure for fast staining in Phast system development unit I. Staining of SDS gels. Electrophoresis, 9: 2832.

Higgins, C. F., Ames, G. F. L., Barnes, W. M., Clement, J. M. and Hofnung, M. (1982). A novel inter cistronic regulatory element of prokaryotic operons. Nature, 298:760-762.

Hildebrand, D. C., Schroth, M. N. and Huisman, O. C. (1982). The DNA homology matrix and non random variation concepts as the basis for the taxonomic treatment of plant pathogenic and other bacteria. Annu. Rev. Phytopathol, 20: 235-256.

Hulton, C. S. J., Higgins, C. F. and Sharp, P. M. (1991). ERIC sequences: A novel family of repetitive elements in the genomes of Escherichia coli, Salmonella typhimurium and other enterobacteria. Mol. Microbiol., 5: 825-834. 
Javadekar, V. S., Sivaraman, H., Sainkar, S. R. and Khan, M. I. (2000). A mannosebinding protein from the cell surface of flocculent Saccharomyces cerevisiae (NCIM 3528): its role in flocculation. Yeast, 16: 99-110.

Joshi, B., Khire, J. M., SivaRaman, H. and Khan, M. I. (1995). Purification and characterization of a lectin from Xanthomonas campestris NCIM 5028. Can. J. Microbiol., 42: 609-612.

Kao, C. C. and Sequeria, L. (1991). A gene cluster required for coordinated biosynthesis of lipopolysaccharide and extracellular polysaccharide also affects virulence of Pseudomonas solanacearum. J. Bacteriol., 173: 7841-7847.

Karkhanis, D., Zeltner, J., Jackson, J. and Carlo, D. (1978). A new and improved micro assay to determine 2-keto 3-deoxyoctonate in lipopolysaccharide of Gram-negative bacteria. Anal. Biochem., 85: 595-601.

Kikuchi, A., Edashige, Y., Ishii, T., Fujii, T. and Satoh, S. (1996). Variations in the structure of neutral sugar chains in the pectic polysaccharides of morphologically different carrot calli and correlations with the size of cell clusters. Planta, 198: 634-639.

King, E. O., Ward, M. K. and Raney, D. E. (1954). Two simple media for the demonstration of pyocianin and fluorescin. J. Lab. Clin. Med., 44: 301-307.

Klement, Z. (1963). Method for the rapid detection of phytopathogenic pseudomonads. Nature, 199: 299-300.

Koerner, R., Limberg, G., Tove Christensen, M. I. E., Mikkelsen, J. D. and Roepstorff, P. (1999). Sequencing and partially methyl esterified oligogalacturonates by tandem mass spectrometry and its use to determine pectinase specificities. Anal. Chem., 71: $1421-1427$.

Kravtchenko, T. P., Penci, M., Voragen, A. G. J. and Plinik, W. (1993). Enzymatic and chemical degradation of some industrial pectins . Carbohydr. Polym., 2: 195-205. 
Krawiec, S. and Riley, M. (1990). Organization of the bacterial chromosome. Microbiol Rev., 54:502-39.

Laux, P. (1998). Zur Rolle der Lipopolysaccharide (LPS) in der Wirt/Parasit-Interaktion phytopathogener Pseudomonaden und Xanthomonaden. Ph. D. Dissertation, University of Göttingen, Göttingen, Germany.

Laux, P., Müller, P., and Rudolph, K. (1996). Interactions between bacterial lipopolysaccharides and plant pectins-A mechanism which may determine host/parasite relations in bacterial plant diseases. In: A. Mahadevan (ed). Plant Pathogenic Bacteria Proc., $9^{\text {th }}$ Intl. Conf. Phytopathogenic Bacteria, Chennai, India, pp. 563-568.

Liehe, A. (1998). Charakterisierung der Resistenz von Korianderlinien (Coriandrum sativum L.) gegen Pseudomonas syringae pv. coriandricola, dem Erreger des bakteriellen Doldenbrandes. Ph. D. Dissertation, University of Göttingen, Göttingen, Germany

Limberg, G., Koerner, R., Bucholt, C, H., Christensen, M. I. E. T., Roepstroff, P. and Mikkelsen, D. J. (2000). Analysis of different de-esterification mechanisms for pectin by enzymatic fingerprinting using endopectin lyase and endopolygalacturonase from $A$. Niger. Carbohydr. Res. 32: 293-307.

Liners, F. and Van Cutsem, P. (1992). Distribution of pectic polysaccharides throughout walls of suspensions-cultured carrot cells. An immmunocytochemical study. Protoplasma, 170: $10-21$.

Little, E. and Gilbertson, R. L. (1997). Phenotypic and genotypic characters support placement of Pseudomonas syringae strains from tomato, celery, and cauliflower into distinct pathovars. In Developments in Plant Pathology Vol. 9, Pseudomonas syringae Pathovars and Related Pathogens, K. Rudolph, T. J. Burr, J.W. Mansfield, D. Stead, A. Vivian and J. V.Kietzell, (eds.), Kluwer Academic Publishers, Dordrecht, pp. 542-547 .

Loh, J. T., Ho, S. C., de Feijter, A. W., Wang, J. L. and Schindler, M. (1993). Carbohydrate binding activities of Bradyrhizobium japonicum: unipolar localization of the lectin BJ38 on the bacterial cell surface. Proc. Natl. Acad. Sci. U. S. A., 90: 3033-3037. 
Louws, F. J., Fulbright, D. W., Stephens, C. T. and De Bruijn, F. J. (1994). Specific genomic fingerprints of phytopathogenic Xanthomonas and Pseudomonas pathovars and strains generated with repetitive sequences and PCR. Appl. Environ. Microbiol., 60 : 2286-2295.

Lowry, O. H., Rosebrough, N. J., Farr, A. L. and Randall, R. J. (1951). Protein measurement with the Folin phenol reagent. J. Biol. Chem. 193: 265-275.

Lüderitz, O., Freudenberg, M. A., Galanos, C., Lehmann, V., Rietschel. E. T. and Shaw, D. W. (1982). Lipopolysaccharides of Gram-negative bacteria. Curr. Top. Membr. Transp., 17: 79-151.

Lupski, J. R. and Weinstock, G. M. (1992). Short, interspersed, repetitive DNA sequences in prokaryotic genomes. J. Bacteriol., 174: 4525-4529.

Martin, B., Humbert, O., Camara, M., Guenzi, E., Walker, J., Mitchell, T., Andrew, P., Prudhomme, M., Allgong, G., Hakenbeck, R., Morrison, D. A., Boulnois, G. J. and Claverys, J. P. (1992). A highly conserved repeated DNA element located in the chromosome of Streptococcus pneumoniae. Nucl. Acids Res., 20: 3479-3483

Martin, G. B., Brommonschenkel, S. H., Chunwongse, J., Frary, A., Ganal, M. W., Spivey, R., Wu, T., Earle, E. D and Tanksley, S. D. (1993). Map-based cloning of a protein kinase gene conferring disease resistant in tomato. Science, 262: 1432-1436.

Mavridis, A. (1982). Untersuchungen zum Vorkommen bakterieller Krankheitserreger (Corynebacterium michiganense pv. michiganense [E. F. SMITH] JENSEN und Pseudomonas syringae pv. tomato [OKABE] YOUNG, DYE and WILKIE) an Tomaten (Lycopersicon esculentum MILL.) in Griechenland, zur Erkennung der Resistenz und zum von P. tomato gebildeten Chlorose-auslösenden Toxin. Ph. D. Dissertation, University of Göttingen, Germany.

McDonnell, M. T. and Colwell, R. R. (1985). The contribution of numerical taxonomy to the systematics of Gram-negative bacteria. In: Goodfellow, M., Jones, D. and Priest, f. 
G. (eds.) Computer-assisted Bacterail Systematics, Aacademic Press, London, pp. 107135

Müller, P. (1998). Zur Wirkungsweise und Struktur bakterieller Lipopolysaccharide (LPS) aus Pseudomonas syringae Pathovarietäten bei der induzierten Resistenz in Nicotiana tabacum und Lycopersicon esculentum. Ph. D. Dissertation, University of Göttingen, Göttingen, Germany.

Müller, P., Zähringer, U. and Rudolph, K. (1996). Induced resistance by bacterial lipopolysaccharides (LPS). A. Mahadevan (ed): Plant Pathogenic Bacteria. Proc., $9^{\text {th }}$ Intl. Conf. Phytopathogenic Bacteria, Chennai, India, pp. 569-575.

Murray, J., Fixter, L. M., Hamilton, L. D., Perombelon, M. C. M., Quinn, C. E. and Graham, D. C. (1990). Serogroups of potato pathogenic Erwinia carotovora strains: Identification by lipopolysaccharide electrophoretic patterns. J. Appl. Bacteriol. 68: 231240.

Nabizadeh-Ardekani, F., Koopmann, B. and Rudolph, K. (1997). Detection of bacterial diseases of tomatoes by the polymerase chain reaction (PCR) and serology. In: Dehne, H-W., Adam, G., Diekmann, M., Frahm, J., Mauler-Machnik, A. and van Halteren, P. (eds.): Diagnosis and Identification of Plant Pathogens, Proc. $4^{\text {th }}$ Intl. Symposium of the European Foundation for Plant Pathology, Sep. 9-12, 1996, Bonn, Germany, pp. 453-455.

Ojinnaka, C., Brownsey, G. J, Morris, E. R. and Morris, V. J. (1997). Effect of deacetylation on the synergistic interaction of acetan with locust bean gum or konjac mannan. Carbohydr. Res., 305: 101-108.

Ovod, V., Rudolph, K., and Kohn, K. (1997). Serological classification of Pseudomonas syringae pathovars based on monoclonal antibodies towards the lipopolysaccharide $\mathrm{O}$ chains. In Developments in Plant Pathology Vol. 9, Pseudomonas syringae Pathovars and Related Pathogens, K. Rudolph, T. J. Burr, J.W. Mansfield, D. Stead, A. Vivian and J. V.Kietzell, (eds.), Kluwer Academic Publishers, Dordrecht, pp 526-531. 
Ovod, V.V, Mikhal'skii, L. A, Vershigora, A. E. and Gvozdiak, R. I. (1991). An analysis of the molecular forms of the lipopolysaccharide from Pseudomonas syringae pv. atrofaciens IMV K-1025. Mikrobiol. Zh., 53: 48-53.

Owens, H. S., McCready, R. M., Shepard, A. D., Schultz, T. H., Pippen, E. L., Swenson, H. A., Miers, J. C., Erlandsen, R. F. and Maclay, W. D. (1952). Methods used at Western Regional Research Laboratory for Extraction of Pectic Materials. USDA Bur. Agric. Ind. Chem. Report No. 340, p 9.

Palva, E. T. and Mäkelä, P. H. (1980). Lipopolysaccharides heterogeneity in Salmonella typhimurium analyzed by sodium dodecyl sulphate/polyacrylamide gel electrophoresis. Eur. J. Biochem. 107: 137-143.

Podani, J. (1993). Syn-tax-PC computer programs for multivariate data analysis in ecology and systematics, Version 5.0. Scientia Publ., Budapest, 104 pp.

Rao, S. S., Lippincott, B. B., and Lippincott, A. J. (1982). Agrobacterium adherence involves the pectic portion of the host cell wall and is sensitive to the degree of pectin methylation. Physiol. Plant, 56: 374-380.

Ray, M. K., Kumar, G. S. and Shivaji, S. (1994). Phosphorylation of lipopolysaccharides in the Antarctic psychrotroph Pseudomonas syringae: a possible role in temperature adaptation. J. Bacteriol., 176: 4243-4249.

Rini, J. M. (1995). Lectin structure. Annu. Rev. Biophys. Biomol. Struct., 24: 551-577.

Rivera, M., Bryan, E. L., Hancock, W.E. R. and McGroarty, E. J. (1988). Heterogeneity of lippolysaccharides from Pseudomonas aeruginosa: analysis of lipopolysaccharide length. J. Bacteriol, 170: 512-521.

Rollin, C., and De Vries, J., (1990). Food Gels, Harris, P. (ed), Elsevier, Amsterdam, 401-434. 
Romantschuk, M., Roins, E., Ojanen, T, van Doorn, J., Louhelainen, J., NurmiahoLassila, E. L. and Haahtela, K. (1994). In Kado and Crosa (ed), Molecular mechanisms of bacterial virulence. Dev. Plant Pathol., Kluwer Academic Publishers, London. pp. 6777.

Round, N. A, Rigby M. N, MacDougall. J. A, Ring. G. S, and Morris. J.V (2001). Investigating the nature of branching in pectin by atomic force microscopy and carbohydrate analysis. Carbohydr. Res., 331: 337-342.

Rudolph, K. and Mendgen, K. (1985). Multiplication of Pseudomonas syringae pv. phaseolicola "in planta". II. Characterization of susceptible and resistant reactions by light and electron microscopy compared with bacterial counting. Phytopathol. Z., 113: 200-212.

Rudolph, K. (2001). Thirty-five years of phytobacteriology research with special emphasis on pathogenicity of Pseudomonas syringae. Plant Pathogenic Bacteria, Solke H. De Boer (ed.), Proc., $10^{\text {th }}$ Intl. Conf. Phytopathogenic Bacteria, Charlottetown, Canada, pp. 109-117.

Sambrook, J., Fritsch, E. F. and Maniatis, T. (1989). Molecular Cloning: A Laboratory Manual. Cold Spring Harbor Laboratory Press, New York.

Schols, H. A. and Voragen, A. G. J. (1996). (Eds.), Progress in Biotechnology, Pectins and Pectinases, Vol. 14, Elsevier Science, Amsterdam, pp. 3-19.

Schramek, S. and Mayer, H. (1982). Different sugar composition of lipopolysaccharides isolated from phase I and phase II of Coxiella burnetii. Infect. Immun., 38: 53-57.

Schroeder. I. (2000). Zur Rolle der Membranvesikel von Pseudomonas syringae als Resistenzinduktoren und Transportvehikel fur Virulenzfaktoren bei Nicotiana tabacum und Lycopersicon esculentum. Ph. D. Dissertation, University of Göttingen, Göttingen, Germany. 
Schultz, T. H. (1976). Methods in Carbohydr. Chem. Academic Press, New York, Vol. 5, p 189.

Sequeira, L., Gaard, G. and Dezoeten, G. A. (1977). Interaction of bacteria and host cell wall: its relationship to mechanisms of induced resistance. Physiol. Plant Pathol., 10: 43-50.

Sharma, V. and Surolia, A. (1997). Analyses of carbohydrate recognition by legume lectins: size of the combining site loops and their primary specificity. J. Mol. Biol., 267: 433-45.

Sharon N. (1987). Bacterial lectins, cell-cell recognition and infectious disease. FEBS Lett., 217: 145-157.

Sharon, N. and Lis, H. (1990). Legume lectins- a large family of homologous proteins. FASEB J., 4:3198-3208.

Sharples, G. S. and Lloyd, R. G. (1990). A novel repeated DNA sequence located in the intergenic regions of the bacterial chromosomes. Nucl. Acids Res., 18: 6503-6508.

Smith, A. R. W., Zamze, S. E. and Hignett, R. C. (1985). Composition of lipopolysaccharide from Pseudomonas syringae pv. morsprunorum and its digestion by bacteriophage A7. J. Gen. Microbiol., 131: 963-974.

Sneath, P. H. and Sokal, R. R. (1973). Numerical Taxonomy: The Principles and Practice of Numerical Classification, W. M. Freeman and Co. San Francisco.

Sonnenberg, B. (1994). Quantifizierung und Markierung bakterieller Polymere und pflanzlicher Oberflächenstrukturen mit Biotin in der Interaktion von Phaseolus vulgaris und Pseudomonas syringae pv. phaseolicola, Ph. D. Dissertation, University of Göttingen, Göttingen, Germany. 
Stadnik, G. I.., Kalashnikova, E. E., Konnova, S. A. and Ignatov, V. V. (2001). Role of the surface and extracellular substances of the phytopathogenic bacterium Xanthomonas campestris in its interactions with cabbage plants. Mikrobiologia, 70: 270274.

Stahl, E. (1967). Dünnschichtchromatographie. Springer-Verlag, Berlin.

Stead, D. E. (1990). Preservation of bacteria. In: Z. Klement, K . Rudolph and D. C. Sands (eds.). Methods in Phytobacteriology, Akademiai Kiado, Budapest. 275-278.

Vance, V. B., Berger, P. H., Carrington, J. C., Hunt, A. G. and Shi, X. M. (1995). 5' proximal potyviral sequences mediate potato virus $\mathrm{X} /$ potyviral synergistic disease in transgenic tobacco. Virology, 206: 583-590

Venkatesh, B. and Rudolph, K. (2001a). Rheological investigation on bacterial lipopolysaccharides and plant pectins. Phytomedizin, Mitteilung. Deutsch. Phytomedizin Gesellsch., 31(1): 39-40.

Venkatesh, B. and Rudolph, K. (2001b). Interactions between bacterial lipopolysaccharides and plant pectins. Phytopathology, 91(6): Suppl. 91.

Versalovic, J., Schneider, M., de Bruijn, F. J. and Lupski, J. R. (1994). Genomic fingerprinting of bacteria using repetitive sequence-based on polymerase chain reaction. Meth. Cell. Mol. Biol., 5: 25-40.

Weibe, W. L. and Campbell, R. N. (1993). Characterization of Pseudomonas syringae pv. maculicola and comparison with P. s. pv. tomato. Plant Dis., 77: 414-419.

Weis, W. I. and Drickamer (1996). Structural basis of lectin-carbohydate recongnition. Annu. Rev. Biochem., 65: 441-473.

Welsh, J. and McClelland, M. (1990). Fingerprinting genomes using PCR with arbitrary primers. Nucleic Acids Res., 18: 7213-7218 
Westphal, O. and Jann, K. (1965). Bacterial lipopolysaccharides: Extraction with phenolwater and further applications of this procedure. Methods Carbohydr. Chem., 5: 83-91.

Wilkinson, S. G. (1977). Composition and structure of bacterial lipopolysaccharides, In: I. Sutherland (ed), Surface Carbohydrates of the Prokaryotic Cell. Academic Press, New York,. pp. 97-175.

Willats, W. G. and Knox, J. P. (1999). Immunoprofiling of pectic polysaccharides.

Woese, C. R. (1987) Bacterial evolution. Microbiol. Rev., 51: 221-271.

Wright, B. G. and Rebers, P. A. (1972). Procedure for determining heptose and hexose in lipopolysaccharides. Modification of cysteine sulphuric acid method. Anal. Biochem., 49: $307-319$.

Yabusaki, K. K., Cohen, R. E. and Ballou, C. E. (1979). Conformational changes associated with complex formation between a mycobacterial polymethylpolysaccharide and palmitinic acid. J. Biol. Chem., 254: 7282-7286.

Zdorovenko, G. M., Shashkov, A. S., Zdorovenko, E. L., Kocharova, N. A., Yakovleval, L. M., Yu, A., Knirel, Y. and Rudolph, K. (2001). Characterization of the lipopolysaccharide and structure of the O-specific polysaccharide of the bacterium Pseudomonas syringae pv. atrofaciens IMV 948. Biochem. (Mosc.) 66: 369-377. 


\section{Acknowledgements}

I express my deepest sense of gratitude to my supervisor Dr. Klaus Rudolph for his inspiring guidance and sustained encouragement during the course of this investigation.

I am highly indebted to Prof. Dr. Botho Bowien for accepting to be my referee and Prof. Dr. Gerhard Braus to be my co-referee. I also extend my sincere thanks to Prof. Dr. Andreas von Tiedemann and Prof. Dr. Dietrich Gradmann for accepting to be my examiners.

I sincerely thank Dr. Ulrich Zähringer, Borstel, for his collaboration to characterize the lipopolysaccharides.

I am indeed thankful to Dr. M. I. Khan and Dr. Aditi Pant, NCL, Pune, India, Dr. Gertrud Lohaus and Dr. Sigrun Reumann, Department of Plant Biochemistry at the Albrecht-von Haller-Institute for Plant Sciences of the University of Göttingen for allowing me to carry out HPLC and protein experiments in their laboratory.

I will be failing in my duty if I do not thank Dr. Athanassios Mavridis, Dr. Irmhild Schröder. Dr. Misi Kecskes, Dr. Birger Koopman Dr. Uli Hettwer, Mr. Friedrich Sundmacher and Dr. Dugassa-Gobena for their constant help and encouragement throughout my research.

I would also like to thank my colleagues Mr. Khalid Abdel Rehim and Dr. Mamdoh Ahmed for their help during my experiments.

I thank Prof. D. Lalithakumari, Director, Center for Advanced Studies in Botany, University of Madras, India, for her encouragement during the course of study.

I thank my family members and friends who have made this venture a success.

I thank the Graduiertenkolleg "Chemische Aktiviatäten von Mikrooganismen” der Deutsche Forschungsgemeinschaft (DFG) for their financial support. 


\section{Curriculum Vitae}

$\begin{array}{ll}\text { Name } & \text { Balakrishnan Venkatesh } \\ \text { Date of Birth } & 18 / 07 / 1974 \\ \text { Place of Birth } & \text { Madras, India } \\ 1978-1980 & \text { Primary school, Madras, India } \\ 1980-1989 & \text { Secondary school, Madras, India } \\ 1989-1992 & \text { Higher Secondary school, Madras, India } \\ 1992-1995 & \text { B. Sc. Microbiology, University of Madras, India } \\ 1995-1997 & \text { M. Sc. Applied Microbiology, P.S.G. College of Arts and Science, } \\ & \text { Coimbatore, India. }\end{array}$

June1997- Dec1997 Asst. Quality Controller, Empee Breweries, Madras, India

1998- Mar 1999 Junior Research Fellow, Centre for Advanced Studies in Botany, University of Madras, India

1999-2002 Graduate student, Faculty of Biology, Georg-August-University, Göttingen, Germany 
